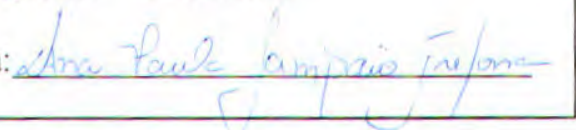

\title{
Implementação de um controlador PID digital para robótica baseado em computação reconfigurável
}

\author{
André Linhares Giorgini
}

Orientador: Prof. Dr. Eduardo Marques

Dissertação apresentada ao Instituto de Ciências Matemáticas e de Computação - ICMC-USP, como parte dos requisitos para obtenção do titulo de Mestre em Ciências de Computação e Matemática Computacional.

USP - São Carlos

Julho/2001 


\section{A Comissão Julgadora:}

Prof. Dr. Eduardo Marques

Prof. Dr. Onofre Trindade Junior

Prof. Dr. Jorge Luiz e Silva

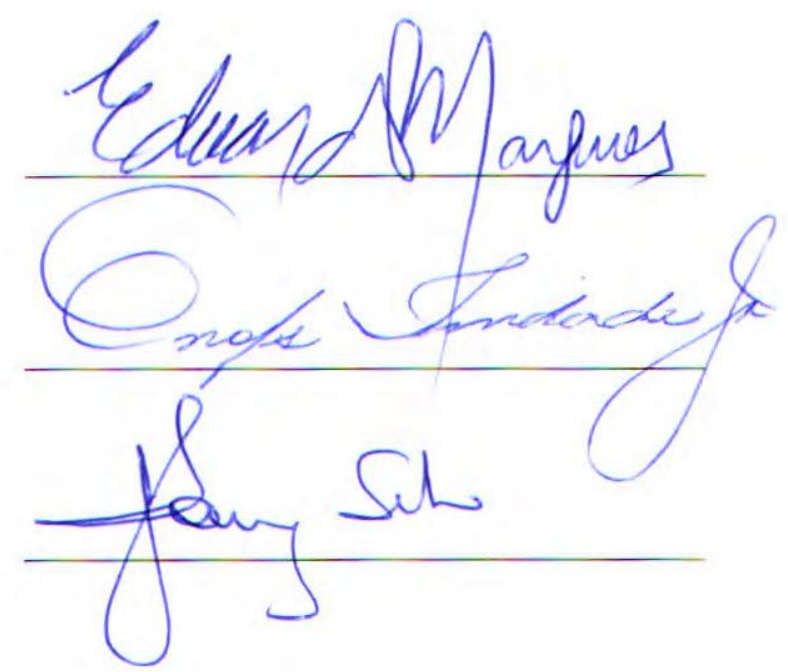




\section{Agradecimentos}

Aos meus pais, pelb amor e incentivo oferecidos durante toda minha vida.

Aos meus avós, por todo o apoio durante todo o período de estudos em São Carlos.

A Samira, pela paciência, ajuda e carinho durante todo o mestrado.

Ao Professor Eduardo Marques, meu orientador, pela oportunidade e incondicional apoio durante em todas as fases deste trabalho.

Aos amigos Marcos Roberto e Walter pela colaboração neste trabalho de mestrado.

Aos amigos do LCR pela ajuda e companheirismo. 


\section{Índice}

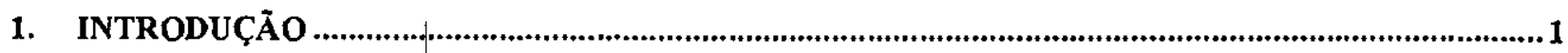

2. METODOLOGIAS AVANÇADAS PARA PROJETO DE HARDWARE ............................................ 3

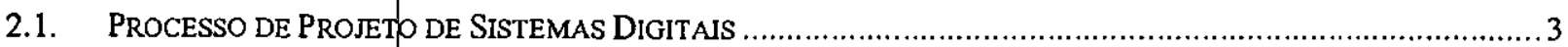

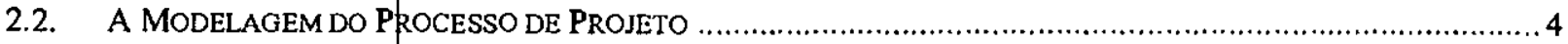

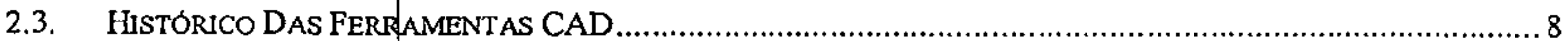

2.3.1. Ferramentas de Projeto Baseadas em Simulação .............................................................................. 8

2.3.2. Ferramentas de Projeto Baseadas em Sintese Automatizada ........................................................... 9

2.3.3. Ferramentas Moddernas de Projeto de Sistemas Digitais........................................................ 10

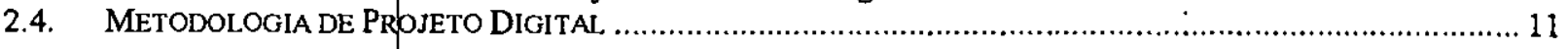

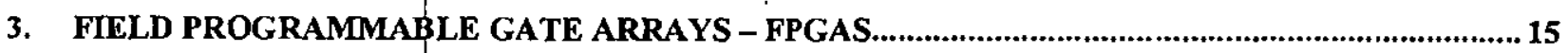

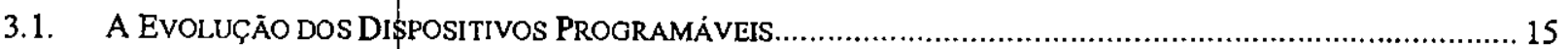

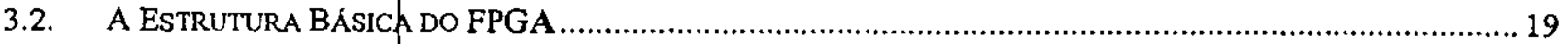

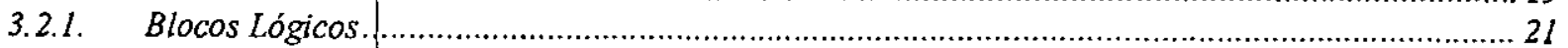

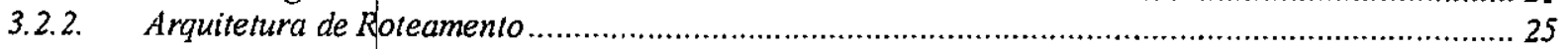

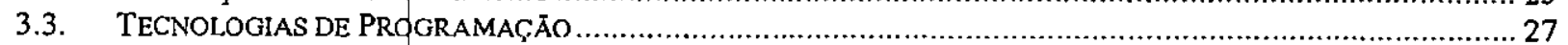

3.3.1. Tecnologia de Programação com RAM Estática ......................................................................... 27

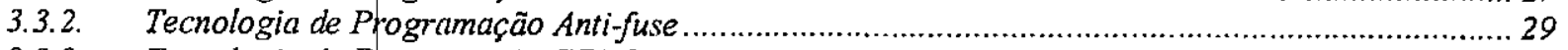

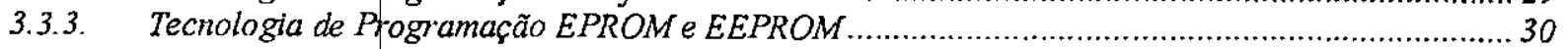

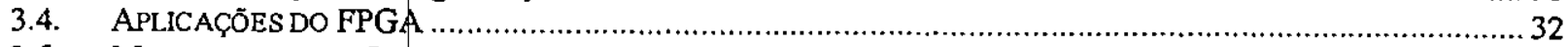

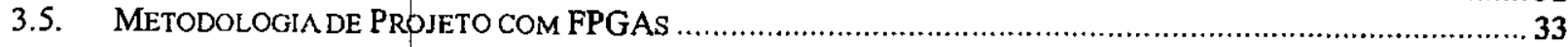

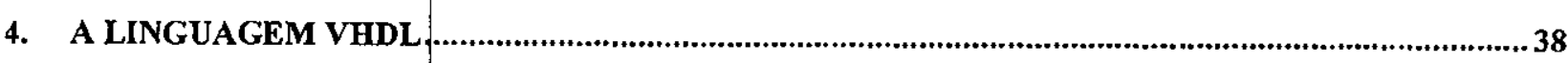

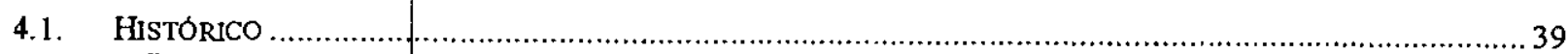

4.2. A LINGUAGEM VHDL COMO UMA FERRAMENT DE PROJETO

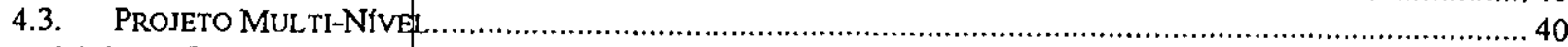

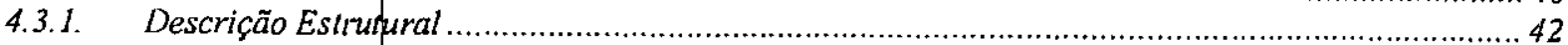

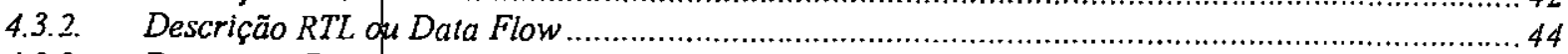

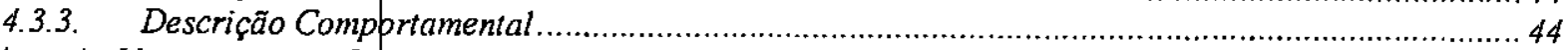

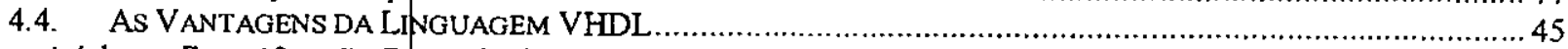

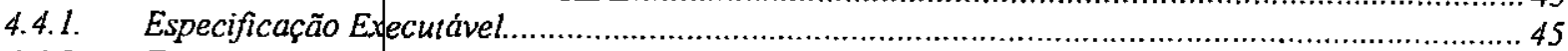

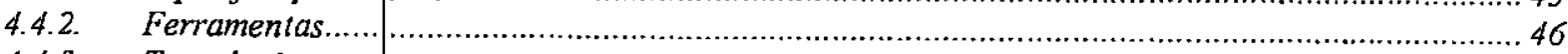

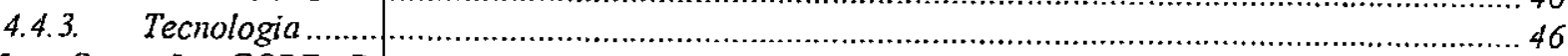

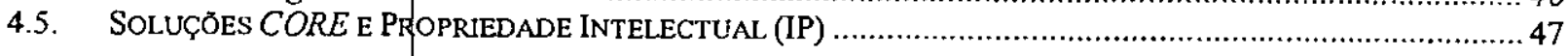

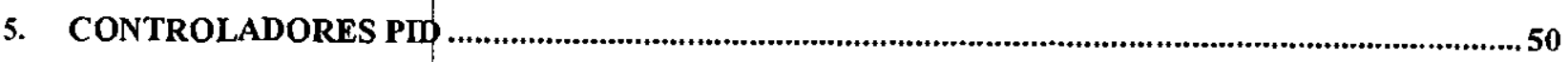

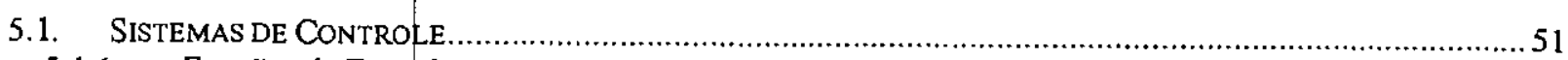

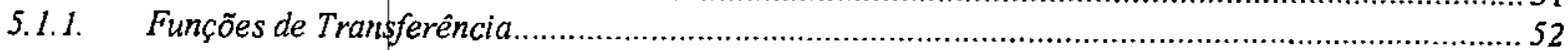

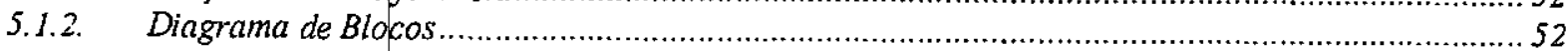

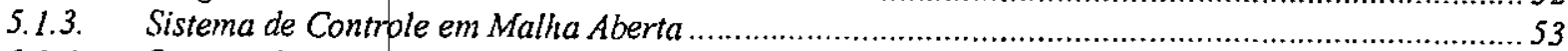

5.J.4. Sistema de Controle em Malha Fechada …................................................................................ 53

5.2. Sistema de Controle em MalHa ABerta Versus MalHa Fechada

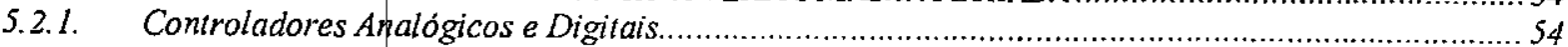

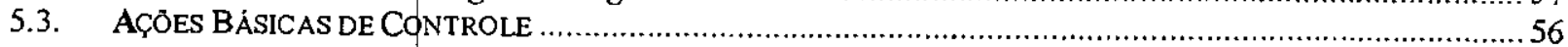

5.3.1. Controlador de Duas Posições ou ON-OFF ...............................................................................57

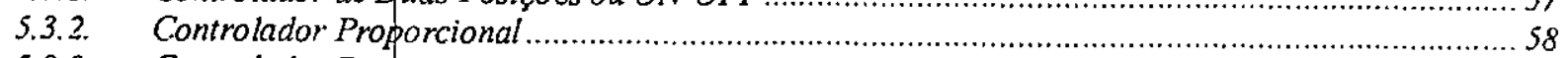

5.3.3. Controlador Proporcional Mais Derivativo ……...................................................................... 59

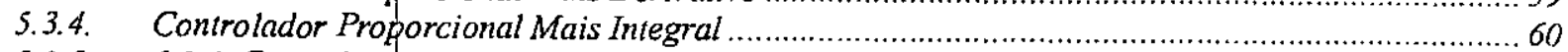

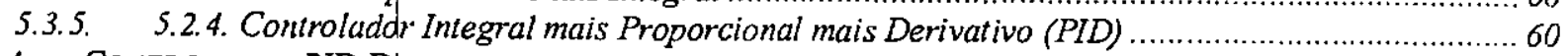

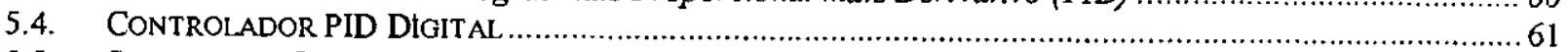

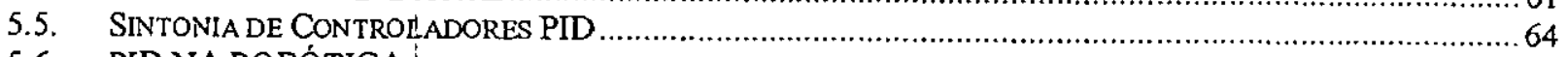

5.6. PID NA ROBÓTICA

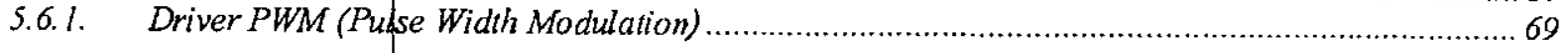

6. DESENVOLVIMENTO DO PROJETO........................................................................................74 


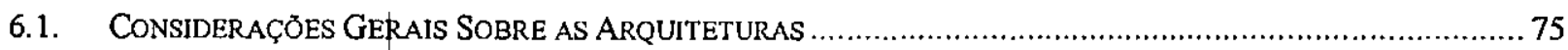

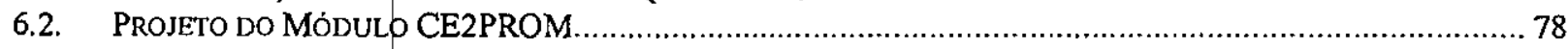

6.2.1. Interface Microwire e memórias EEPROM ..................................................................... 78

6.2.2. Detalhamento do Projeto do Módulo CE2PROM ................................................................... 80

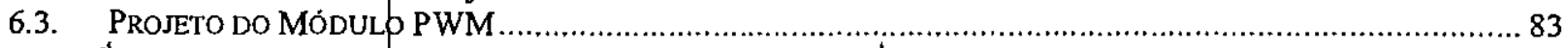

6.3.1. Detalhamento do Projeto do Módulo PWM.............................................................................. 84

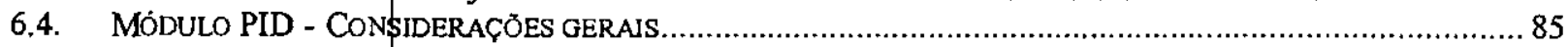

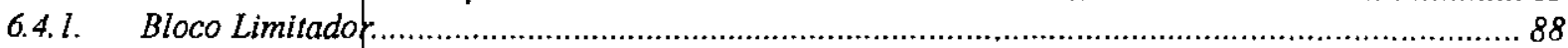

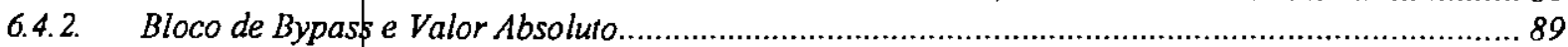

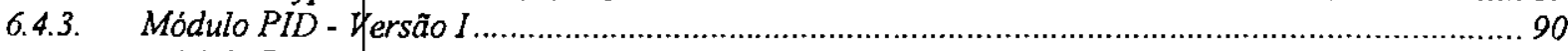

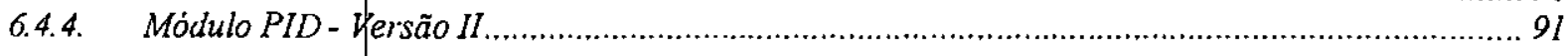

7. IMPLEMENTAÇÃO DAS ARQUITETURAS EM FPGA E ANÁLISE DOS RESULTADOS................94

7.1. SIMULAÇÃO DAS ARQUITETURAS E IMPLEMENT AÇÃO EM FPGA .................................................... 94

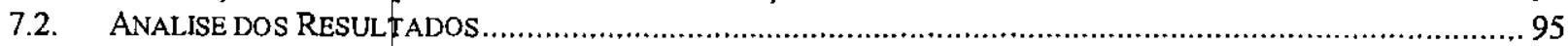

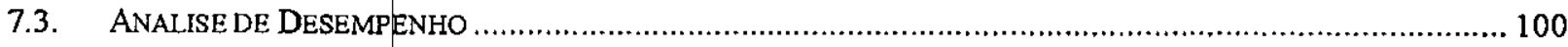

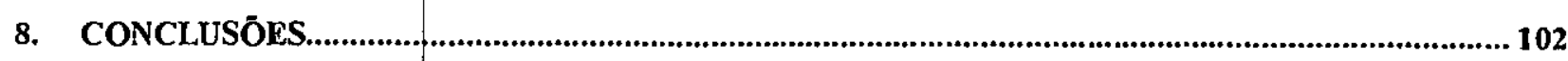

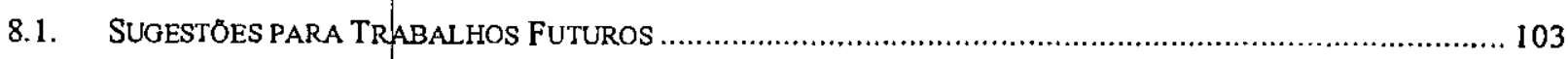

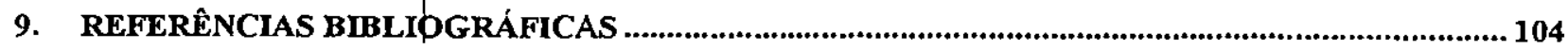




\section{Índice de Figuras}

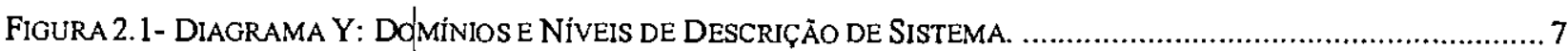

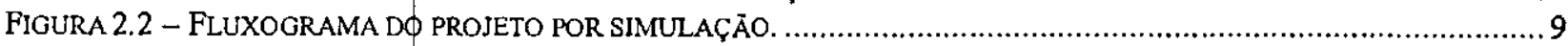

FIGURA 2.3 - FLUXOGRAMA DO PROJETO POR SÍNTESE AUTOMATIZADA......................................................

FIGURA 2.4 - TECNOLOGIA DE PROJETO DE CIRCUITOS INTEGRADOS DigITAIS. ................................................ 12

FIGURA 3.1 - ESTRUTURA DE UM PROGRAMMABLE ARRAY LOGIC. ................................................................ 17

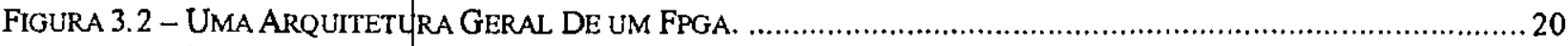

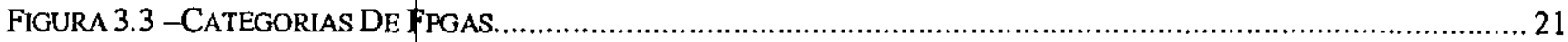

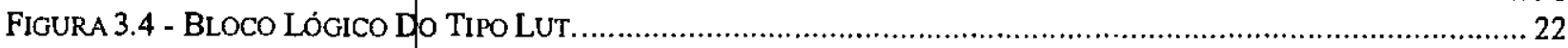

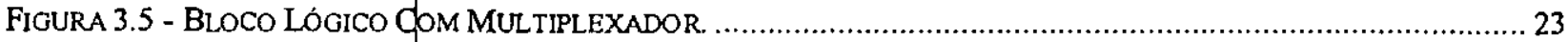

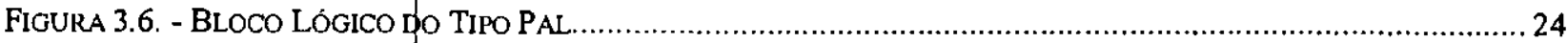

FIGURA 3.7. - BLOCO LÓGICO BASEADO EM CAM ……............................................................................... 25

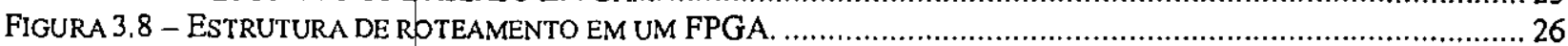

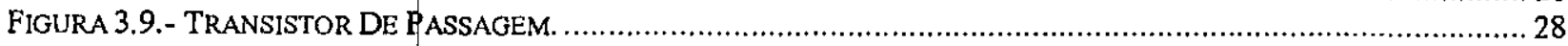

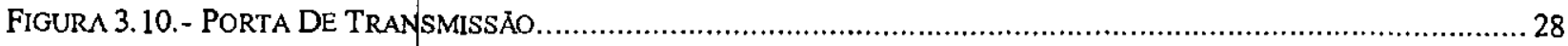

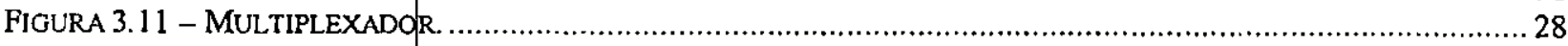

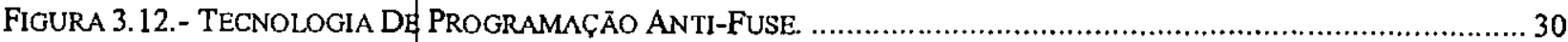

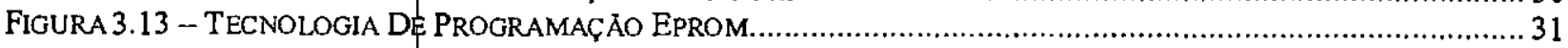

Figura 3.14 - Método De Projeto Simples, Para Dispositivos Simples. .................................................... 34

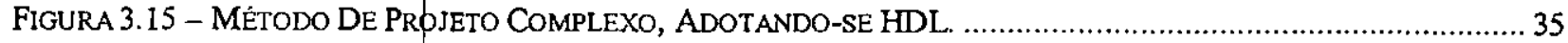

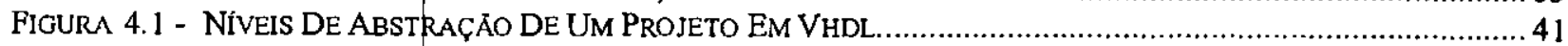

FIGURA 4.2 - DIAGRAMA ESQUEMATIICO DE UM CONTADOR. ...................................................................... 42

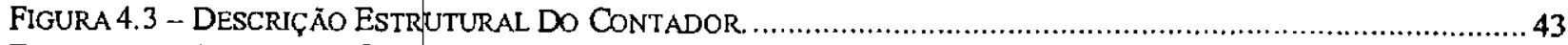

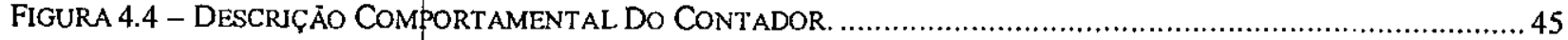

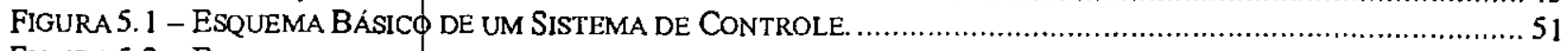

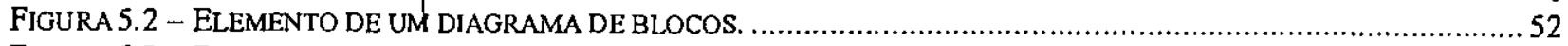

FIGURA 5.3 - DIAGRAMA DE BLOCOS DE UM SISTEMA DE CONTROLE EM MALHA ABERTA..........................................5 53

FIGURA 5.4 - DIAGRAMA DE BLOCOS DE UM SISTEMA DE CONTROLE EM MALHA FECHADA. ............................... 54

FIGURA 5.5 - DIAGRAMA ESQUEMÁTICO DE UM CONTROLE ANALÓGICO. .......................................................... 55

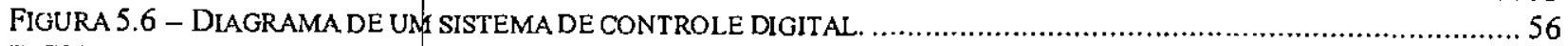

FIGURA 5.7 - ESQUEMA DE UM CONTROLE DE TEMPERATURA DE UM FORNO ELÉTRICO. ...................................5 56

FIGURA 5.8 - RESPOSTA DE UM CONTROLADOR ON-OFF [WIL99] ............................................................. 57

FIGURA 5.9 - RESPOSTA DO CONTROLADOR PROPORCIONAL [WIL99] .............................................................5 59

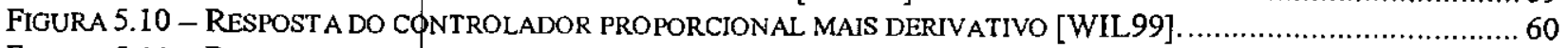

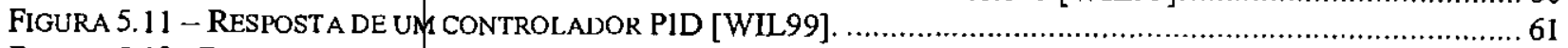

FIGURA 5.12- DIAGRAMA DE BLOCOS DE UM SISTEMA DE CONTROLE COM PID NA FORMA CONTÍNUA..........................62 62

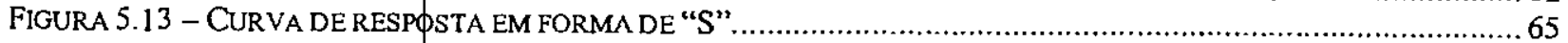

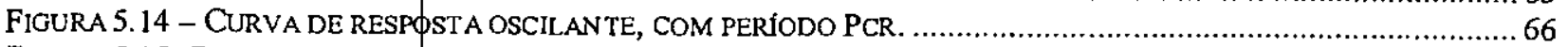

FIGURA 5.15- REPRESENTAÇÃO DO SISTEMA DE CONTROLE DO ROBÓ. ................................................................69

FIGURA 5.16- CONTROLE DE MO TOR CC POR VARIAÇÃO DA TENSĀO DE ALIMENTAÇĀO............................................. 70

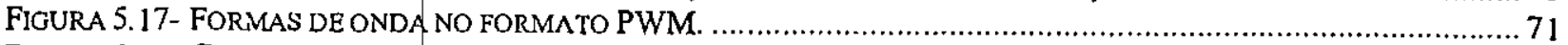

FIGURA 5.18- CIRCUITO BÁSICO DE UMA PONTE H.

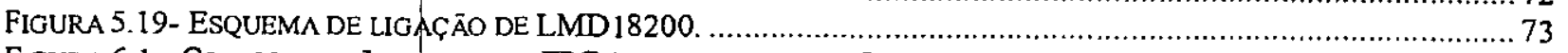

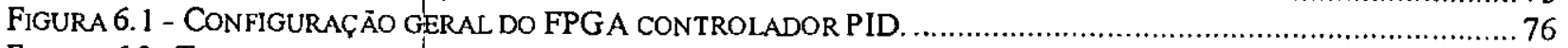

FIGURA 6.2- TAREFAS EXECUTADAS PELO CONTROLADOR PID DURANTE UM CICLO . ............................................. 77

FIGURA 6.3 - ESQUEMA DE LIGÁÇÃO ENTRE A EEPROM E O CONTROLADOR PID …............................................... 79

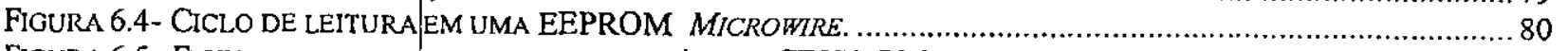

FIGURA 6.5- FLUXOGRAMA REPRESENT ATIVO DO MÓDULO CE2PROM. ……..................................................... 82

FIGURA 6.6- FLUXO DE DADOS ENTRE OS MÓDULOS PID E PWM.

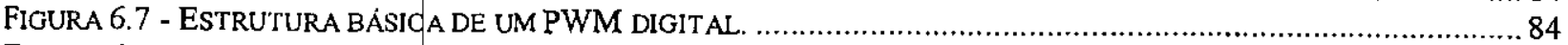

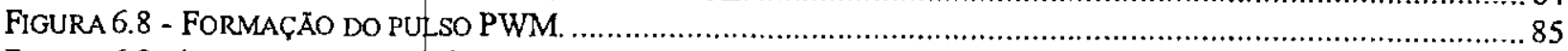

FIGURA 6.9- ARQUITETURA DO MÓDULO PID BASEADA EM REGISTRADORES DE DESLOCAMENTO ............................. 86

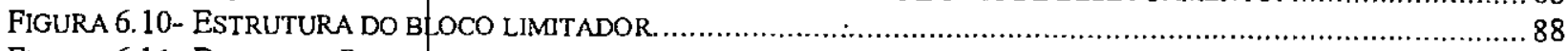

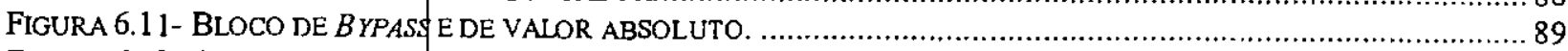

FIGURA 6.12- ARQUITETURA SIIPIPLIFICADA DO CONTROLADOR PID. ............................................................ 90

FIGURA 6.13- ARQUITETURA SI YYPLIFICADA DO CONTROLADOR PID TOTALMENTE PARALELO. .................................. 92 


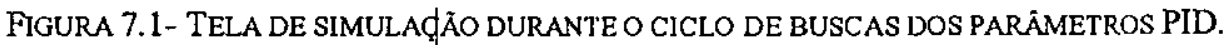

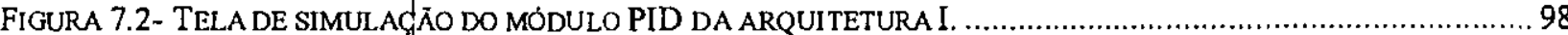

FIGURA7.3- TELA DE SIMULAÇ 


\section{Índice de Tabelas}

TABELA 3. I- CARACTERISTICAS DaS TECNOLOGIAS DE PROGRAMAÇĀo EM FPGAS............................................. 32

TABELA 6. I- DESCRIÇÃO DAS ENTRADAS E SÁDAS DO CONTROLADOR PID ................................................... 76

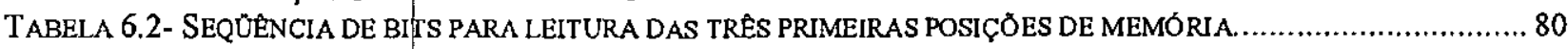

TABELA7. 1- DETALHAMENTO DO CÁlCULO DA ROTINA PID PARA COMPARAÇĀO COM A SIMULAÇÃO. ...................... 98

TABELA7. 2- COMPARAÇÃO ENTRE TRĖS SOLUÇÕES COMERCIAIS E AS ARQUITETURAS DESTE TRABALHO ................ 101 


\section{Lista de Abreviações}

\begin{tabular}{|c|c|}
\hline AMBA & Advanced Microcontroller Bus Architecture \\
\hline ASIC & Application Specific Integrated Circuit \\
\hline $\mathrm{CAD}$ & Computer Aided Design \\
\hline CAM & Content Address Memories \\
\hline CAN & Controller Area Network \\
\hline CMOS & Complementary Metal Oxide Semiconductor \\
\hline CPLDs & Complex Programmable Logic Devices \\
\hline DMA & Direct Memory Acess \\
\hline DSP & Digital Signal Processing \\
\hline EDA & Electronic Design Automation \\
\hline EEPROM & Electrically Erasable Programmable Read-Only Memory \\
\hline EPROM & Erasable Programmable Read-Only Memory \\
\hline FIR & Finite Impulse Response \\
\hline FPGAs & Field Programmable Gate Arrays \\
\hline HDLs & Hardware Description Languages \\
\hline HDTV & High Definition TV \\
\hline IEEE & Institute of Electrical and Eletronic Engineers \\
\hline IIR & Infinite Impulse Response \\
\hline IP & Intellectual Property \\
\hline IRL & Internet Reconfigurable Logic \\
\hline LC & Logic Cell \\
\hline LCA & Logic Cell Array File \\
\hline LUT & Look Up Tables \\
\hline MARBLE & Manchester AsynchRonous Bus for Low Energy \\
\hline MPGA & Mask-Programmable Gate Array \\
\hline PAL & Programmable Array Logic \\
\hline PID & Proporcional, Integral e Derivativo \\
\hline PLA & Programmable Logic Array \\
\hline PLD & Programmable Logic Devices \\
\hline
\end{tabular}


PLICE Projrammable Logic Interconect Circuit Element

PROM Programmable Read-Only Memory

PWM Pulse Width Modulation

RAM Random Acess Memory

RTL Register Transfer Language

SOC System-On-Chip

SPICE Simulation Program Integrated Circuits Especially

SPLD Simple Programmable Logic Devices

SRAM Static Random Acess Memory

UARTs Universal Assinchronuous Receiver/Transmitter

VHDL VHSIC Hardware Description Language

VHSIC Verp High Speed Integrated Circuits

VLSI Very Large Scale Integrated circuits 


\section{Resumo}

Neste trabalho de |mestrado foram desenvolvidas duas arquiteturas de controlador PID (Proporcional, Integral e Derivativo) digital para controle de motores CC. O controlador PID foi desenvolvido para ser integrado a um sistema mais complexo de gerenciamento de um robô. $\mathrm{O}$ controlador PID permite que se obtenha respostas mais rápidas e precisas do sistema a ser controlado, que, no caso deste trabalho, é um motor. Por ser relativamente simples de implementar e também por possuir parâmetros de fácil sintonia, o PID é o tipo de controle mais utilizado para esta classe de aplicação. Para o desenvolvimento do controlador foram utilizadas metodologias e ferramentas avançadas para projeto de hardware, tendo como alvo da implementação, os dispositivos reconfiguráveis FPGA (Field Programmable Gate Arrays). Os resultados de desempenho apresentados pelas arquiteturas e a flexibilidade de projeto proporcionados pela implementação em FPGAs indicam que a metodologia escolhida é adequada para esta aplicaçạo. 


\begin{abstract}
This work presents and describes two architectures of digital PID (Proportional, Integral and Derivative) controller for the purppose of DC motor control. The goal is to integrate the PID controller to a more complex robot control system. A PID controller provides a faster and more precise response from the controlled system, in this case, a DC motor. Because it is simple to implement and easy to tune, the PID controller is the widely used in this type of application. The process of developing such a controler was performed with the help of advanced metodology and tools for digital hardware design using FPGAs (Field Programmable Gate Arrays). The achieved hardaware performance and the flexilbility of the FPGAs show that the chosen methodology is adaquate for this application.
\end{abstract}




\section{Introdução}

Nestas três últimas décadas, houve avanços significativos na tecnologia de projeto de circuitos digitais. Paralelamente, os componentes de circuito evoluíram de simples transistores a circuitos VLSI (Very Large Scale Integrated circuits), que possibilitam a implementação de circuitos digitais de alto desempenho, a exemplo dos microprocessadores atuais. Contudo, devido ao fato deste tipo de circuito ser "customizado", sendo projetado para atender as especificações de um cliente, as técnicas para sua construção necessitam de um grande investimento, o que pode significar vários meses de preparação e um custo elevado [CAL95].

$\mathrm{Na}$ industria eletrônica é importante que o tempo de desenvolvimento e de produção seja o mais reduzido possivel e que o risco financeiro presente no desenvolvimento de um novo produto seja limitado. $Q$ s FPGAs (Field Programmable Gate Arrays) surgiram como uma solução para estes problemas. A sua estrutura pode ser configurada pelo usuário final, permitindo uma rápida fabricação (em minutos) e a construção de protótipos a custos muito reduzidos, da ordem de algumas centenas dólares [BRO96], [CHA94], [OLD95], [PAY97].

As linguagens de descrição de hardware, HDLs (Hardware Description Languages), têm acelerado o ciclo de projeto, sendo, atualmente, uma ferramenta fundamental para descrição e especificação de projetos. As Ferramentas modernas de síntese lógica automática possibilitam o projeto de circuitos que prontamente podem ser mapeados em silício [ASH96], [COE95].

Nas últimas duas décadas a aplicação de controle digital a sistemas industriais cresceu vertiginosamente. Nestel contexto, destaca-se o controle PID (Proporcional, Integral e Derivativo), com grande aplicação na industria, permitindo um controle mais fiel e mais otimizado de sistemas. O§ robôs como ferramentas industriais e de serviços podem ser móveis e, ao mesmo tempo, dotados de membros articulados. Nestes dois casos, a propulsão do robô e a movimentação de seus membros são feitas, na maioria das vezes, por servo-motores do tipo CC (Corrente Contínua). Para o controle deste tipo de motor, o algoritmo PID é o mais amplamente utilizado por ser relatiyamente simples e pela facilidade de sintonia de seus parâmetros [BOW99]. 
A escolha dos FPGAs para implementar um controlador PID digital, está fundamentada nos requisitos de alto desempenho, baixo custo e facilidade de reconfiguração, vantagens ainda não oferecidas pelos propessadores DSP (Digital Signal Processor), geralmente utilizados para esta tarefa. As estruturas paralelas e o fluxo de dados em um FPGA permitem a implementação de algoritmos DSP de forma que a utilização dos recursos seja minimizada e o desempenho seja aumentado, em relação aos sistemas que utilizam DSP de propósito geral [GOS96], [TEX96]. 


\section{Metodologias Avançadas para Projeto de Hardware}

Este tópico tem Łomo objetivo principal proporcionar uma visão geral do processo de projeto de sistemas digitais modemos, visando a compreensão dós diferentes métodos e ferramentas computacionais utilizados para esse fim e o papel do projetista humano neste contexto. O projeto de hardware atual é baseado em ferramentas de alto nível, o que permite um ciclo de desenvolvimento menor aliada a uma confiabilidade maior.

\subsection{Processo de Projeto de Sistemas Digitais}

Em meados do século passado, G. Boole desenvolveu um sistema matemático de análise lógica que ficou conhecido como álgebra de Boole. Neste sistema, está baseada a lógica dos circuitos elétricos digitais, que apenas podem assumir dois estados elétricos distintos. Utilizando os blocos básicos digitais, conhecidos como portas lógicas $O R, A N D, N O$, e FLIP-FLOPS, podese implementar sistemas mais complexos tais como codificadores, decodificadores, sistemas de controle, memórias, ULA\$, registradores, processadores, etc.

A construção de sistemas e subsistemas digitais, como os mencionados anteriormente, pode ser particionada em dois conjuntos de tarefas. O primeiro conjunto de tarefas é o chamado processo de fabricação, que engloba a manipulação direta dos elementos do mundo fisico, tais como a difusão de impurezas em regiões de um substrato semicondutor para a criação de transistores, ou a solda de pinos de Circuitos Integrados (CIs) em determinadas posições de uma placa de circuito impresso. A segunda etapa da fabricação é o processo de projeto e envolve as tarefas de manipulação de modelos abstratos capazes de representar o sistema que se deseja implementar, tais como a simulação de um diagrama de interconexão de portas lógicas, ou a minimização de equações Booleanas que representem a funcionalidade de um módulo do sistema [CAL95].

$O$ processo de fabricação pode ser considerado como um algoritmo, que tem como entrada o processo de projeto e cuja saída é o sistema digital desejado. Este processo envolve não só a construção do $\mathrm{Cl}$, mas também o teste, encapsulamento e montagem de placas. Devido a essas características, a automatização do processo de fabricação pode ser feita sem maiores problemas. 
Já o processo de projeto de sistemas digitais envolve uma certa porção de criatividade e conhecimento do subseqüente processo de fabricação por parte do projetista, sendo a sua automatização uma tarefa muito mais complexa. Este processo pode ser caracterizado como uma transformação de uma descrição inicial ou especificação em uma descrição final ou projeto final. A descrição final contém todas as informações necessárias à fabricação do sistema.

Pode-se dividir o processo de projeto em duas atividades principais. A primeira delas é a sintese, que acrescenta informação a uma descrição, produzindo uma descrição mais próxima da final. Na segunda atividade, que é a de análise, verifica-se se as decisões foram acertadas durante a etapa de síntese.

Dois aspectos importantes e que devem ser avaliados quando se faz um projeto de um sistema digital são a correção e a otimização. Uma descrição final de um projeto é correta se esta atende a todos os requisitos da descrição inicial e, portanto, pode ser fabricada. Uma descrição final é ótima se além de estar correta, possui um desempenho melhor e um custo mais baixo que qualquer outra solução correta [CAL95].

Características ótimas de sistemas digitais podem ser avaliadas sob três aspectos. $O$ primeiro é o espaço, que deve ser o menor possível. Em seguida, tem-se o tempo, que está relacionado com a velocidade de operação do sistema, que é desejável que seja a maior possível. A última característica importante é a energia, que especifica qual a potência de operação do sistema e, portanto, deve ser mínima.

\subsection{A Modelagem do Processo de Projeto}

Para se reduzir a complexidade de um tratamento global, o processo de projeto deve ser decomposto em um conjunto de passos. Essa decomposição é feita de maneira hierárquica e baseia-se na quantidade de informação contida nas descrições associadas a cada passo. Esses passos ou níveis de hierarquia de projeto são denominados níveis de abstração. Exemplo de níveis de abstração seria um diagrama de portas lógicas ou um conjunto de equações Booleanas. 
O grau de abstração varia de maneira inversamente proporcional à quantidade de informação agregada, ou seja, um grau mais alto de abstração está associado à descrição inicial do projeto e um grau de abstração mais baixo descreve um projeto em sua fase final, com todos os detalhes pertinentes a sua construção.

Podem ser listado quatro niveis em ordem crescente de abstração:

Nível elétrico - os modelos dos componentes são baseados na teoria de circuitos elétricos e eletrônicos, e/ou na física de semicondutores. Como por exemplo, transistores, resistores, capacitores, equações diferenciais, diagramas elétricos, etc.

Nível lógico - neste caso, o sistema digital é descrito a partir da teoria de circuitos digitais, como portas lógicas, flip-flops, equações Booleanas, tabelas e grafos de transição, etc.

Nível arquitetural - neste nível hierárquico, os modelos de base são componentes digitais mais complexps, como por exemplo, registradores, decodificadores, ULAs, multiplexadores, linguagens de transferência entre registradores, grafos de fluxo de dados e de controle, etc.

Nível sistêmico- neste último nível, o sistema digital é descrito como um conjunto de algoritmos e módulos mais complexos, que podem ou não ter um mapeamento direto para um "hardware" existente: processadores, memórias, componentes abstratos implementados no "software" básico do sistema, tais como um pacote de ponto flutuante em um sistema sem coprocessador aritmético, ou monitores de sistemas operacionais.

Além de representar o sistema por estes conjuntos de niveis, que retratam a quantidade de abstração das descrições đo projeto, pode-se, também, classificar as descrições de acordo com o tipo de informação que carregam. Dessa forma, tem-se o conceito de domínio de descrição, que nada mais é do que o tipo de informação contida em uma determinada descrição de um sistema digital. Esses domínios podem ser representados ao longo de três eixos, onde o refinamento do projeto é conduzido em niveis de abstração. Esses eixos ou domínios de descrição para sistemas digitais estão mais explicitados a seguir: 
Comportamentą ou funcional - neste nível mais alto, há um enfoque no que o "chip" faz e como este foi construído, descrevendo o comportamento do sistema, sem entrar em detalhes de como esse comportamento pode ser obtido e não levando em conta o lado físico ou estrutural. Como exemplo, pode-se citar uma expressão Booleana ou um algoritmo.

Estrutural - esta representação é o elo entre as representações funcional e geométrica, sendo uma forma de mapeamento de uma representação funcional em um conjunto de componentes e ligações, fendo como limitantes o custo, área ocupada e tempo (velocidade). Por exemplo, uma expressão booleana é mapeada, por essa representação, em um conjunto de portas lógicas, não especificando os parâmetros físicos, como o posicionamento das portas lógicas em uma placa de circuito impresso ou em um "chip" de silício. Por exemplo, um diagrama esquemático de um circuito digital é uma representação estrutural que serve como representação funcional, isto é, pode ser simulada para representar o comportamento temporal.

Físico ou geométrico - esta representação final, ignora o máximo possível o que o projeto deve fazer, estando relacionada à estrutura espacial (projeto fisico) ou ao silício (projeto geométrico). Tipos de níveis de representação geométrica são planejamento de "layout" com blocos, células e máscaraș fisicas de tamanho arbitrário.

Estes niveis de abstração provêem uma forma ao mesmo tempo simples e poderosa de interpretar o processo de projeto de sistemas digitais. Uma forma de representação desse modelo bidimensional é o diagrama $\mathrm{Y}$, que foi proposto originalmente por Gajski e Kuhn [GAJ83]. Neste diagrama, há três eixos centrados em círculos concêntricos. Os eixos radiais representam os dominios de descrição (comportamental, estrutural e fisico) e os círculos correspondem aos niveis de abstração (elétrico, lógico, arquitetural e sistêmico). Cada interseção de um círculo com um segmento radial repreșenta um tipo de descrição distinta do sistema digital em projeto. 
No diagrama Y, da FIGURA 2.1, pode-se notar os níveis de refinamento de projeto. Quando se faz a síntese de um projeto de uma visão mais geral para uma mais detalhada, o projetista deve ter em mente uma representação de alto nível mostrando o que o "chip" deverá fazer até a geometria que fará parte de sua máscara.

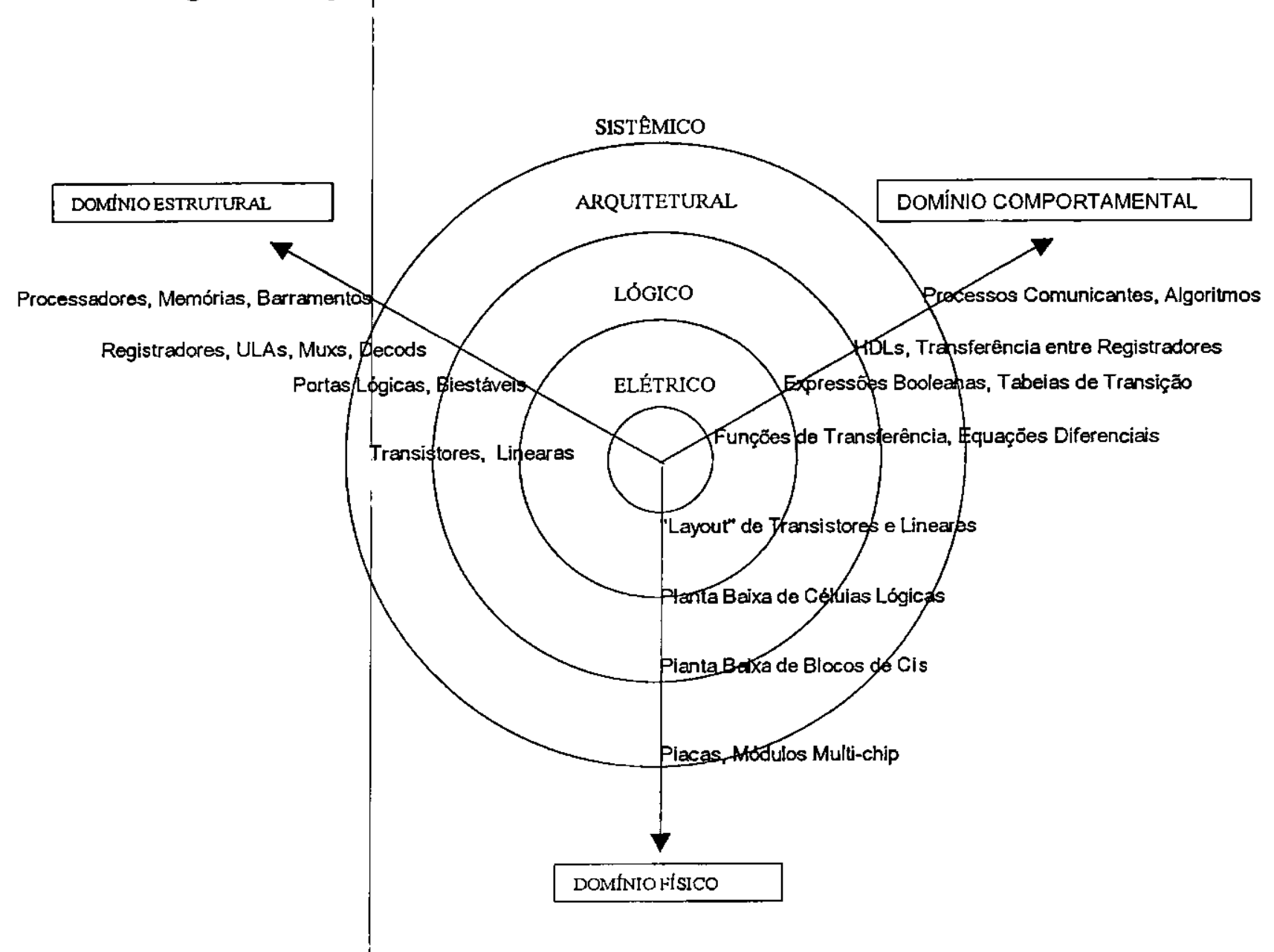

Figura 2.1- Diagrama Y: Domíntos e Niveis de Descriçāo de Sistema.

Para representar um método de projeto em um diagrama $\mathrm{Y}$, dispõe-se o processo na forma de um dígrafo (grafo dirigido) sobreposto ao diagrama Y. Nesta representação, o conjunto de vértices representa o conjunto de descrições de projeto e as arestas são os métodos e ferramentas empregados no sistema. Deseja-se neste caso, atingir o centro do diagrama, que corresponde à especificação final do projeto, contendo toda a informação necessária à fabricação do sistema digital. 


\subsection{Histórico Das Ferramentas CAD}

\subsubsection{Ferramentas de Projeto Baseadas em Simulação}

Já na década de 60, quando o projeto de Circuitos Integrados passou a utilizar centenas de componentes, houve a necessidade de se utilizar ferramentas computacionais que auxiliassem o projetista, as ferramentas $\mathrm{CAD}$ (Computer Aided Design). Devido à complexidade atingida pelos projetos, não era mais viável que este fosse feito manualmente, ficando passivel a erros $\mathrm{e}$ consumindo um tempo de projeto excessivo. Essas ferramentas computacionais tinham como função a captura de descrições fisicas do circuito, sendo chamadas de editores de "layout". Para que ficasse garantida a oorreção das descrições feitas por projetistas humanos com auxilio de ferramentas de desenho, surgiram as ferramentas de verificação de regras de desenho e os extratores de circuito, que geram uma descrição estrutural em nivel elétrico de abstração a partir de uma descrição geométrica [CAL95].

A etapa seguinte da evolução das ferramentas $\mathrm{CAD}$, foi o uso de simuladores de circuitos elétricos, tal com o SPICE, (Simulation Program Integrated Circuits Especially) que automatizam e dimensionam o funcionamento de transistores, permitindo a previsão do comportamento do circuito em simulação. Da mesma forma, surgiram para os circuitos digitais, os editores de diagramas de portas lógicas e os simuladores lógicos.

Neste estilo de projeto, baseado em simulação, a importância do projetista está bem clara, sendo a criatividade um fator fundamental para que se faça um bom projeto. $O$ projetista humano, além de fazer uma descrição estrutural e/ou comportamental do sistema, deverá também criar um conjunto de entradas para excitar a descrição. Provido das excitações, o programa simulador calcula as saídas de acordo com os modelos dos componentes envolvidos na simulação. Após a simulaçãa, o projetista deve fazer uma análise dos resultados ou saídas, para verificar se estas satisfazem os requisitos do projeto. A FIGURA 2.2 mostra um fluxograma ilustrativo do processo de projeto por meio de simulação. 


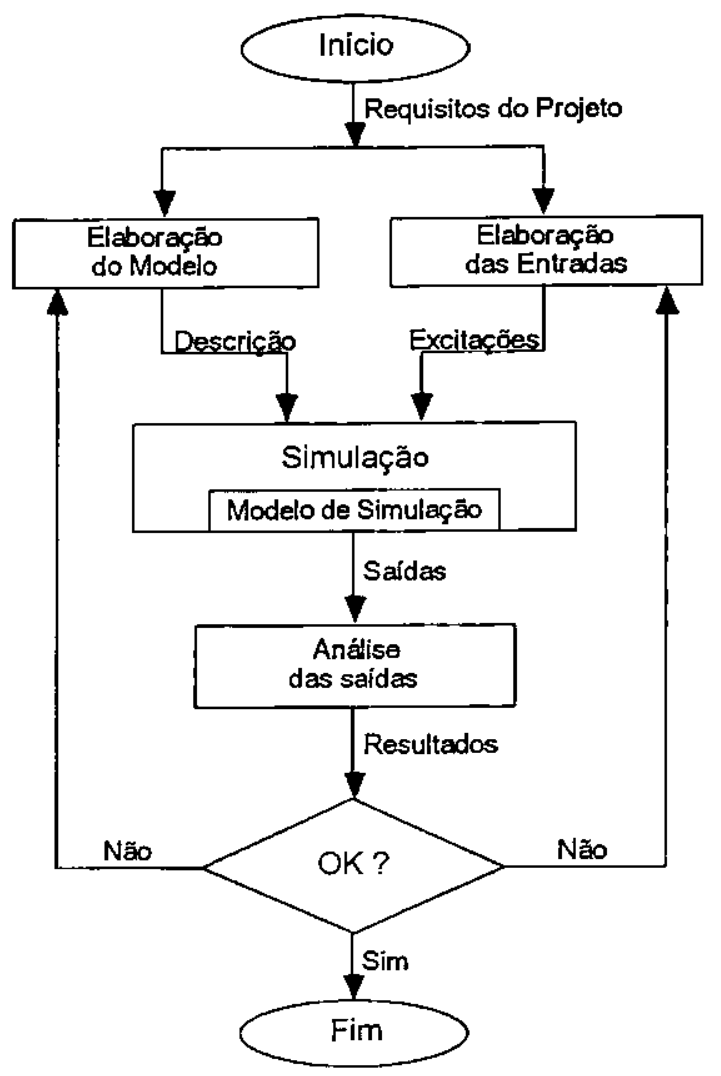

FIGURA 2.2 - FLUXXGRAMA DO PROJETO POR SIMULAÇÃO.

\subsubsection{Ferramentas de Projeto Baseadas em Síntese Automatizada}

Teorias e métodos de síntese automatizada para equações Booleanas são conhecidos desde a década de 50, porém, o seu emprego para o projeto de sistemas digitais só se tornou relevante nos meados da década de 70 . Com os projetos de sistemas digitais tornando-se mais complexos, não bastava| apenas ao software facilitar a captura e manipular descrições, era necessário que este também fosse capaz de gerar novas descrições. As descrições, através desse método seriam corretas por construção, tomando se como padrão os mesmos requisitos utilizados pelos projetistas.

Nas ferramentas baseadas em síntese automatizada o projetista não está mais incumbido da tarefa de gerar uma descrição inicial e as devidas excitações. A ferramenta é a responsável por essa parte inicial, sendo capaz de gerar descrições corretas por construção e de até analisar o desempenho dessa descrição. Tudo isso é possível graças ao conjunto de modelos de síntese que essas ferramentas possuepm internamente. 
O projetista ao final da síntese deve avaliar os resultados para decidir se os aceita ou rejeita. Caso os resultados da síntese não sejam favoráveis, um novo modelo de sintese, ligeiramente diferente pode ser escolhido, de forma que se possa explorar de maneira contínua um conjunto de soluções corretas. Juntamente à síntese, pode-se empregar a simulação dos resultados obtidos, o que provê mais informações a respeito da implementação. A FIGURA 2.3 mostra um fluxograma representativo do processo de projeto por meio de sintese automatizada.

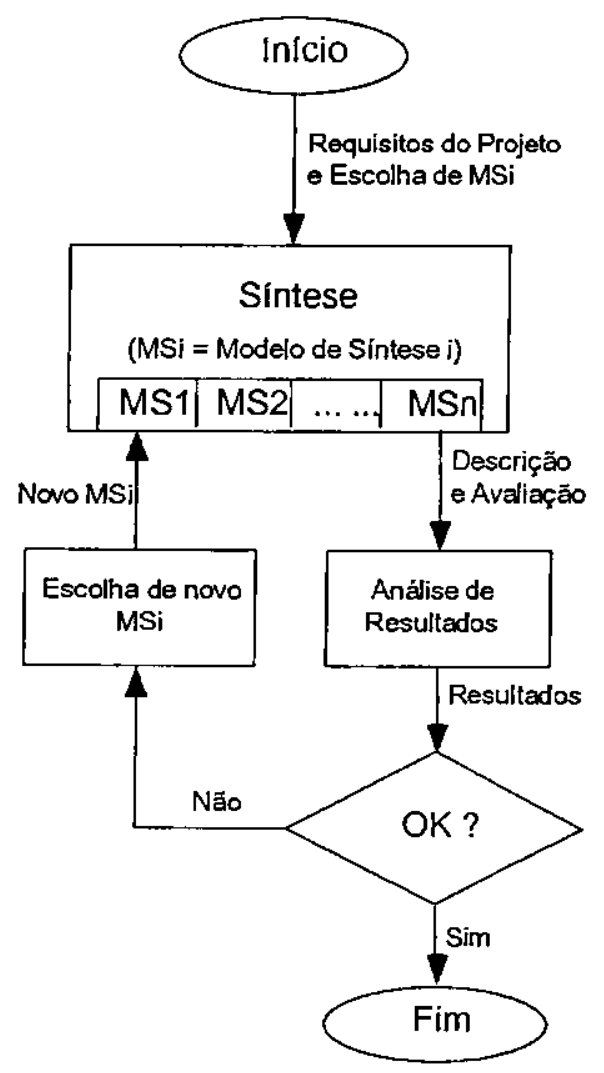

\section{Figura 2.3 - Fluxograma Do Projeto Por Síntese automatizada.}

\subsubsection{Ferramentas Modernas de Projeto de Sistemas Digitais}

Graças a grandes mudanças ocorridas na tecnologia, o projeto de circuitos digitais evoluiu significativamente nestas últimas décadas. Com estas mudanças, pode se observar que os componentes progrediram de simples transistores discretos até circuitos VLSI (Very Large Scale Integration), atingindo a 'casa de milhões de transistores em um mesmo encapsulamento. As Ferramentas CAD modernas, aceleram o ciclo de projeto, não sendo mais necessário o desenho 
de componentes individuais tais como portas lógicas. Desde a década de 80 , ocorreu uma mudança de enfoque entre a as ferramentas de projeto digital, quando as ferramentas de síntese passaram a ser mais valorizadas, servindo hoje como base para projetos [CHA94]

Ferramentas de síntese lógica automatizada estão disponiveis para criar circuitos que são rapidamente mapeados em silício. Todo esse avanço tecnológico nas técnicas de projeto de circuitos VLSI está fazendo com que o ciclo de vida dos produtos torne-se menor que o seu tempo de projeto, criando assim, uma necessidade de uma prototipação mais rápida.

A automatização do tratamento de descrições de sistemas digitais desempenha um papel fundamental na redução do tempo de projeto, assim como na qualidade dos circuitos e nos produtos desenvolvidos. Entretanto, à medida que se aumenta a escala de integração de CIs, cresce também a dificuldade de se obter projetos livres de erros. Dessa forma, as ferramentas utilizadas para automatizar um processo de projeto devem estar em constante evolução, para que sejam capazes de lidar dom a crescente complexidade dos módulos usados na construção de sistemas digitais. A indústria de ferramentas de Projeto Auxiliado por Computador (CAD) tornou-se hoje, ela própria, um setor substancial da indústria eletrônica global.

\subsection{Metodologia de Projeto Digital}

A implementação de um sistema digital não é independente do estilo de projeto. Sistemas digitais podem ser implementados em várias tecnologias, dependendo do seu tamanho, da sua função e do seu custo. As implementações de circuitos podem ser agrupadas em duas categorias principais: circuitos completamente customizados e semicustomizados, como ilustrado na FIGURA 2.4. A categoria de circuitos semicustomizados consiste de várias abordagens, as quais têm facilitado o projeto e a fabricação de circuitos digitais [ARA97]. 


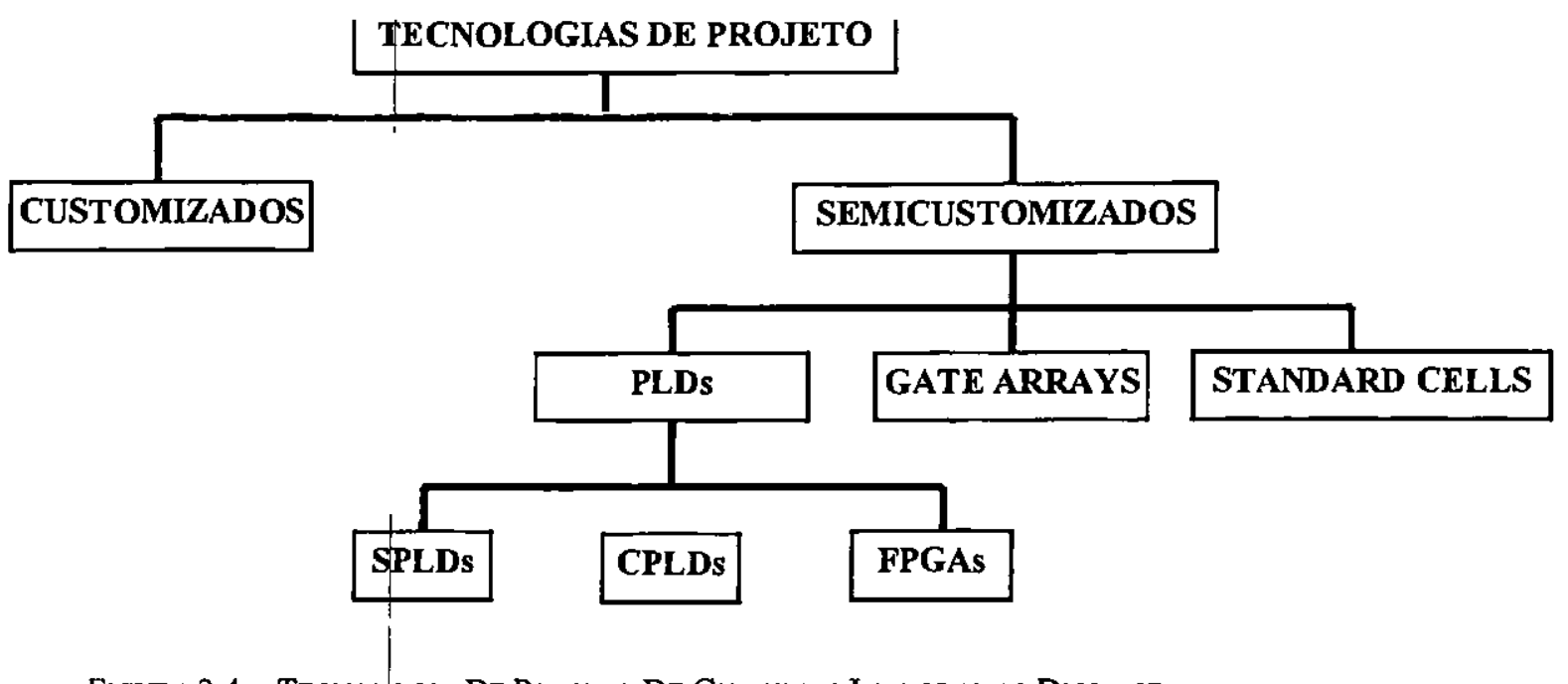

Figura 2.4 - TeCnologia De Projeto De Circuitos Integrados Digitais.

$\mathrm{Na}$ hierarquia de projeto de circuitos digitais, o nível mais complexo é o projeto totalmente "customizado" ou feito sob medida. Em um projeto totalmente customizado, o projetista trabalha em nivel de transistor, tendo, portanto, total controle sobre todas as variáveis de projeto, tais como velpcidade, layout, tensão elétrica, consumo de potência, etc. Dessa forma, pode-se escolher um compromisso entre uma ou mais variáveis de projeto para que se consiga um melhor desempenho nas outras variáveis [WIS97]. O preço a se pagar por este desempenho é alto, já que esse tipo de circuito é geralmente o mais caro em termos de engenharia de desenvolvimento. A sua confeç̧ão requer um processo de fabricação especial que exige máscaras específicas para cada projeto e ferramentas de desenvolvimento sofisticadas, com especialistas altamente treinados e fábricas de alta tecnologia. Para aplicações que requerem grande volume de produção, o alto custo do projeto e dos testes pode ser amortizado.

Circuitos semicustomizados foram desenvolvidos para dar aos projetistas de sistemas digitais a possibilidade de implementar circuitos com desempenho próximo aos dos "chips" customizados, mas com/custos de desenvolvimento, tempos de projeto e de fabricação mais baixos. Essa nova metbdologia tem facilitado o projeto e fabricação de circuitos ASIC (Application Specific Integrated Circuit). ASICs podem ser definidos como Cls projetados para uma aplicação específica, sendo geralmente utilizados nas áreas de telecomunicações, automotiva e outras [CHA94]. 
Um exemplo particular de dispositivos semicustomizados é o MPGA (MaskProgrammable Gate Array), no qual o processo de fabricação é acelerado pelo uso de máscaras genéricas de módulos pté-projetados, mas ainda necessitando de máscaras específicas para a interconexão dos módulos. O projeto é usualmente facilitado por uma biblioteca de células, permitindo um tempo de desenvolvimento mais curto e custos mais baixos que $\mathrm{Cls}$ customizados.

Um outro tipo de circuito semicustomizado é o Standard Cell, que como no caso dos MPGA, tem o seu projeto é facilitado pelo uso de módulos pré-projetados. Os módulos standard cells são geralmente salyos em um banco de dados. Os projetistas selecionam as células do banco de dados para tealizar o projeto. Comparado aos Cls customizados, os circuitos implementados em standard cells são menos eficientes em desempenho e apresentam um tamanho maior. Uma vantagem de sua utilização está no seu custo de desenvolvimento mais baixo.

Os Programmable Logic Devices ou PLDs têm como característica principal a capacidade de ser programado ou configurado pelo usuário. Este fato elimina o processo de fabricação e permite que se faça alterações de projeto mais facilmente, tornando o ciclo de projeto mais curto. Os PLDs são classificados em várias categorias conforme as características de sua arquitetura e sua capacidade lógica.

Pertencente ao grupo dos PLDs, está a tecnologia FPGA (Field Programmable Gate Arrays), que apresenta una alta densidade de portas lógicas (mais de 2.5 milhões) operando com freqüência de clocks eleyados (maiores que $600 \mathrm{MHz}$ ). Nos FPGAs, uma matriz de portas ou elementos lógicos são đispostos sem conexão em um substrato, sendo que as conexões são definidas pelo projetista e seu software de projeto. Detalhes a respeito da tecnologia FPGA serão discutidos mais adiante em um capítulo exclusivo.

O mercado para PLDs tem crescido exponencialmente na última década ao ponto que há uma grande variedade de dispositivos atualmente disponiveis. Um projetista hoje depara com a dificil tarefa de pesquisar os diferentes tipos de chips, entender qual sua melhor utilização, 
escolher um fabricante especifico, aprender a utilizar as ferramentas EDA (electronic design automation) ou CAD para só então começar a projetar o hardware [ARA97].

O nivel mais baixo de projetos de sistemas digitais (não contando transistores discretos) é feito com circuitos integrados de pequena e média escala, tais como a família de CIs TTL 7400 e CMOS 4000, que reinaram da década de 60 até a década de 70. Projetos com esse tipo de "chip" apresentam sérios problemas quando se empregam dezenas e muitas vezes até centenas de chips em uma placa. Exemplos de problemas são: particularidades próprias de cada tecnologia, atrasos de tempo entre chips, interferências entre fios (no caso de protótipos em wire-wrapping, atrasos de clock, consumo de energia e dificuldades em se alterar um projeto já implementado).

No próximo capítulo serão descritas a tecnologia FPGA e as ferramentas que auxiliam o projeto e a simulação de produtos com este dispositivo. 


\section{Field Programmable Gate Arrays - FPGAs}

FPGA ou Field Programmable Gate Array é um tipo de dispositivo relativamente novo, especifico para construção de sistemas digitais. Um FPGA é implementado como uma matriz de blocos funcionais em uma rede de interconexão, cercado por blocos de entrada e saída (I/O blocks) [XIL99a]. Com o próprio nome sugere, o termo Field (campo) indica que sua programação pode ser fejta em campo, ou seja, no lugar de aplicação. A função de cada bloco lógico do sistema $\mathrm{e}$ as suas conexões são especificadas pelo usuário no momento da programação [OLD95].

Os FPGAs apresentam uma solução a custos mais baixos em uma ampla gama de aplicações, se comparados aos circuitos VLSI "customizados", permitindo também, novas possibilidades no projeto de sistemas digitais reconfiguráveis [BRO97].

\subsection{A Evolução dos Dispositivos Programáveis}

Há muito tempo, os dispositivos programáveis desempenham um papel fundamental no projeto de hardware digital. Estes são circuitos integrados de propósito geral que podem ser configurados para uma grande variedade de aplicações.

O primeiro tipo de dispositivo programável utilizado foi o Programmable Read-Only Memory (PROM), cuja característica é ser programável apenas uma vez. A PROM apresenta como arquitetura intema uma matriz de célula apenas de leitura. Pode-se implementar com as PROMs um circuito lógico utilizando-se suas linhas de endereço como entradas do circuito e seus bits armazenados como saída, dessa forma, qualquer tipo de tabela verdade pode ser construída [BRO96b].

Existem duas versões de PROMs disponíveis: as que são programadas pelo fabricante, conhecidas como mask-programmable e as que podem ser programadas pelo usuário final, sendo conhecidas como field programmable.

Quando um circuito lógico é implementado, um desempenho superior pode ser obtido utilizando-se CIs do tipo mask programmable, uma vez que as conexões internas do dispositivo 
podem ser estabelecidas durante o processo de fabricação. Por outro lado, conexões programáveis sempre utilizam algum tipo de chave (como por exemplo, um fusível), que é inerentemente mais lento que uma conexão feita em fábrica. Apesar disso, dispositivos do tipo field programmable oferecem vantagens que compensam o menor desempenho:

- CIs do tipo field programmable podem ser programados imediatamente, em minutos, enquanto que os dispositivos do tipo mask programmable têm de ser fabricados em uma foundry, que pode levar semanas ou até meses.

- Dispositivos do tipo field programmable são componentes diretamente disponíveis no mercaqo e por este motivo, são mais baratos, em volumes menores, do que os dispositivos mask programmable.

Dois dispositivos do tipo field programmable variantes da PROM, o Erasable Programmable Read-Only Memory (EPROM) e o Electrically Erasable Programmable

Read-Only Memory (EEPROM) oferecem a vantagem adicional de ambos poderem ser apagados e reprogramados várias vezes. Em algumas aplicações, particularmente durante os primeiros estágios de um projeto de circuito lógico, a reprogramabilidade é uma característica atrativa.

A primeira família de dispositivos programáveis, projetada especificamente para implementar circuitos lógicos é a dos Programmable Logic Devices (PLDs). Um dispositivo do tipo PLD é composto internamente por uma matriz de portas lógicas AND, seguida de uma matriz de portas lógicas $\phi R$. Um circuito lógico para ser implementado em PLD é representado na forma de soma de produtos.

Lançado pela Philips em 1970, o Programmable Logic Array (PLA) foi o primeiro dispositivo do tipo PLD a ser comercializado. O PLA apresenta uma estrutura de plano AND programável, seguida de uma estrutura de plano OR programável. A estrutura do PLA permite que quaisquer entradas, qu seus complementos, sejam combinadas umas com as outras no plano AND, de forma que cada saída do plano AND pode corresponder a qualquer termo produto das entradas. De modo similar, cada saída do plano OR pode ser configurada para produzir a soma lógica de qualquer saída do plano AND. Os PLAs são ideais para implementar funções lógicas 
na forma de soma de prфdutos, sendo também, devido ao grande número de entradas, muito versáteis.

As principais desvantagens dos PLAs eram o seu alto custo de produção e um baixo desempenho, causados pelo fato de haver dois planos configuráveis. Para sanar este problema, a MMI (Monolitic Memories' ${ }^{\mathrm{TM}}$ ) desenvolveu o PAL (Programmable Array Logic). Um PAL possui apenas um nível de programabilidade, consistindo de um plano AND programável, seguido de um plano OR fixo. Para possibilitar a implementação de circuitos seqüenciais, as saidas das portas lógicas OR podem ser opcionalmente registradas por um Flip-Flop, ver a FlGURA 3.1. Para compensar a falta de generalidade causada pelo plano OR fixo, os PALs são produzidos com números diferentes de entradas e saídas, tamanhos variados de portas $O R$ [BRO96a].

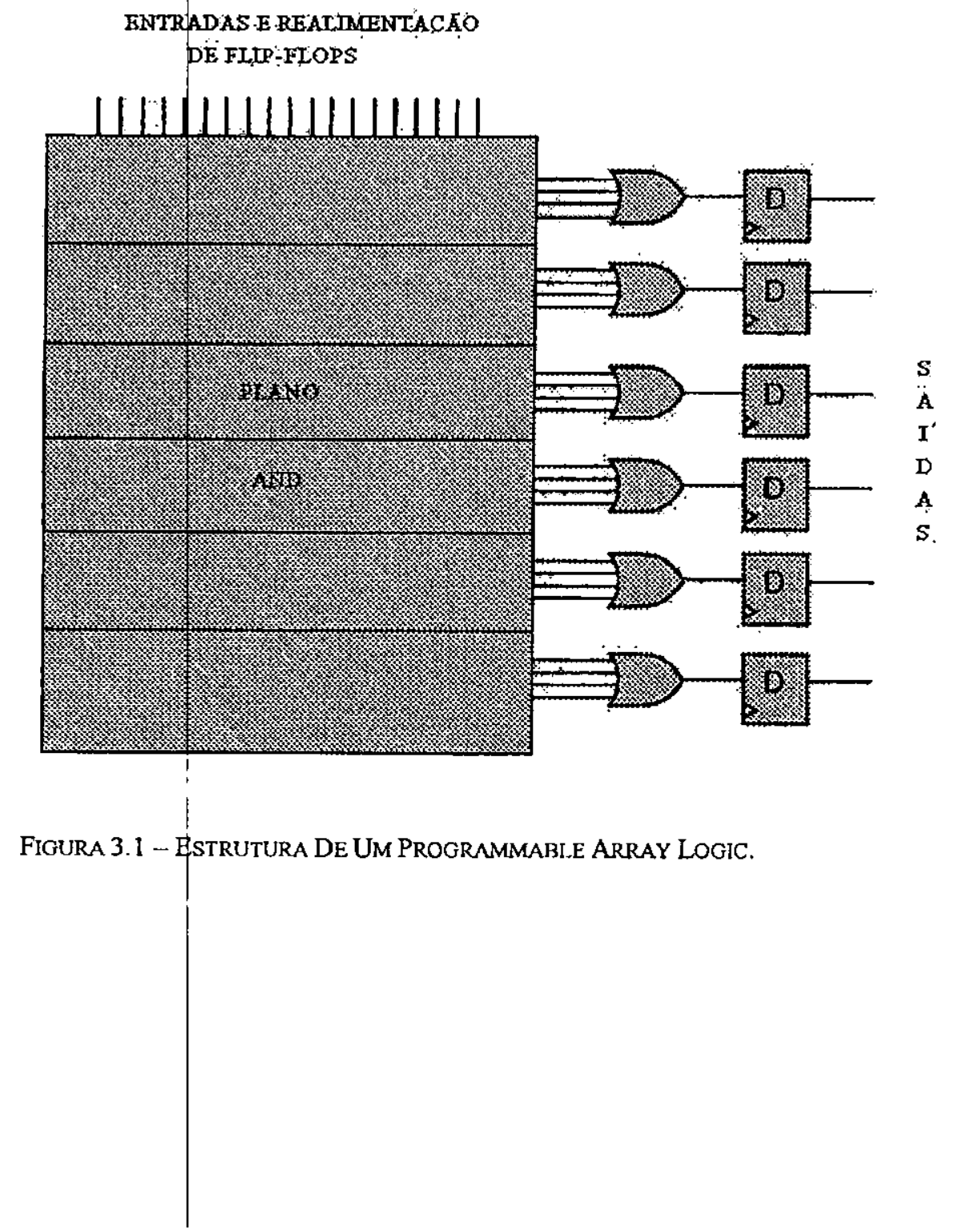


Contendo estruturas simples com dois níveis, os dois tipos de PLDs descritos anteriormente, permitem implementações de circuitos lógicos de alto desempenho, no entanto, a simplicidade das suas estruturas é a causa da sua maior desvantagem. Os PLDs podem implementar somente pequenos circuitos lógicos que são representados por um número modesto de termos produto, já que sua estrutura de interconexão cresceria a números impraticáveis se o número de termos produt $\oint$ fosse aumentado.

Os pequenos dispositivos lógicos programáveis, incluindo os PLAs e PALs, podem ser agrupados em uma categoria chamada de SPLD (Simple Programmable Logic Devices), cujas principais características são o baixo custo e a alta velocidade entre pinos.

Devido ao plano de portas programáveis crescer muito com o do número de entradas, há dificuldade em se aumentar a capacidade da arquitetura dos SPLDs. A única maneira de superar este problema e conseguir alta capacidade lógica para os dispositivos baseados na arquitetura SPLD, é interconectando-se vários (cerca de 50) SPLDs em um único CI. Atualmente, muitos dispositivos do mercado estão baseados nesta arquitetura, sendo conhecidos por CPLDs (Complex Programmable Logic Devices). A Altera foi a empresa pioneira no ramo de CPLDs [BRO96].

O tipo mais geral de dispositivo programável consiste de uma matriz de elementos independentes que podem ser interconectados de acordo com as especificações do usuário. A esta classe, pertencem os dispositivos conhecidos como (MPGAs) ou Mask Programmable Gate Arrays.

Para a implementação de um circuito em MPGA, são utilizadas máscaras genéricas para todo o circuito, exceto para as camadas de metalização, que são especificadas ao fabricante pelo usuário. As máscaras genéricas criam uma matriz de blocos funcionais. Módulos de transistores são arranjados em linhas separadas por canais de tamanho fixo, sendo a lógica desejada implementada por configuração dos transistores em funções lógicas e fazendo a conexão dos diferentes módulos. O projeto é geralmente facilitado pelo uso de uma biblioteca de células, tornando a experiência do projetista menos crítica para o caso de projetos com metodologia totalmente "customizada" [CHA94]. 
Os MPGAs possuem um alto custo inicial de fabricação devido à necessidade de gerar a camada metálica de máscara e fabricar o chip. No entanto, o custo unitário cai significativamente quando grandes volumes (mais de 1000 chips) são fabricados. A principal vantagem dos MPGAs em relação aos PLDs é a possibilidade de se utilizar uma grande estrutura geral que permite a implementação de circuitos muito maiores, fato possível graças a sua estrutura de interconexão que pode ser aumentada proporcionalmente a quantidade de lógica. Por outro lado, uma vez que MPGAs utilizam tecnologia de máscaras para sua fabricação, estes não são programáveis em campo, ou diretamente pelo usuário e requerem, portanto, um tempo significativo de manufatura, o que resulta em um custo inicial alto.

O FPGA combina a programabilidade de um PLD (chaves programáveis eletricamente) e a estrutura de interconexão maleável de um MPGA, resultando em dispositivos programáveis com densidade lógica muito maior [BRO97].

\subsection{A Estrutura Básica do FPGA}

O Field Programmable Gate Array ou FPGA é um dispositivo programável de propósito geral, que pode ser configurado para uma ampla variedade de aplicações. Neste circuito integrado, as conexões entre os elementos lógicos internos são programadas pelo usuário.

O FPGA foi introduzido em 1985 pela empresa americana Xilinx Inc, fundada em 1984 com sede em San Jose, Califórnia. Logo após, muitos tipos de FPGAs foram lançados por várias empresas do ramo, tais como Actel, Altera, Plessey, Plus, AMD, Quick Logic, Algotronix, Concurrent Logic, Crosspoint Solutions, Atmel e outras [VCC97].

Para uma melhor compreensão dos vários tipos de estrutura intema de FPGAs, é interessante analisar, em primeira instância, um diagrama conceitual de um FPGA típico. Como pode ser observado na FIqURA 3.2, um FPGA consiste de uma matriz bidimensional de blocos lógicos que podem ser conectados através de recursos de interconexão gerais. A interconexão é feitas com segmentos de trilha que podem ter tamanhos variados. Chaves programáveis fazem a 
ligação dos blocos lógicфs aos segmentos de trilha ou entre segmentos. Nas extremidades do FPGA, blocos especiais de entrada e saída fazem a conexão do FPGA aos sinais externos [PAY97].

Em um FPGA, a implementação de circuitos lógicos é feita particionando-se a lógica em blocos e então, interconectando-se os blocos de um modo conveniente com chaves [BRO97].

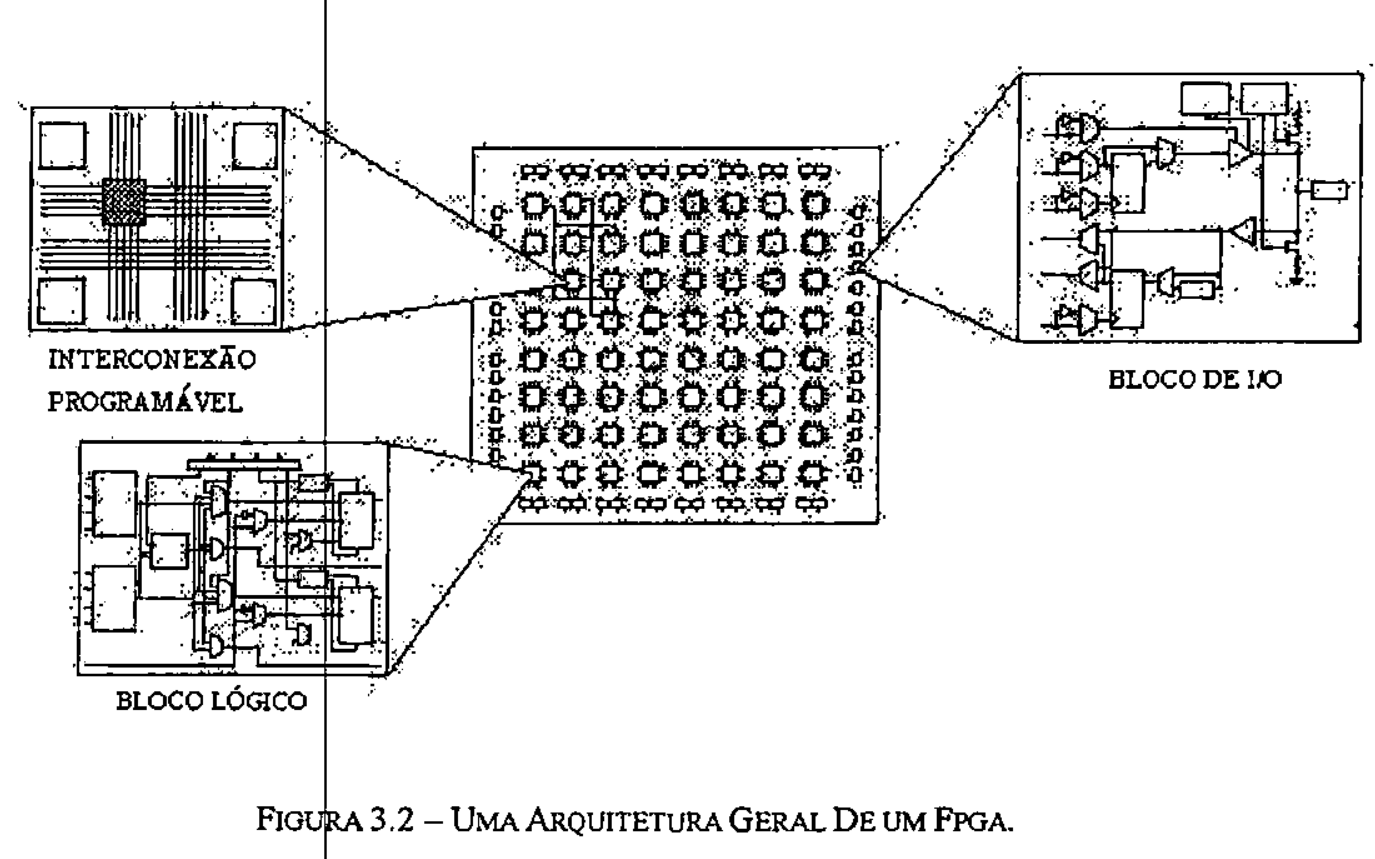

Atualmente, há quatro principais categorias de FPGA no mercado, como pode ser visto na FIGURA 3.3.

- Array ou Matriz simétrica.

- Baseado em colunas.

- PLD hierárquico.

- Mar de portas.

Em todas as categorias de FPGAs apresentados anteriormente, a arquitetura de interconexão e o estilo de programação variam. Um FPGA tem sua arquitetura definida a partir de três aspectos: arquitetura dos blocos lógicos, a arquitetura de roteamento e a tecnologia de programação. Esses três aspectos têm influência direta sobre o desempenho e a densidade dos diferentes tipos FPGAs, todavia, não se pode afirmar que há uma melhor arquitetura, e sim, uma mais adequada a uma deteıminada aplicação [ROS93]. 


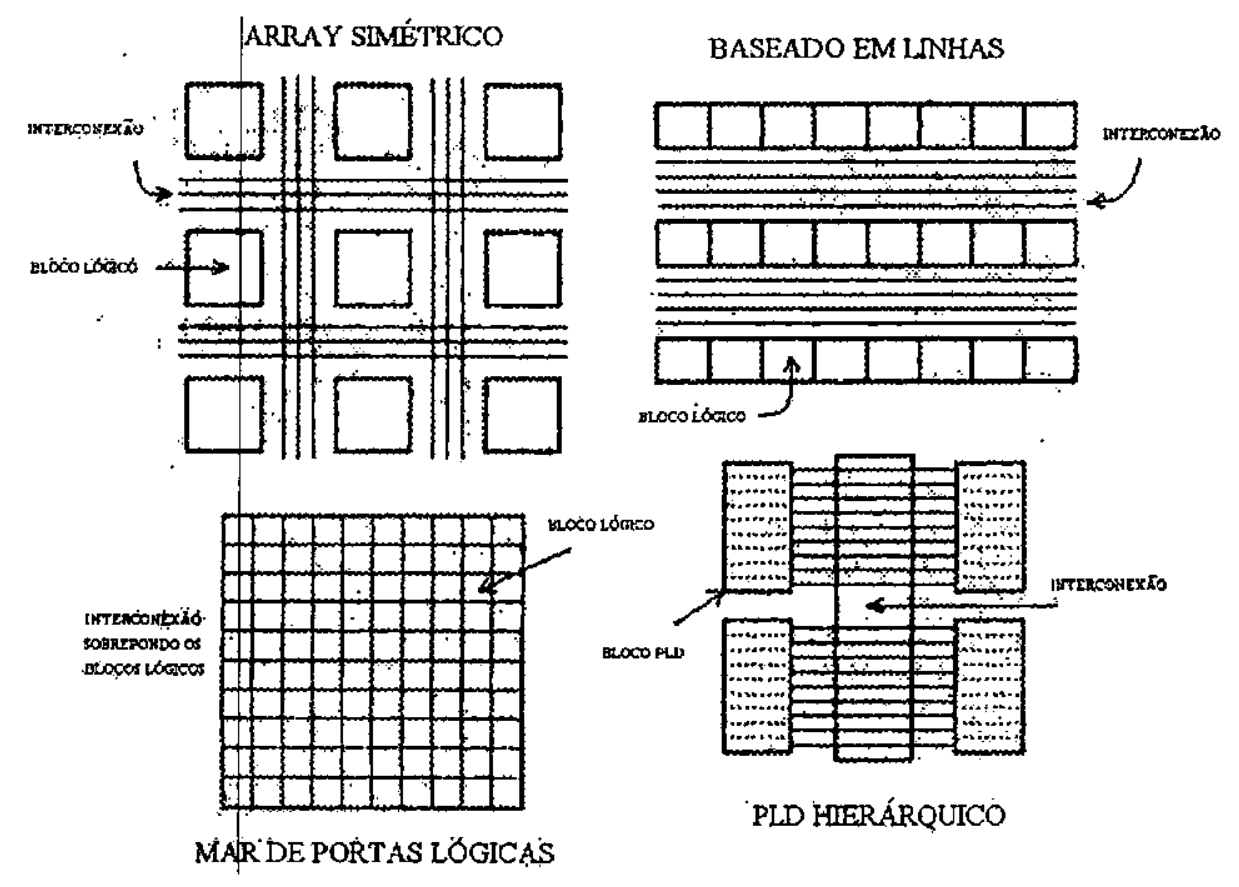

Figura 3.3 -CATEgorias DE FPGAS.

Para facilitar a implementação de uma grande variedade de circuitos é importante que um FPGA seja o mais versát ll possivel, para tal, o projeto dos blocos lógicos juntamente com os recursos de interconexão devem facilitar a implementação de uma grande variedade de circuitos lógicos digitais. Há muitas maneiras de se projetar um FPGA fazendo-se um balanço entre complexidade e flexibilidade dos blocos lógicos e dos recursos de interconexão.

\subsubsection{Blocos Lógicos}

Os blocos lógicos podem ser projetados de muitos modos diferentes e, atualmente, existem diversos tipos de blocos funcionais lógicos no mercado. Um requisito básico que deve ser atendido por um bloco lógico é a capacidade de construção de qualquer tipo de função lógica em sua estrutura. A arquitetura de um bloco lógico pode variar de uma simples porta lógica NAND de duas entradas até blocos mais complexos, contendo multiplexadores e lookup tables (FIGURA 3.4). Há casos de alguns FPGAs em que os blocos lógicos são formados por uma estrutura completa de um PAL. 
Pode-se definir um bloco lógico mais complexo de inúmeras maneiras. De um modo geral, um bloco lógico é formado por muitos sub-circuitos que geralmente possuem mais que uma saída. A maioria dos blocos lógicos também apresenta algum tipo de flip-flop para permitir a implementação de elementos de memórias e circuitos seqüenciais. As arquiteturas atuais de FPGA utilizam cinco tipфs básicos de blocos lógicos: Portas lógicas básicas ou primárias, Look Up Tables, Multiplexadores, PALs (Programmable Array Logic) e CAMs (Content Address Memories). Em seguida, discute-se brevemente cada uma dessas arquiteturas [PAY97].

\subsubsection{Portas lógicas básicas}

O tipo de bloco lógico funcional mais simples neste caso é a implementação de portas lógicas NAND ou NOR de duas entradas. Todas as outras funções lógicas podem ser implementadas a partir destas portas, desde que esteja disponivel um número suficiente delas. A vantagem do uso deste tipo de bloco básico é a facilidade de projeto e o seu tamanho reduzido. A maior desvantagem é a necessidade de uma grande quantidade de interconexões reconfiguráveis, que torna o sistema mais lento.

\subsubsection{Look Up Tables (LUTs)}

Para este tipo de configuração de bloco lógico, um multiplexador é utilizado para selecionar um determinadф valor de saída, armazenada em uma memória de configuração. Cada bloco funcional opera como uma pequena ROM, cuja saída é selecionada pelos sinais de entrada (FIGURA 3.4). Para se obter uma função booleana com $\mathrm{N}$ variáveis de entrada, necessita-se de $2^{\mathrm{N}}$ bits de configuração [PAY97].

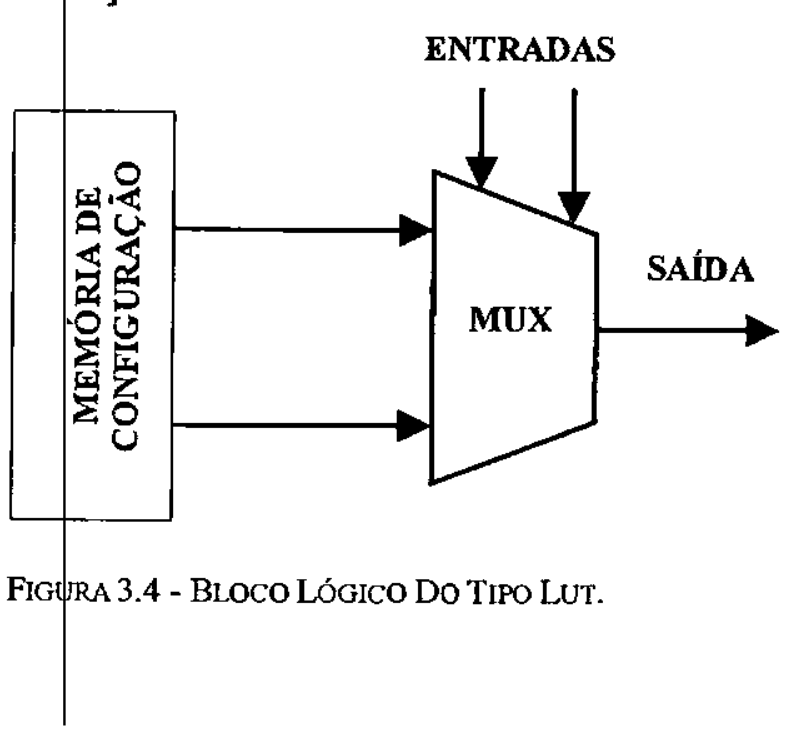




\subsubsection{Multiplexadores}

Nesta arquitetura de bloco lógico, um multiplexador com $\mathrm{N}$ entradas de seleção é capaz de implementar todas as funções booleanas de $\mathrm{N}+1$ variáveis de entrada. A configuração neste tipo de bloco não é feita por uma memória, como no caso dos Look up Tables. A função é determinada através da configuração do roteamento para as entradas de seleção e de dados do multiplexador. A FIGURA 3.5 mostra o bloco lógico de um multiplexador [PAY97].

\subsubsection{PALs (Programmable Array Logic)}

Nos blocos lógicos baseados na arquitetura PAL, cada saída é implementada como uma soma "booleana" de produtos. Os termos produto são gerados por portas AND que na seqüência são somados por portas $\phi R$ fixas. Pode-se substituir as portas AND e OR por portas NAND, como pode ser notado na FIGURA 3.6. As funções implementadas pela estrutura PAL estão limitadas ao número de termos produto disponivel. Quando são utilizadas memórias de configuração do tipo FUSE, os projetos baseados em PAL podem ser implementados com alta densidade. 


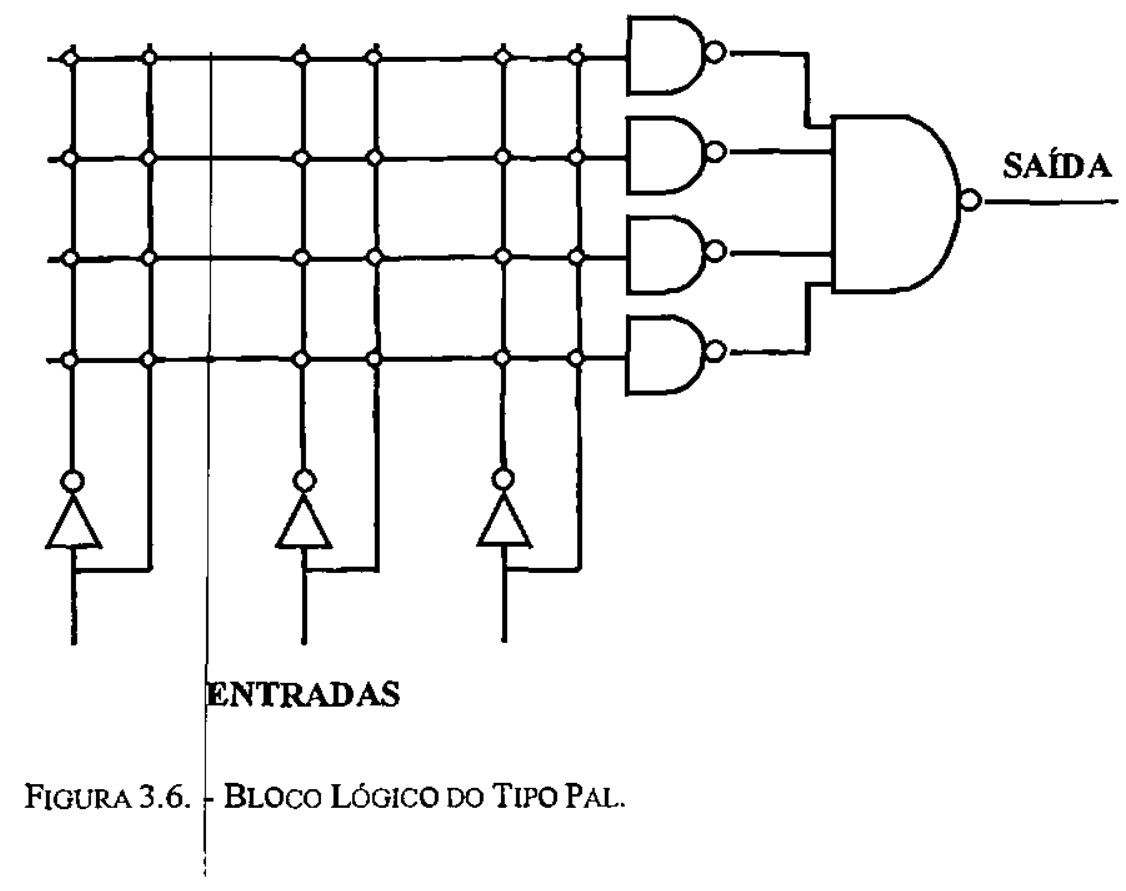

\subsubsection{CAMs (Content Adress Memories)}

As memórias acessadas pelo conteúdo ou CAMs, podem operar de dois modos. No primeiro modo, a célula funciona como uma memória RAM (Random Acess Memory) convencional. Uma palavtra (byte) da memória é selecionada com as linhas de endereçamento $\mathrm{e}$ através dos sinais de leitura e escrita, os dados podem ser lidos ou armazenados. Operando deste modo, a célula CAM tern a mesma funcionalidade de um bloco lógico do tipo LUT. A FIGURA 3.6 mostra a representaçẳo do bloco lógico baseado na célula CAM.

No segundo modo de operação, a célula CAM compara o valor das entradas com o conteúdo armazenado na RAM. Se os dados coincidirem, uma determinada linha muda para o nível alto. Neste segundo modo, a célula CAM opera do mesmo modo que os termos produto de um bloco do tipo PAL, que somente mudam para o nível alto quando suas linhas de entrada coincidem com um determinado valor.

A vantagem dos blocos lógicos baseados em CAMs está na variedade de estruturas que podem ser implementadas, como LUTs e PALs, além da capacidade de implementação de RAMs e CAMs de altas densidades. 


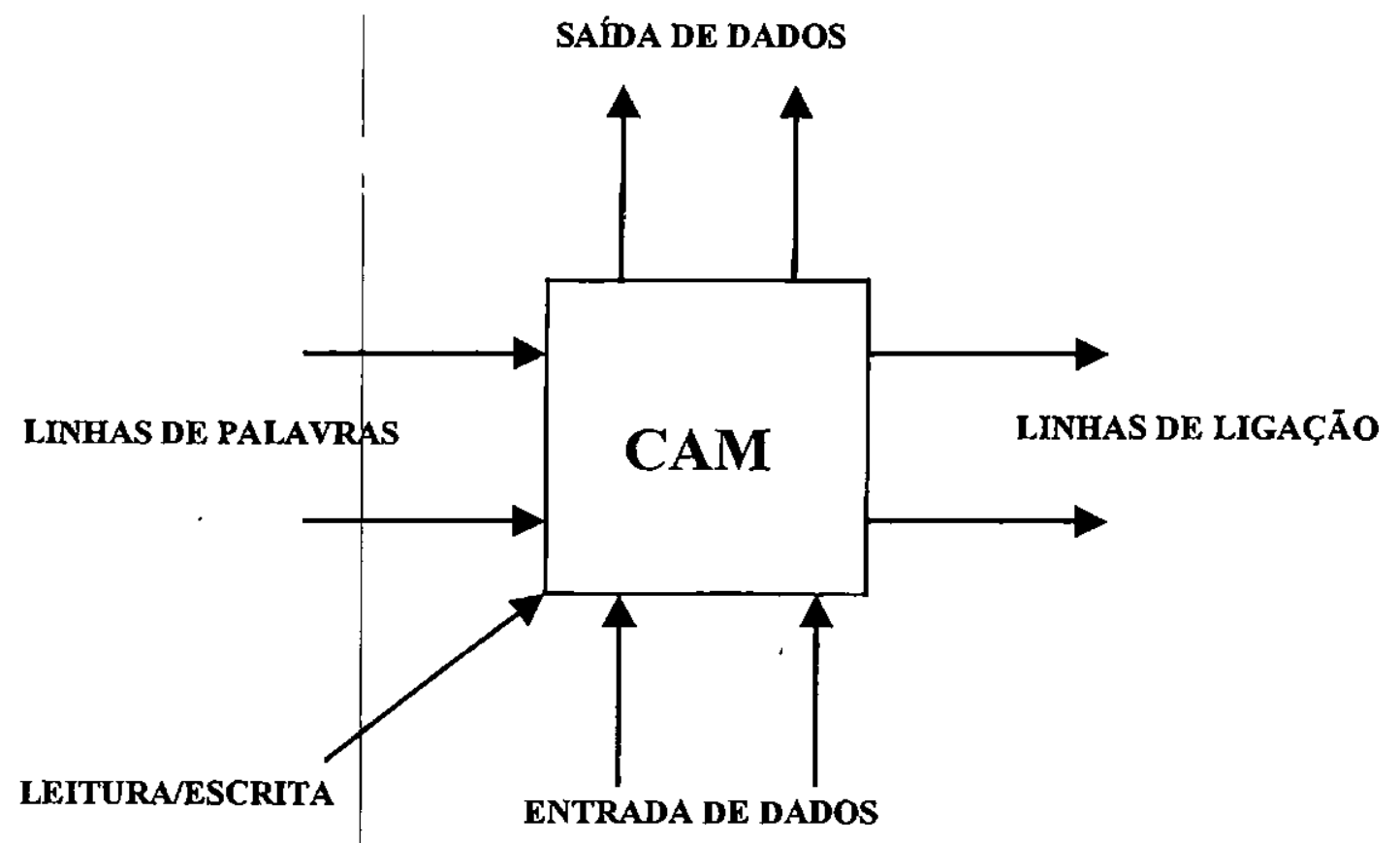

Figura 3.7. - Bloco Lógico Baseado Em CAM.

\subsubsection{Arquitetura de Roteamento}

As arquiteturas de interconexão ou estruturas de roteamento definem a maneira pela qual é feita a interconexão dos blocos lógicos em um FPGA. A interconexão dos blocos lógicos é feita tanto com segmentos de trilhas fixos quanto com comutadores programáveis, também conhecidos por blocos de comutação.

As arquiteturas de interconexão podem ser classificadas de acordo com o recurso de conexão oferecida e de como os elementos básicos de interconexão são agrupados para formar uma rede de roteamento. Os comutadores programáveis podem ser implementados de vários modos, podendo-se citar: transistores de passagem controlados por células RAMs estáticas, antifuses, transistores EPROMs e transistores EEPROMs. De uma maneira similar aos blocos lógicos, há várias maneiras de se projetar uma arquitetura de roteamento. Alguns FPGAs possuem um grande número de conexões simples entre os blocos, enquanto que outros 
dispositivos, apresentam łum número menor de conexões, no entanto, estas são mais complexas. A FIGURA 3.8 ilustra uma estrutura genérica de roteamento em um FPGA.

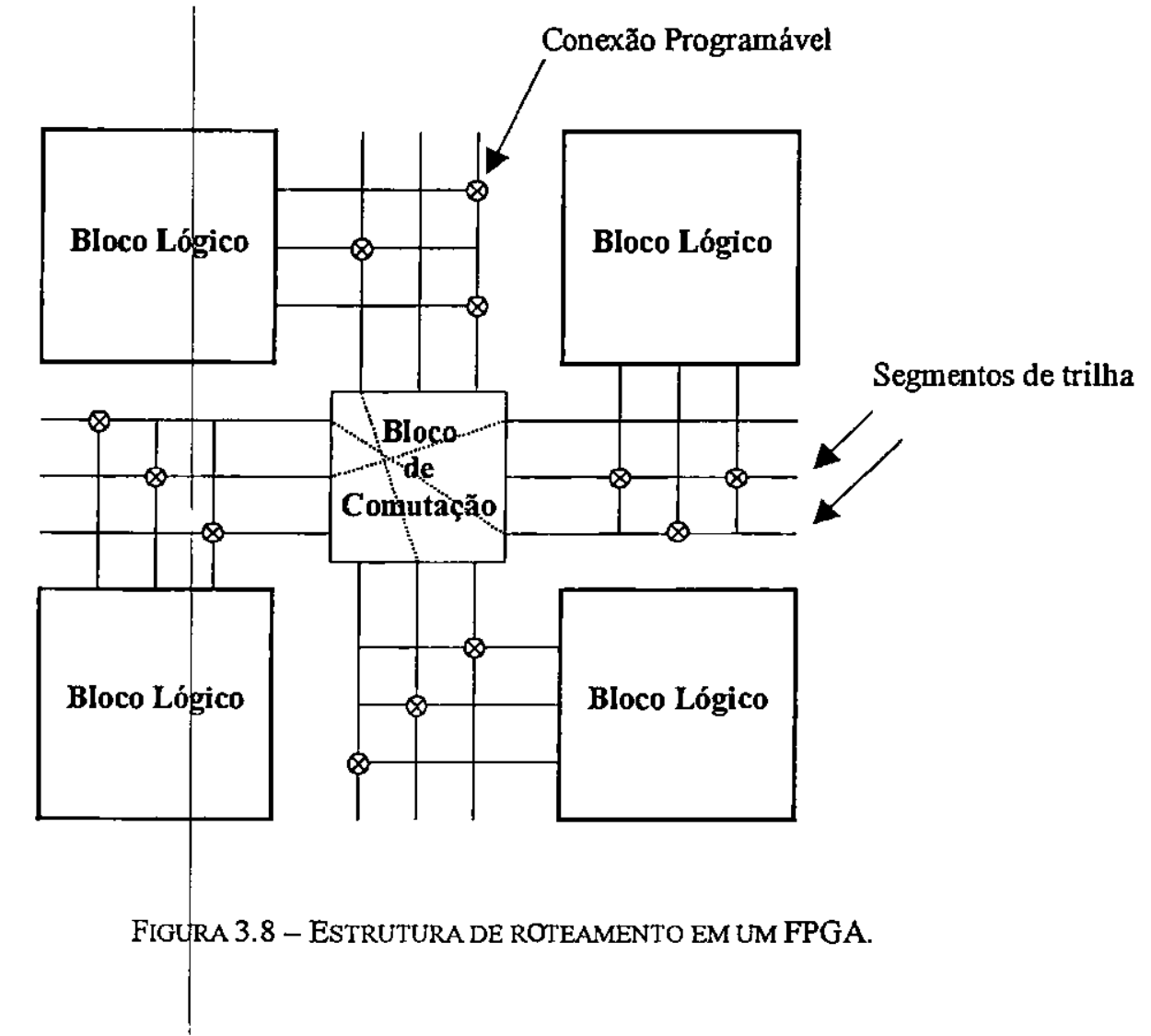

Os blocos de comutação são responsáveis por fazer a conexão elétrica de dois segmentos de trilha. As conexões programáveis permitem conexões entre as entradas e saídas de um bloco lógico com os segmentos de trilha. A figura 3.8 apresenta um diagrama básico de estrutura de roteamento. Dependendo/do FPGA, o modelo de arquitetura de roteamento pode ser bastante diferente deste. 


\subsection{Tecnologias de Programação}

O termo tecnologia de programação é utilizado para especificar a metodologia empregada para implementar as conexões entre os blocos lógicos de um FPGA. Os elementos responsáveis por essa tarefa, que usualmente são chamados de chaves, podem ser classificados mais precisamente como elementos de programação. Existem várias maneiras de se implementar elementos de programação, sendo que atualmente há quatro tecnologias comerciais de interconexão diferentes. Essas tecnologias são: células RAM estáticas, anti-fuse, transistores EPROM e transistores EEPROM. Mesmo sendo tecnologias muito diferentes, todos os elementos de programaçẫo possuem a mesma propriedade de serem configuráveis em apenas um de dois estados: ligado ou desligado.

Os elementos de programação devem ocupar o mínimo de área possivel, devendo apresentar uma baixa resistência elétrica quando estão no estado ligado e uma alta resistência quando estão no estado desligado. Dependendo da aplicação, pode se escolher a utilização de elementos de programaçấb não voláteis ou voláteis. A utilização de chaves programáveis voláteis torna possível a utilização do FPGA para aplicações em que este pode ser reconfigurado, possivelmente, até na própria placa de circuito [VCC97].

\subsubsection{Tecnologia de Programação com RAM Estática}

A principal empresa fabricante de FPGAs que utiliza esta tecnologia de programação é a Xilinx. Neste tipo de FPGA, as conexões programáveis são estabelecidas com transistores de passagem, portas de transmissão e multiplexadores, todos controlados por células de SRAM (Static RAM) [ROS93].

No caso do transistor de passagem (FIGURA 3.9) e das portas de transmissão (FIGURA 3.10), a célula RAM determina o estado das portas de passagem em abertas ou fechadas. Quando o transistor de passagem está acionado, este apresenta uma baixa impedância, fazendo a conexão das trilhas aos quais está ligado. De modo inverso, quando o transistor está desativado, a impedância|torna-se alta deforma que não há mais contato elétrico entre as trilhas que estão ligadas aos seus terminais. 


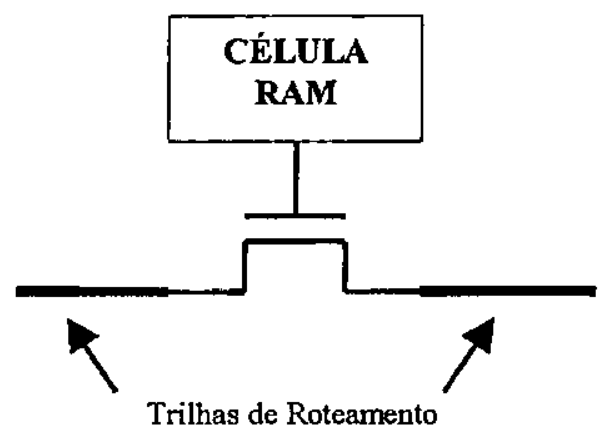

Figura 3.9.- Transistor de Passagem.

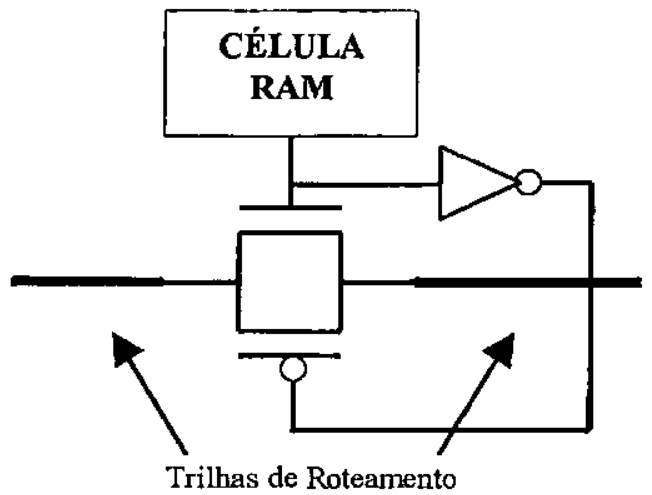

Figura 3.10.- Porta de transmissão.

$\mathrm{Na}$ abordagem da tecnologia SRAM com multiplexadores, FIGURA 3.11, células RAM são utilizadas para o endereçamento de um multiplexador, fazendo com que uma dentre várias trilhas se conecte a entrada de um bloco lógico.

Trilhas de Roteamento

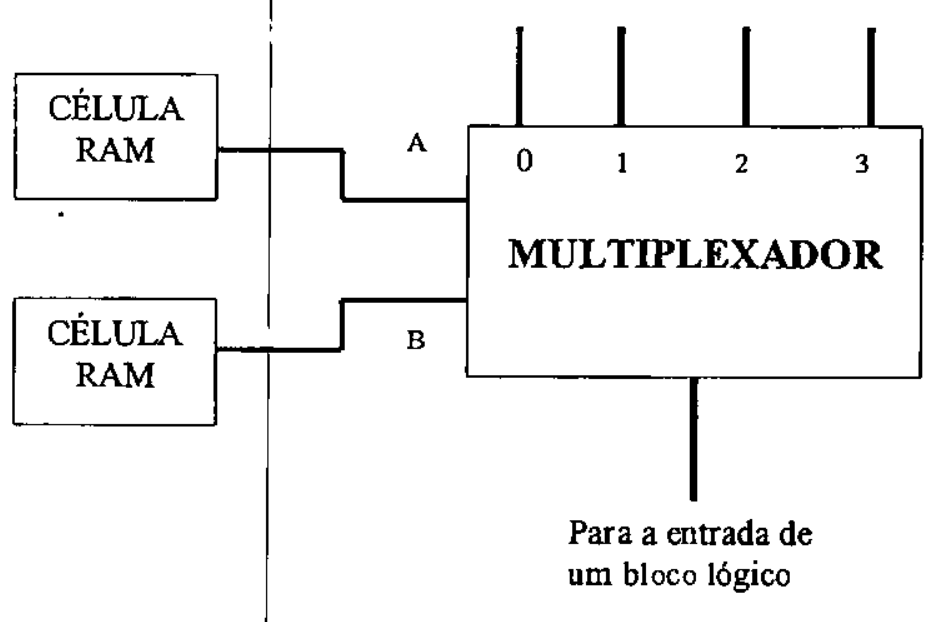

FIGURA 3.11 - MULTIPLEXAdOR. 
Sendo as RAMs estáticas voláteis, o FPGA baseado nesta tecnologia perde a sua configuração toda vez que sua alimentação for interrompida, sendo necessário algum tipo de mecanismo que armazene a sua programação ou configuração. A configuração das células RAM pode ser "carregada" para o FPGA de forma serial ou paralela, de modo que cada célula RAM pode ser endereçada como um elemento de uma matriz, como ocorre em um chip convencional de memória RAM.

As vantagens desta tecnologia são a possibilidade de reconfiguração do chip no próprio circuito e a possibilidade de produção do FPGA através de processos convencionais com tecnologia CMOS.

\subsubsection{Tecnologia de Programação Anti-fuse}

Os FPGAs com tecnologia de programação anti-fuse são fornecidos pelas empresas Actel, QuickLogic e CrossPoint Solutions, que apresentam um mesmo princípio de funcionamento, porém, com tecnologias diferentes.

Os anti-fuses são dispositivos de dois terminais e de área reduzida, que podem ser programados eletricamente. Como o próprio nome indica, os anti-fuses são fusíveis que funcionam de maneira oposta à tradicional, ou seja, quando fundidos, passam a conduzir. Os anti-fuses são construídos com tecnologia CMOS modificada e originalmente apresentam alta impedância. Quando programados ou fundidos através de uma alta tensão elétrica, os anti-fuses passam a apresentar um estado de baixa impedância, fazendo, desse modo, a conexão elétrica de duas trilhas [GRE93].

Como exemplo desta tecnologia, pode-se citar a estrutura anti-fuse da Actel, chamada de PLICE (Programmable Logic Interconect Circuit Element). A estrutura desse anti-fuse é fornada por três camadas. A / camada superior e a inferior são condutoras, sendo formadas respectivamente por poli-silício e silício dopado positivamente. A camada intermediária é isolante, formada por Oxigênio-Nitrogênio-Oxigênio, separando a camada superior da inferior. A FIGURA 3.12 ilustra a estrutura anti-fuse. 


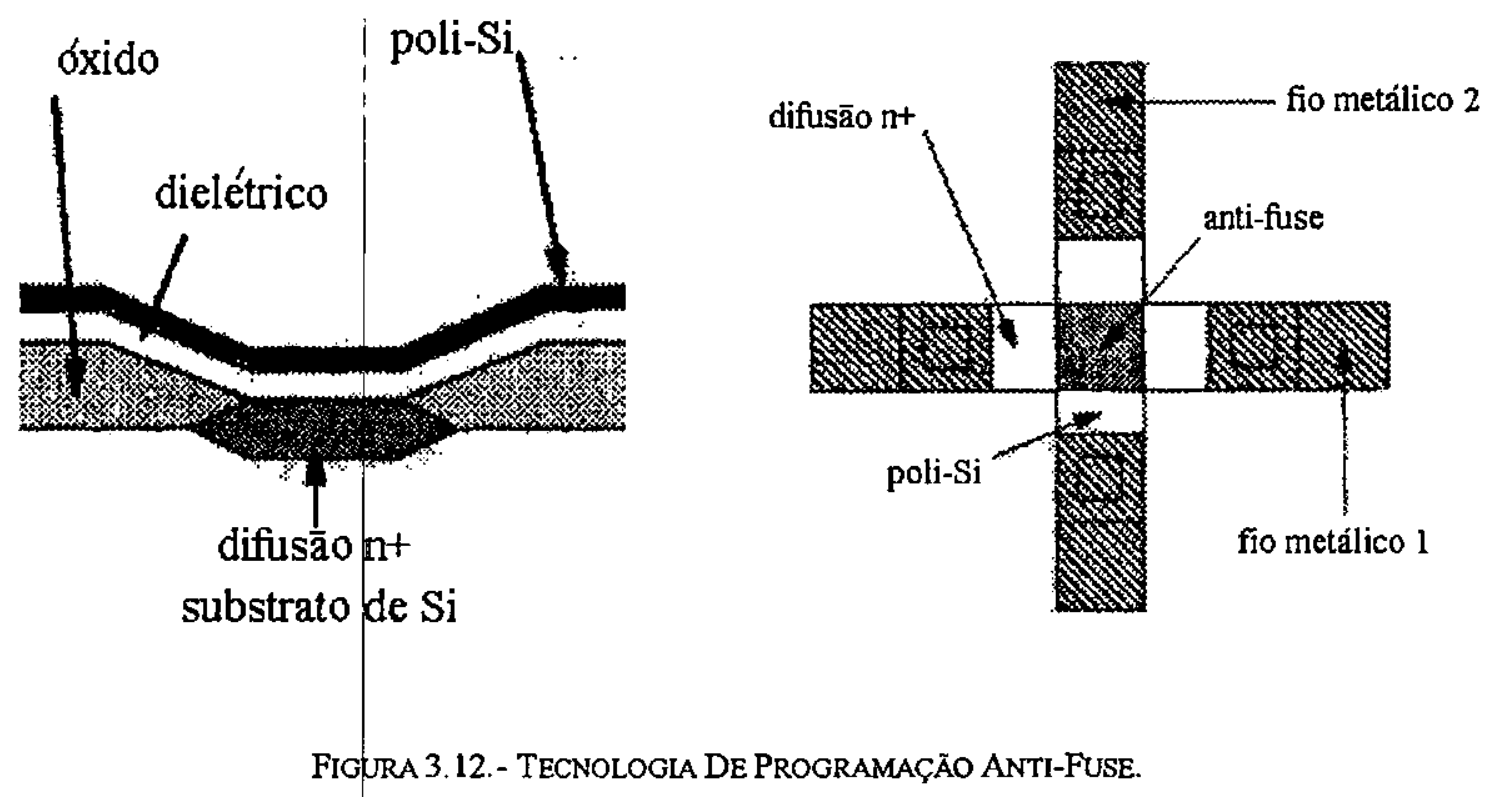

A programação dos anti-fuses da Actel é feita aplicando-se 18 Volts entre seus terminais. Esse procedimento gera calor e funde o dielétrico, tornando-o condutivo. Se comparada às outras tecnologias de prpgramação, a tecnologia anti-fuse ocupa uma área muito reduzida do circuito integrado, por dutro lado, uma grande área é ocupada pelos transistores responsáveis pela corrente de programação. Uma desvantagem da técnica anti-fuse é a sua fabricação, que exige modificações no processo básico de CMOS [BRO97].

\subsubsection{Tecnologia de Programação EPROM e EEPROM}

A tecnologia de programação baseada em EPROM, também conhecida como gate flutuante é empregada em FPGAs das empresas americanas Altera e Plus Logic, sendo similar àquela utilizada em memórias EPROM. Transistores do tipo EPROM, diferentemente dos transistores convencionais CMOS, possuem duas Portas ou Gates. Uma das portas é a porta de seleção (select gate), que tem a mesma função da porta de um transistor CMOS, a outra, é a porta flutuante (floating gate), que fica posicionada entre a porta de seleção e o canal do transistor. A porta flutuante é responsável pela programação do transistor, sendo chamada de flutuante por não estar cónectada eletricamente a nenhum circuito. Quando um transistor do tipo EPROM não está programado, não há carga no gate flutuante e este pode ser acionado ou não 
através de seu gate convencional. Quando o transistor é programado, através da passagem de corrente entre a fonte e o dreno, há um armazenamento de cargas no gate flutuante, fazendo com que o transistor fique permanentemente no estado desligado. Para se "desprogramar" o transistor basta que seja aplicada luz ultravioleta em sua estrutura interna, desse modo, a carga acumulada em seu gate flutuante flui para o substrato. Desta forma, um transistor CMOS pode ser utilizado como um elemento programável.

Na tecnologia de programação EPROM, o transistor não é utilizado como um comutador, como ocorre com as células SRAM e os anti-fuses [ARA97]. Neste caso, o transistor opera como um elemento de pull down para as entradas dos blocos lógicos. Como pode ser visto na FiGURA 3.13, temos uma ligação bu tritha chamada de word line e uma outra trilha chamada de bit line, que está ligada a um resistor pull up e a entrada de um bloco lógico. Através do word line, podese controlar o estado de condução do transistor, que conduzindo, força o bit line ao estado lógico zero. Em FPGAs, muitos transistores EPROM, cada um com seu word line, podem ser ligados ao mesmo bit line, dessa forma, além de implementar conexões, pode-se também implementar uma lógica do tipo wired $A N D$.

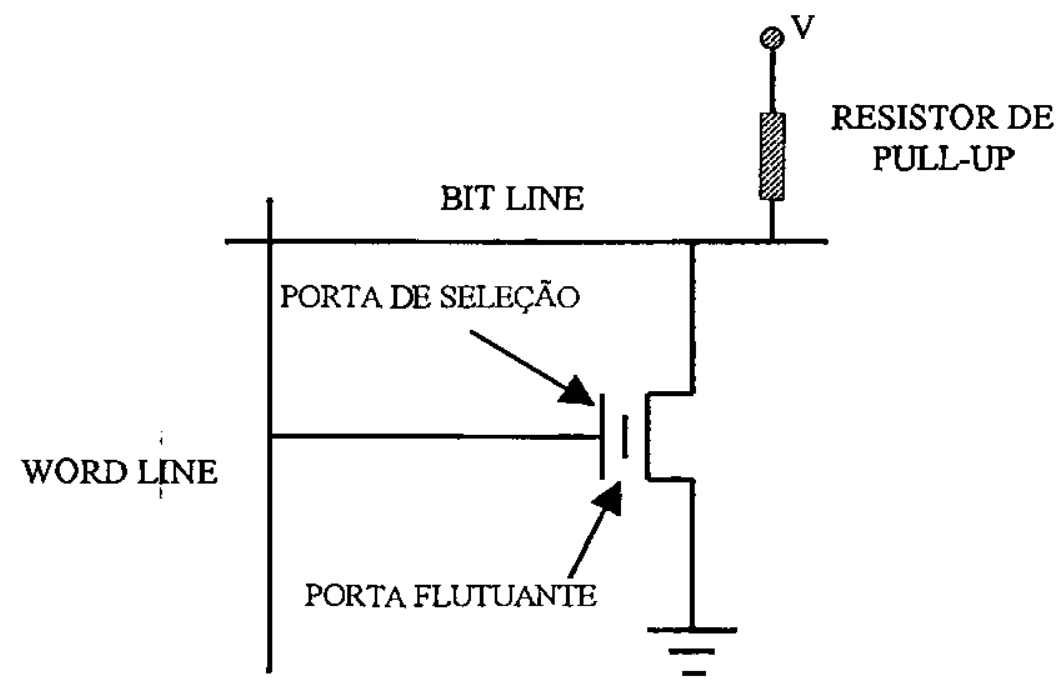

Figura 3.13 - TeCNologia De Programação EProm. 
Uma desvantagem dessa tecnologia é o alto consumo de energia estática pelo resistor de pull-up. Uma vantagem dos transistores EPROM é que estes são reprogramáveis mas não necessitam de armazenamento externo. No entanto, os transistores EPROM não podem ser reprogramados no circuito, como ocorre com a tecnologia de programação com RAMs estáticas.

A tecnologia de programação EEPROM, oferecida pela AMD (Advanced Micro Devices), é similar a tecnologia EPROM descrita anteriormente, exceto pelo fato dos transistores EEPROM poderem ser reprogramados no próprio circuito. Uma desvantagem é que esses transistores ocupam duas vezes mais área de chip do que os seus similares EPROM, além de necessitarem de fontes com múltiplas tensões.

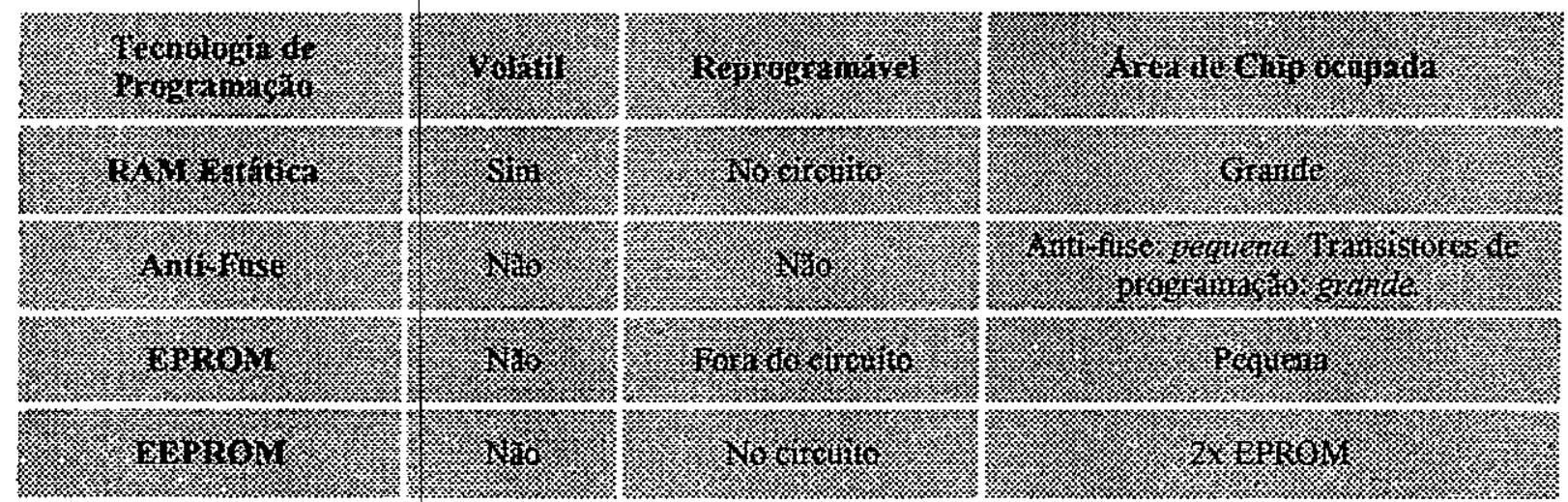

TABELA 3. 1- CARACTERÍSTICAS DAS TECNOLOGIAS DE PROGRAMAÇÃO EM FPGAS.

\subsection{Aplicações do FPGA}

Os FPGAs são um meio genérico para a implementação de lógica digital, sendo particularmente adequado para a implementação de ASICs. Exemplos de utilização de FPGAs que podem ser citados, são : dispositivos para solução de sistemas de equações lineares [ARA98], controlador de FIFO de 1 megabit, interface micro channel do IBM PS/2, controlador de DRAM com correção de erros, controlador de impressora, acelerador gráfico, circuito ótico de reconhecimento de carạcteres, um transmissor/receptor $\mathrm{T} 1$ de rede e muitas outras aplicações [BRO97]. 
Devido ao seu baixo custo e ao curto período de tempo necessário para a implementação de um circuito lógico, os FPGAs são especialmente adequados à construção de protótipos. Versões iniciais de protótipos podem ser implementadas rapidamente e alterações podem ser feitas facilmente sem nenhum custo adicional.

Uma característica muito interessante dos FPGAs que utilizam comutadores reprogramáveis é a capacidade de reconfiguração em campo. Esta qualidade permite a alteração da estrutura de um deterninado equipamento que está em operação [BRO97]. Um exemplo deste tipo de aplicação é a metodologia Xilinx chamada de IRL (Internet Reconfigurable Logic) que permite a atualização, reparo ou modificação do hardware após este ter sido instalado em campo, através da Internet. As vantagens de utilização desta tecnologia se mostram na extensão da vida útil do sistema e na diminuição significativa de custos de manutenção, pois neste caso, não é necessário enviar nenhuma equipe de manutenção a campo.

Exemplos de aplicações que utilizam a metodologia IRL são:

- Manutenção de equipamentos de rede, tais como switches ATM e estações de telefonia celular.

- Atualização de protocolos em sistemas de comunicação por satélite.

- Vídeo, HDTV (High Definition TV) e sistemas de processamento de imagens [WES99].

\subsection{Metodologia de Projeto com FPGAs}

Nos últimos 15 anфs, houve uma grande evolução na tecnologia de fabricação de FPGAs, que passaram de dispositivos contendo centenas de portas lógicas para dispositivos com mais de um milhão dessas portas Da mesma forma, inicialmente, os FPGAs foram projetados para substituir com uma única ou poucas unidades, um sistema digital completo, contendo algumas centenas de portas lógicas. Atualmente, a complexidade dos FPGAs permite a substituição de CIs do tipo ASIC, reduzindo cada vez mais o número de componentes de um sistema [XIL99b].

Na época do surgimento do FPGA, quando este era utilizado para a integração de até algumas centenas de portas lógicas, a metodologia de projeto era fundamentada em captura de diagramas esquemáticos, como pode ser visto na FIGURA 3.14. Com os diagramas esquemáticos, 
era fácil e eficiente a inserção de um novo nível de hierarquia (macro funções) em um outro esquemático de FPGA. Depois da minimização e da captura do projeto em nível booleano e de macrocells, a única ferramenta adicional necessária era uma ferramenta de posicionamento e roteamento em FPGA, que gerava o arquivo de configuração do chip. A verificação era geralmente feita com a construção de protótipos.

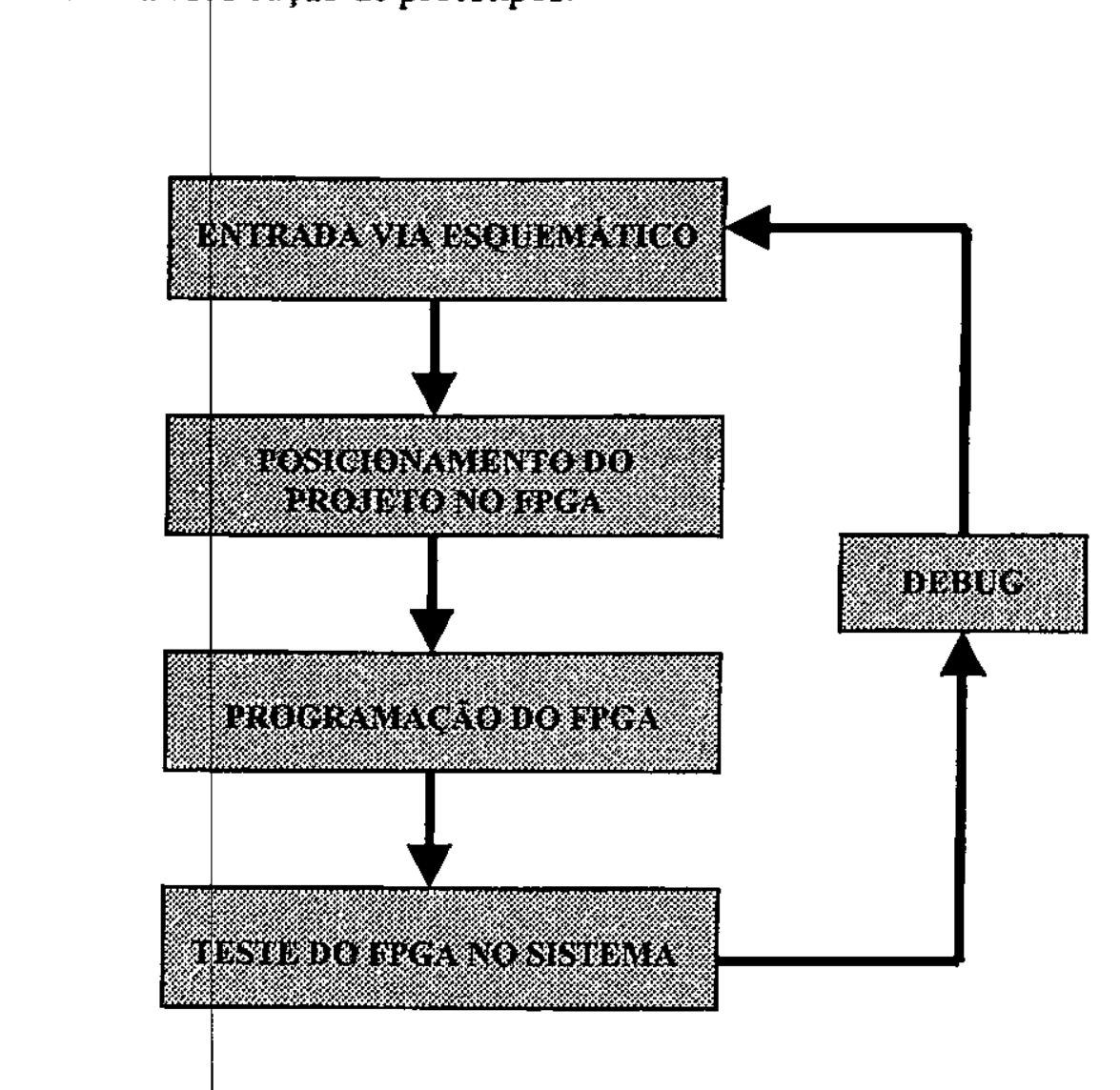

Figura 3.14 MÉtodo De Projeto Simples, Para Dispositrvos Simples.

Atualmente, os FPGAs contêm mais de 2,5 milhões de portas lógicas e o desenvolvimento de projetós utilizando-se apenas diagramas esquemáticos parece ser uma tarefa praticamente impossivel. Por esta razão, os projetistas estão adotando cada vez mais o projeto de FPGAs baseado em HDL (Hardware Description Language). A utilização de ferramentas baseadas em HDL permite um aumento de produtividade, pois o projeto pode ser feito em um nivel de abstração mais alto, à nível de transferência de registradores (RTL), ao invés de nível lógico booleano ou de portas.

Juntamente ao projeto baseado em HDL e à grande capacidade dos FPGAs, estão duas ferramentas importantes: a de simulação, para a verificação do projeto e a de síntese, para a 
implementação automática do projeto em RTL para um nível de portas (Nível de posicionamento e roteamento de FPGAs), ilustrado na FIGURA 3.15. Devido ao custo de se verificar a funcionalidade após o layout, a prototipação já não é mais um método aceitável para a verificação do projeto. A simulação, no entanto, permite que os problemas de projeto sejam descobertos mais cedo, enquanto o custo é baixo para se fazer a correção.

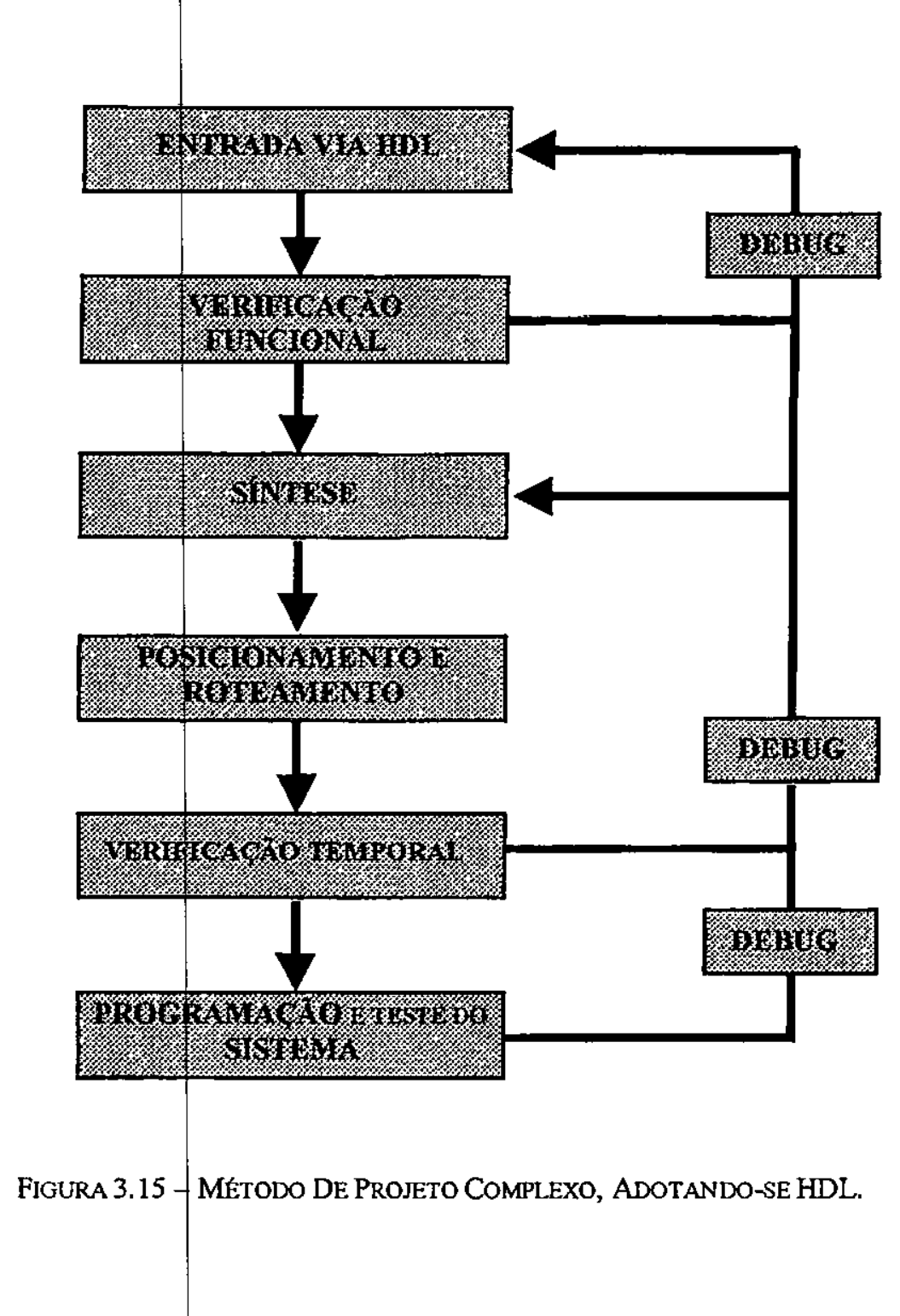

Os diagramas de bloco e os diagramas esquemáticos ainda são utilizados no projeto de FPGAs, mas, limitados à implementação manual de blocos funcionais com restrições ou para auxiliar o gerenciamento de complexidade, particionando graficamente o projeto em blocos menores. 
Como pode ser observado na FIGURA 3.15, o primeiro passo de um projeto digital é efetuado com a ajuda de um editor de diagramas esquemáticos de circuitos digitais ou através de uma linguagem de desqrição de hardware (HDL). O programa de entrada via diagrama esquemático trabalha corn símbolos gráficos de circuito (Xilinx Foundation, Altera MAX+Plus II) e o programa de entrada via HDL utiliza uma linguagem descritiva (Verilog, ABEL ou VHDL). No mercado há uma grande variedade de ferramentas disponíveis para projeto, sendo que suas saídas geram 'Netlists', os quais devem ser direcionados ao tipo de FPGA específico, escolhido na ferramenta de projeto.

Após a tradução do esquemático ou do $\mathrm{HDL}$ para o formato de Netlist, passa-se ao estágio de implementação do projeto, no qual o Netlist produzido é convertido em um arquivo binário que configura o FPGA. Na primeira etapa, há o mapeamento do projeto para o FPGA. No segundo passo, ocorre o posicionamento dos blocos lógicos, criados no processo de mapeamento, em posições específicas no FPGA. No terceiro passo, há o roteamento dos caminhos de interconexão entre os blocos lógicos. A saída desse processo é um arquivo de matriz de blocos lógicos ou Logic Cell Array File (LCA), específico para o FPGA escolhido. Este arquivo LCA é, então, convertido em um arquivo binário para a configuração do FPGA. Algumas das ferramentas de implementação presentes no mercado são: Xilinx XACT/Foundation, Altera MAX+Plus II, Synopsys, Exemplar Logic Synthesis System, ALDEC Active FPGA, DATA I/O - Synario, etc.

O próximo passo é a simulação para verificação funcional do projeto. Nesta etapa, são feitos o teste lógico e de temporização, através da aplicação de estímulos na entrada do sistema. Vários pacotes de software oferecem ferramentas de verificação e simulação, que através da caracterização detalhada do projeto, fazem a simulação temporal e funcional. Uma forma de testar o projeto em condiçōes típicas de funcionamento, é verificação no próprio circuito. Ferramentas de verificação que podem ser utilizadas nesta etapa são: Altera MAX+Plus II, Viewlogic Proseries, Synopsys, CadenceVHDL-XL Verilog XL, ALDEC - Active FPGA, DATA I/O - Synario. Se $p$ resultado da simulação não for satisfatório, retorna-se a etapa inicial do projeto, caso contrário, passa-se a próxima etapa, que é a de configuração do FPGA.

A configuração é o processo no qual o projeto do circuito (arquivo binário de configuração) é carregado no FPGA. O método utilizado para configurar o FPGA determina o 
tipo de arquivo binário para a configuração. Os FPGAs podem ser configurados por uma PROM, sendo o modo serial o mais comumente utilizado. O FPGA pode também ler seus dados de configuração de uma EPROM serial externa ou paralela (modo mestre), ou os dados de configuração podem ser gravados no FPGA (modo escravo ou periférico). Se o FPGA for utilizado em uma plataforma computacional reconfigurável, o arquivo de configuração poderá ser convertido em uma função de linguagem de alto nível (como "C"), por este método, o FPGA pode ser configurado por um programa aplicativo [VCC97].

No próximo capítılo, será abordada a forma mais utilizada para definição e descrição de um projeto digital: a linguagem VHDL. 


\section{A Linguagem VHDL}

VHDL é uma lihguagem de programação padrão, aceita na indústrịa, utilizada para modelar e descrever o funcionamento de hardwares do nivel abstrato até o nivel concreto. VHDL é a sigla para VHSIC Hardware Description Language, sendo que VHSIC é uma outra sigla, significando Very High Speed Integrated Circuits [PER94].

As linguagens para descrição de Hardwares ou HDLs (Hardware Description Languages) podem ser empregadas de diversas formas. A primeira forma é uma alternativa para a representação de diagramas de circuitos digitais e a segunda forma é a de um algoritmo de alto nível para resolver um determinado problema específico. Esses dois tipos de representação, estrutural (diagrama) e comportamental (algoritmo), representam duas maneiras de se descrever um modelo de um sistemą digital.

A linguagem VHPL pode ser utilizada também para documentação, verificação e síntese de grandes sistemas digitais. Estas são, na verdade, as características que diferenciam essa linguagem das demais linguagens de descrição de hardware existentes. Em VHDL, o mesmo código pode atingir todos os propósitos mencionados anteriormente, reduzindo, em grande parte, o esforço do projetista e minimizando a introdução de erros durante tradução da especificação do projeto para sua implementação.

Mesmo sendo utilizada para documentação, verificação e síntese, a linguagem VHDL pode ser também empregada para descrever um hardware com três abordagens distintas: a abordagem estrutural, a data flow e a comportamental. Normalmente, é empregada uma mistura das três abordagens, de modo que um projeto completo será formado por diferentes seções, expressas de diferentes modos. Os termos "algorítmico" e RTL (Register Transfer Language) também são utilizados em|lugar de "comportamental" e de "data flow", respectivamente. 


\subsection{Histórico}

A linguagem VHDL foi desenvolvida como parte do programa. VHSIC (Very High Speed Integrated Circuits), iniclado pelo departamento de defesa dos Estados Unidos no final dos anos 70 e começo dos anos 80. O objetivo do programa VHSIC era produzir a nova geração de circuitos integrados, utilizando-se os limites da tecnologia em cada etapa do processo de projeto e fabricação. Os objetivos do programa foram atingidos com sucesso, porém, no processo de desenvolvimento de circuitos integrados extremamente complexos, os projetistas notaram que as ferramentas utilizadas para desenvolver grandes sistemas eram inadequadas. As ferramentas disponíveis para os projetistas na época, operavam, em sua maioria, em nível de portas lógicas e por este motivo, o projeto de sistemas com centenas de milhares de portas era uma tarefa complexa, exigindo, portanto, um novo método de descrição.

Para sanar este problema, em 1983, uma equipe de engenheiros da IBM, Texas Instruments e Intermetrics foi contratado pelo departamento de defesa dos Estados Unidos para completar a especificação e a implementação de um novo método de descrição de projeto baseado em linguagem. Em 1985 foi lançada a primeira versão publica da linguagem de descrição, chamada de VHDL. Essa linguagem tinha inicialmente dois objetivos principais: primeiro, os projetistas queriam uma linguagem que pudesse descrever circuitos complexos. Segundo, desejava-se una linguagem que fosse padrão, para que todos os integrantes do programa VHSIC pudessem trocar projetos entre si de um modo padronizado[DOU99]

Em 1986, os direitos da linguagem VHDL, foram transferidos ao IEEE (Institute of Electrical and Eletronic Engineers), sendo que em 1987 foi publicado o primeiro padrão IEEE (VHDL-1076). Como todo padrão do IEEE, o VHDL é revisado a cada cinco anos. A linguagem já passou por duas revisø̄es, sendo que a mais utilizada é a versão de 1987 (Std 1076-1987), referida por VHDL'87, sendo conhecida também por VHDL. No entanto, há uma versão mais nova da linguagem, referida como VHDL'93, que é bastante nova e ainda está em processo de substituição do VHDL'87 


\subsection{A Linguagem VHDL como uma Ferramenta de Projeto}

Uma importante medida do sucesso de uma linguagem de descrição de hardware é a sua fúncionalidade e eficácia como uma ferramenta de projeto. Uma característica muito importante é o fato da definição da linguagem VHDL ser independente das ferramentas que a incorporam. $\mathrm{A}$ linguagem VHDL pode ser utilizada juntamente com uma ampla gama de ferramentas, que văriam desde ferramentas de simulação, passando por ferramentas de síntese até ferramentas de layout. A linguagem VHDL, mesmo apresentando toda funcionalidade descrita anteriormente, possui uma especificação precisa, estando sob o controle do IEEE [COE95].

A linguagem VHDL oferece uma ampla variedade de niveis de abstração, variando do nípel arquitetural ao níyel de portas lógicas. Uma característica importante do VHDL é a possibilidade de mesclar os níveis de abstração durante a simulação, tornando possível a adoção de um estilo de projeto verdadeiramente top-down. Como características adicionais, a linguagem VIIDL possui recursos excepcionais para modelagem de temporização em hardware, provendo, tanbbém, mecanismos para construção de modelos genéricos que podem ter especificaçðes de termpo para determinados tipos de dispositivos. Uma biblioteca de modelos genéricos apresenta vantagens significativas, permitindo que um único modelo (como por exemplo, uma porta AND) represente um dispositivo de qualquer fabricante.

Outro aspecto importante da linguagem VHDL é a sua constituição em camadas que permite que sua utilização, inicialmente, de forma parcial, possibilite o seu rápido aprendizado. A medida do necessário, of projetista pode expandir seus conhecimentos para características mais avançadas da linguagem.

\subsection{Projeto Multi-Nível}

Tradicionalmente òs projetos eletrônicos têm sido realizados em nível de portas, utilłzando componentes comerciais padrão. A complexidade dos projetos de hardware aumentou significativamente nas últimas décadas, de modo que os blocos básicos de um sistema típico atual são microprocessadores ou ASICs, compostos por milhares de portas. Como resultado, as metodologias de projeto tradicionais do tipo botton-up estão cedendo lugar às práticas de projetos hierárquicos que tornam possíveis o gerenciamento desta complexidade causada pelo 
grande número de portàs. Uma abordagem eficiente é a incorporação de uma linguagem de descrição de hardware hierárquica, como o VHDL no processo de projeto. Utilizando-se o VHDL como uma ferramenta de especificação, é possível simular sistemas complexos antes que os detalhes pertinentes à implementação sejam completamente especificados. Juntamente a ișso, o VHDL facilita o processo de projeto top-down no qual uma especificação de alto nível é desenvolvida primeiro, sendo então corrigida e posteriormente utilizada para julgar a correção do próximo nível (mais baixo) de implementação [COE95].

A linguagem VHDL opera com vários estilos de descrição de projeto, os quais diferem na fórma em que estão relacionados ao hardware básico do projeto. Os estilos de descrição são na realidade os níveis de abstração possíveis para a linguagem. Como um exemplo, pode-se descrever um circuito oontador de vários modos. No nível de abstração mais baixo (nível eștrutural), pode-se utilizar as propriedades hierárquicas do VHDL para conectar uma sequência de portas lógicas e Flip-Flops para formar o contador [ACC97]. A FIGURA 4.1 mostra os vários niveis de abstração possivedis em um projeto em VHDL.

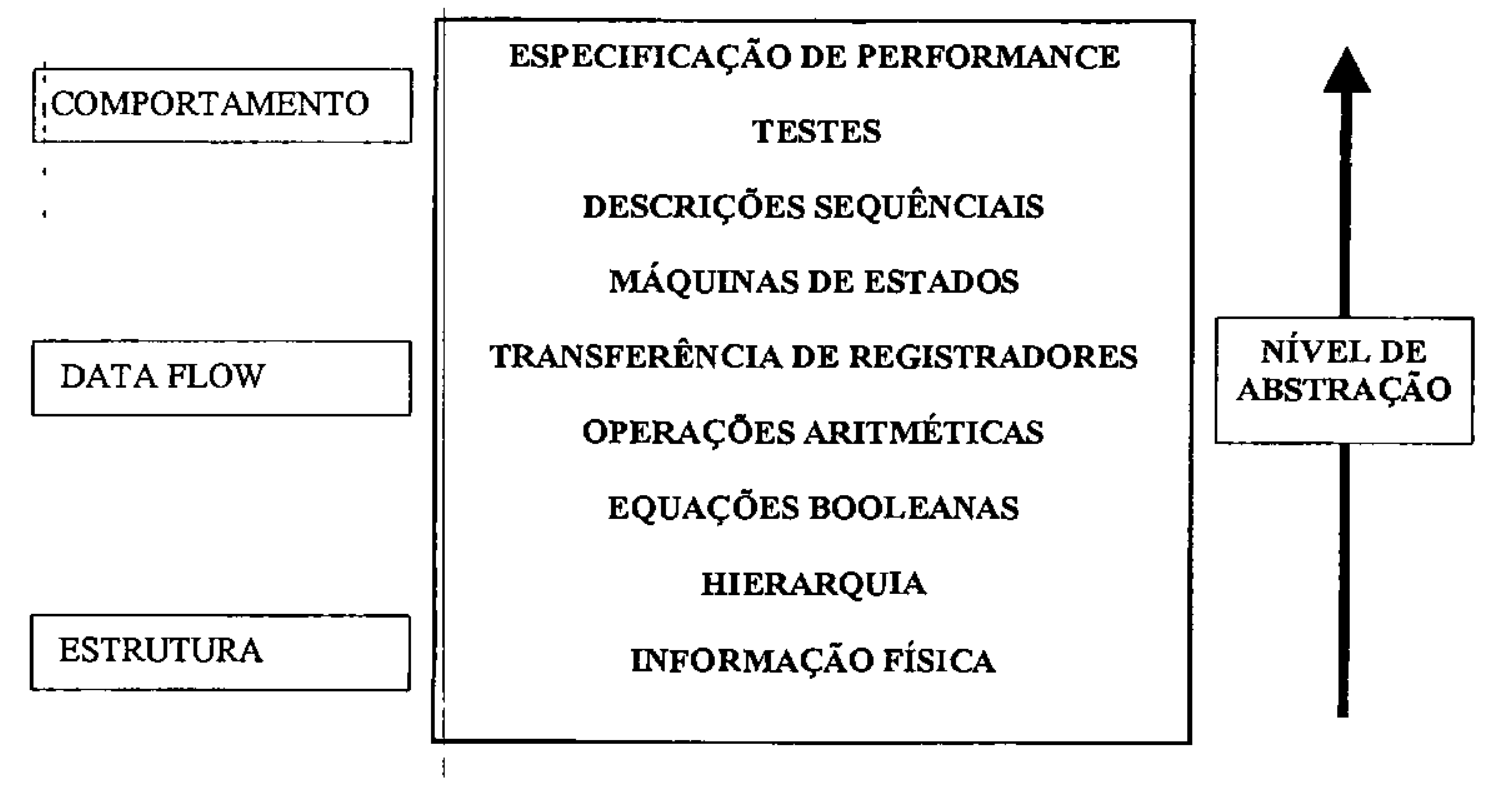

FIgURA 4.1 Niveis De ABSTRAÇÃo De UM Projeto EM VhdL. 


\subsubsection{Descrição Estrutural}

O VHDL estrutural permite o encapsulamento de uma parte da descrição do projeto (çomo por exemplo, una porta lógica, um flip-flop ou um subcircuito maior) como um componente reusável. Este nível estrutural do VHDL pode ser interpretado como análogo a um e\$quemático textual (ou netlist), ou como um diagrama de blocos textual para um nível de projeto de mais alto nível.

O VHDL estrutural fornece o equivalente de um netlist, no qual vários componentes dijscretos são interconectados formando um sistema maior. A hierarquia de projeto é criada quando os componentes do sistema são agrupados utilizando o VHDL estrutural.

Para tornar um projeto mais claro e mais facilmente manuseável, normalmente faz-se o particionamento do mesmo em vários blocos. Esses blocos são, então, interconectados para formar um projeto completo. Pode-se utilizar uma abordagem de captura de diagrama e§quemático para o projeto (através de um editor de diagramas esquemáticos) ou pode-se representar os diagramas de blocos através de esquemas hierárquicos. Na linguagem VHDL, cada parte do projeto é considerada um bloco e um projeto pode ser completamente descrito em ự único bloco ou este pode ser decomposto em vários blocos. Cada bloco em VHDL é análogo a um componente comercial, sendo chamado de entidade.

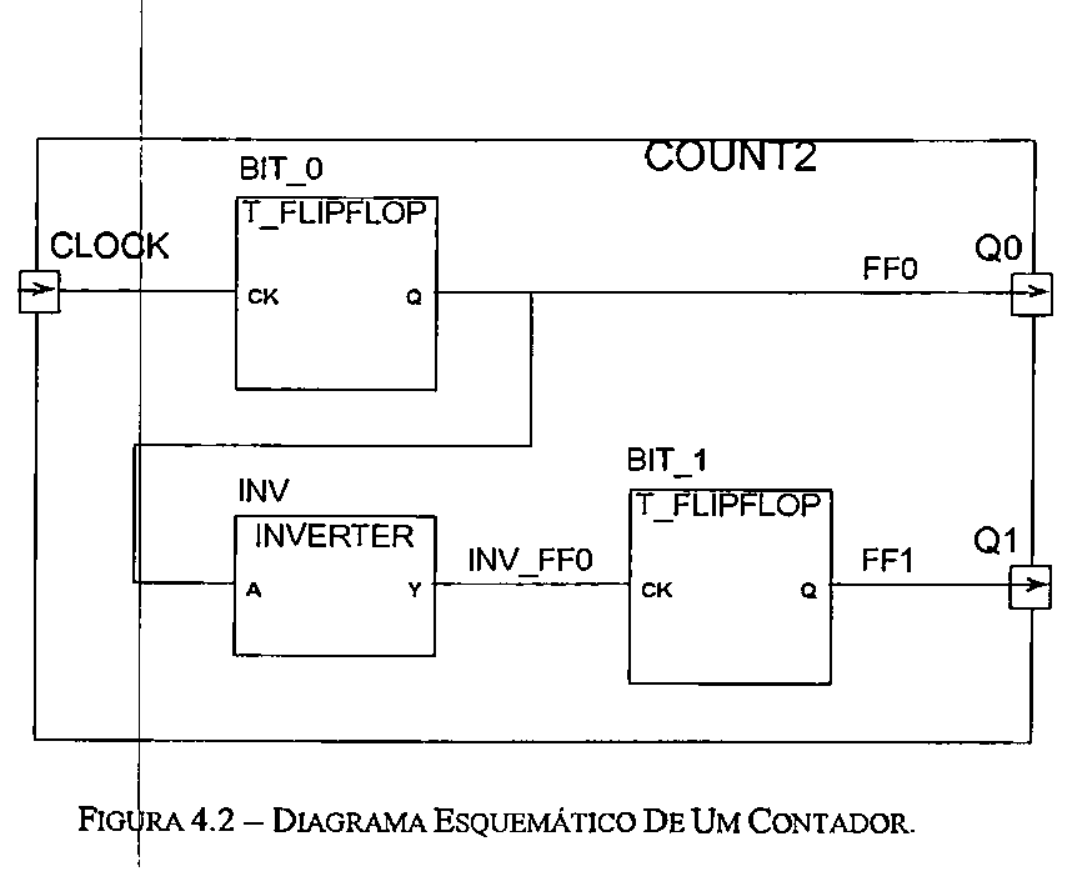


Uma entidade (Entity) descreve a interface do bloco e uma parte em separado, associada à entidade (Architecture), descreve como o bloco opera. A definição da interface é como uma descrição de pino em um data book, especificando as entradas e as saídas do bloco. A descrição da operação do componente é como um esquemático do bloco. Um bloco é um projeto e um projeto completo pode ser formado por uma coleção de muitos blocos interconectados. A seguir está exemplificada a descrição estrutural, de um contador de 2 bits. $O$ digrama esquemático do contador é apresentado na FIGURA 4.2 e a descrição estrutural deste contador pode ser feita como indicado na FIGURA 4.3.

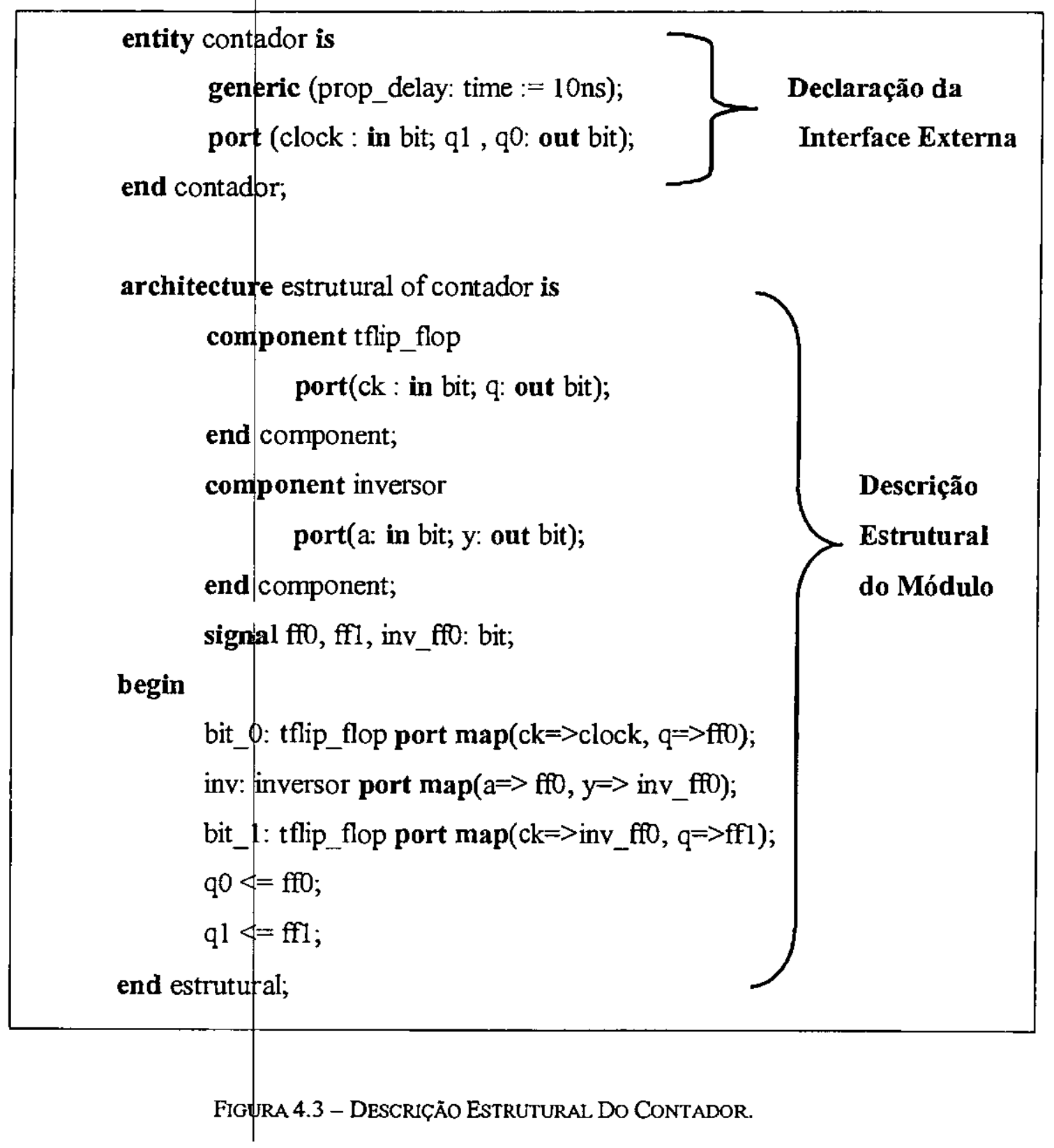




\subsubsection{Descrição RTL ou Data Flow}

A abordagem Data Flow é um nível intermediário de abstração que permite que a parte trabalhosa da lógica combinacional seja ocultada, enquanto partes mais importantes do circuito, como os registradores, sejam mais completamente especificadas. No nível Data Flow, ưm circuito é completamente descrito com registradores e com lógica combinacional, indicando como os sinais (dados) fluem pelo circuito [ACC97].

Em nível RTL, o contador da FIGURA 4.2, pode ser considerado um bloco funcional, podendo ser utilizado para a construção de sistemas maoires.

\subsubsection{Descrição Comportamental}

A abordagem comportamental para modelar componentes de hardware é diferente das qutras duas abordagens descritas anteriormente, por não ser necessário o conhecimento de como a' projeto é implementadф. É basicamente a versão de "caixa preta" de modelagem, especificando de forma precisa o que acontece nas entradas e nas saídas da mesma. O que está dentro da caixa ,øu seja, como o sistema opera, é irrelevante.

A descrição comportamental é normalmente utilizada de duas maneiras em VHDL: A primeira maneira seria para modelar componentes complexos os quais seriam tediosos de modelar utilizando-se outros métodos. Este seria o caso da simulação da operação de um hardware conectado a um microprocessador comercial (Glue logic). Neste exemplo, o microprocessador é um sistema complexo e sua operação interna é irrelevante (somente o comportamento externo é importante). Portanto, neste caso, utiliza-se um estilo de modelagem comportamental. No segundo modo, as capacidades comportamentais do VHDL podem ser mais poderosas, sendo mais convenientes para projetos que necessitem de alguma estrutura da implementação.

No início do projeto, modelos comportamentais podem ser utilizados para verificar rapidamente um algoritmo e simulá-lo utilizando-se dados reais. De uma forma alternativa, se for adotada uma abordagem top-down, cada bloco do projeto pode operar com um modelo comportamental até que este seja implementado estruturalmente. Finalmente, há a possibilidade 
de . . para o estrutural, com as devidas restrições de cada tecnologia alvo.

A FIGURA 4.4 mostra a descrição estrutural do contador de 2 bits da FIGURA 4.2.

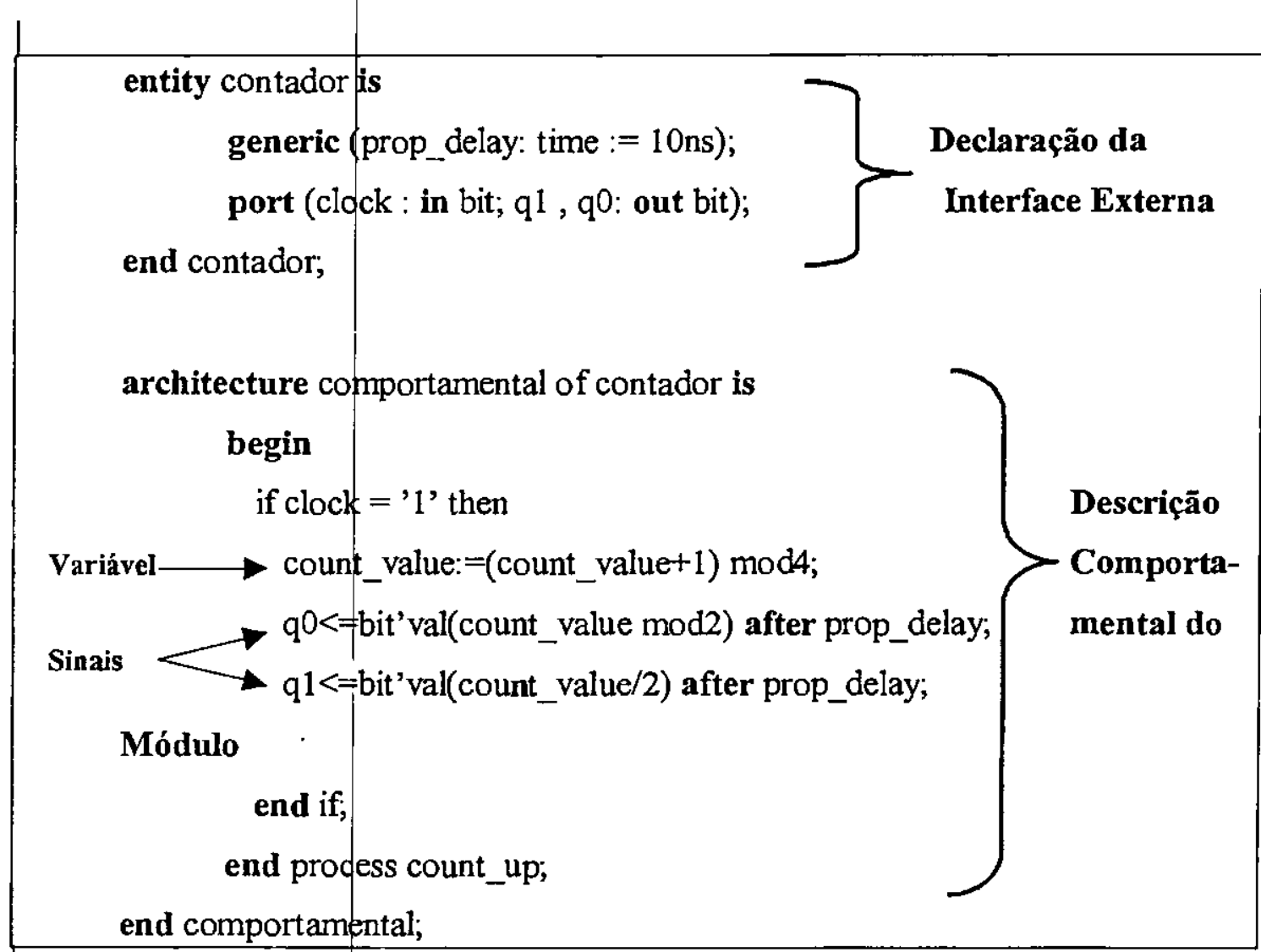

FIGURA 4.4 - DESCRIÇÃo COMPORTAMENTAL DO CONTADOR.

\subsection{As Vantagens da Linguagem VHDL \\ 4.4.1. Especificação Executável}

Há relatos de um grande número de circuitos ASIC com especificações de projeto sem erros, que não funcionam corretamente ao serem conectados a um sistema real. A linguagem VHDL permite que este problema seja abordado de duas formas: 
Uma especificação VHDL pode ser feita para que seja atingido um alto nível de confiança e correção, antes de se começar o projeto, podendo este ser simulado até duas ordens de magnitude mais rápido do que uma descrição em nível de porta lógica.

Uma especificação VHDL para uma parte do projeto, pode formar a base para o modelo de simulação, de modo que se possa verificar a operação dessa parte em um contexto de sịtema mais amplo (por exemplo, em uma simulação de uma placa de circuito integrado). Isso depende de quão precisamente a especificação manipula aspectos como temporização e inicialização dos sinais.

A simulação comportamental pode reduzir o tempo de projeto por permitir a detecção ptematura de problemas, descartando a necessidade de reprojetar em nível de portas. A simulação comportamental também permite a otimização do projeto por explorar arquiteturas alfernativas, resultando em projetos melhores.

\subsubsection{Ferramentas}

O Projeto de hardware e os conjuntos de testes com descrição em VHDL são perfeitamente intercambiáveis entre ferramentas de projeto, podendo-se seguramente investir em modelagem e treinamento da ferramenta VHDL sem o receio de estar preso a uma única marca de ferramenta ou platafárma. Ao mesmo tempo, os vendedores (empresas desenvolvedoras) continuamente fazem grandes investimentos na tecnologia VHDL, provendo a continuidade e 0 suprimento do estado da arte em ferramentas VHDL.

\subsubsection{Tecnologia}

Uma das principais razões para o sucesso da linguagem VHDL está na independência de suạ implementação em relação às ferramentas que a integram. Esta característica permite projetos independentes da tecnologia através de suporte a projetos top-down e síntese lógica. Para transportar o projeto para uma nova tecnologia não há necessidade de recomeçar do zero ou fazer engenharia reversa de uma especificação. Ao invés disso, sobe-se um degrau (retrocede-se um grau) na árvore de projeto para uma descrição comportamental de VHDL e efetua-se a implementação na nova tecnologia, sabendo-se que a funcionalidade correta será preservada. 
Em resumo, o VHDL é claramente uma das mais importantes linguagens de descrição de hardware desta última dẹcada. Como uma linguagem de projeto, o VHDL apresenta um mérito signnificante e em virtude de seu status de padrão industrial, provê uma alternativa de risco muito menor se comparada às linguagens proprietárias. Um fator importante, neste contexto, é o rápido surgimento de uma grande variedade de ferramentas de produção que operam com o VHDL de vários distribuidores [COE95].

\subsection{Soluções CORE e Propriedade Intelectual (IP)}

Um dos grandes avanços deste final de século na área de projetos de circuitos integrados é a possibilidade de integrar sistemas inteiros em um único chip. Estes sistemas são conhecidos ppr SOC (System-On-Chip). Apesar de existirem a pouco tempo (início da década de 90), os sistemas integrados em um chip já evoluíram significativamente, passando de projetos baseados em um número limitado de processadores até a definição atual de SOC, a qual inclui múltiplos processadores, periféricbs, subsistemas de comunicação, hierarquias de barramentos, componentes analógicos è de rádio freqüência [RIN99].

Funções CORE, MEGACELLS ou IP (Intellectual Property), este último termo erfoneamente empregado, são arquivos de projeto pré-testados, implementados em HDL, de fuhçð̃es em nível de sistema, que podem ser integrados a outros cores em um mesmo chip [ALT96a].

A industria de cores ou funções pré-definidas para CIs, já vem se desenvolvendo por mạis de uma década e neste contexto, existem atualmente uma infinidade de funç̃es cores prontamente disponiveis de diversos distribuidores. Os atuais fornecedores de soluções core são distribuidores ASIC, empresas de EDA (Electronic Design Automation) e empresas desenvolvedoras de IP (como são conhecidas as empresas especializadas apenas em desenvolvimento de cores).

As formas disponiveis de core podem variar dependendo do fabricante. De um lado temse os soft cores que estão disponiveis tanto em HDL (Hardware Description Language) quanto em Netlists. Os soft cores não contém qualquer informação fisica e, por esse motivo, são 
flexíveis e "portáveis", podendo ser utilizados em chips com diversas tecnologias de silício. Em virtude de o desempenho depender da implementação física do core, uma inconveniência dos soft cores é que o seu desempenho não é constante. Uma outra forma de core é o hard core, que apresenta um layout fixo para um processo específico ou está disponível no formato netlist com informações de posicionamento e roteamento. Apesar de não ter a flexibilidade dos soft cores, os hard cores apresentam características de desempenho bem conhecidas, incluindo posicionamento fixo de cêlulas e de interconexões.

Atualmente, com o desenvolvimento de FPGAs que comportam mais de um milhão de portas lógicas, a utilizaçẳo de funções pré definidas (cores) não só é uma possibilidade como também é um requisito importante para quem deseja continuar competitivo em um mercado que requer o estado da arte em desenvolvimento de hardware, exigindo ao mesmo tempo ciclos de desenvolvimento cada vez mais curtos. A utilização de cores permite que o projetista enfoque mais energia e tempo na diferenciação do produto final e não no desenvolvimento de sistemas comerciais comuns [ALT96a]. Conseqüentemente, em virtude dos rígidos requisitos de mercado, os fabricantes de cores ASIC (Application Specific Integrated Circuit) e os desenvolvedores de sistemas já consideram os cores como peças fundamentais para o projeto de hardware [XIL99a].

Dentre as inúmerăs soluções core existentes atualmente, destacam-se as seguintes:

- Interfaces de barramento: PCI, PCMCIA, USB e ISA plug-and-play.

- Funções DSP (Digital Signal Processing): Multiplicadores, filtros FIR (Finitelmpulse Response).

- Telecomunicađ̃ões e Redes: os blocos funcionas mais comuns.

- Funções Básicas: blocos mais simples ate UARTs (Universal Assinchronuous Receiver / Transmitter) e controladores de DMA (Direct Memory Acess) [XIL99a].

Apesar de o termo IP ser constantemente utilizado para designar um core, os dois termos não são sinônimos. IP é um termo mais genérico representando qualquer conhecimento adquirido por uma empresa que permite alguma vantagem competitiva sobre a concorrência. Um core de silício é um IP, assim como uma patente da empresa, um processo especial de chip e assim por diante, mas um IP não é necessariamente um core [LIP99], [FOR99]. 
Aplicações que requeriam soluções SOC diversificaram-se e expandiram rapidamente, indo além das definições originais relacionadas a circuitos computacionais e memórias. Novas aplicações exigiam Ethernet, SONET, USB (Universal Serial Bus), MPEG, NTSC / PAL , vídeos DACs, AGP4X, VGA, PCI, Rambus, componentes RF e DSPs. A lista de cores tornou-se tão grande e diversa que é praticamente impossível para uma só empresa de SOC desenvolver, manter e migrar todos os tipos de cores exigidos pelos clientes. O mercado respondeu com uma explosão de empresas terceirizadas desenvolvedoras de cores, tais como ARM ( Advanced RISC Machines), Rambus Corporation, Virtual Chips e Inventra.

Um problema surgido do fornecimento de cores por diferentes empresas foi a falta de padronização dos mesmos. Os cores não eram iguais para que uma integração fosse bem sucedida e para que pudessem ser utilizados por vários usuários em várias aplicações. Para solucionar este problemá a padronização da interconexão de cores foi necessária. Interfaces padronizadas ou on-chip buses foram criados para possibilitar a integração de componentes core em um único chip. Alguns barramentos existentes no mercado para interconexão de cores são:

- AMBA: Advanced Microcontroller Bus Architecture, (ARM).

- CoreConnect TM,(IBM).

- CoreFrameß, (Palmchip).

- FISPbus ${ }^{\mathrm{TM}}$, (Mentor Graphics - Inventra Business Unit)

- IPbus ${ }^{\mathrm{TM}}$ : IDT Peripheral Bus, (Integrated Device Technology)

- MARBLE: Manchester AsynchRonous Bus for Low Energy, (University of Manchester).

- PI-Bus: Peripheral Interconnect Bus, (Open Microprocessor Systems Initiative) (OMI).

- SiliconBackplane ${ }^{\mathrm{TM}}$, (Sonics, Inc.)

- VSIA On-chip Bus, (Virtual Socket Interface Alliance).

- WISHBONE Interconnect, (Silicore Corporation). 


\section{Controladores PID}

Nas três últimas décadas, as técnicas de automação exerceram grande influência tanto na operação quanto no prøjeto de processos técnicos. Esse fato ocorreu devido às próprias exigências dos processos e também pelas possibilidades oferecidas pelos equipamentos eletrônicos, juntamente com um profundo entendimento teórico de sistemas automáticos de controle [ISE89].

O controle automático tem sido vital para o avanço da ciência e da engenharia. Suas aplicações são inúmeras, sendo parte fundamental de sistemas bélicos (mísseis), aeronaves, robôs e muitos outros. $\mathrm{O}$ controle automático é atualmente parte importante dos atuais processos industriais e de fabricação. Neste contexto, o controle automático é essencial no controle numérico de máquinas-ferramenta nas indústrias de fabricação, sendo também fundamental em operações industriais tais como: controle de pressão, temperatura, umidade, viscosidade e fluxo em processos industriais.

Recentes desenvolvimentos em teoria de controle moderno estão no campo do controle ótimo, tanto de sistemas determinísticos ${ }^{1}$ quanto de estocásticos ${ }^{2}$, bem como do controle de aprendizado e adaptativo de sistemas complexos. Com os computadores digitais tornando-se mais baratos e mais compactos, estes são utilizados como partes integrantes destes sistemas de controle [OGA93].

Neste contexto, os controladores PID (Proporcional, Integral e Derivativo) desempenham um papel de extrema importância, permitindo um controle mais preciso e mais fiel do processo ao qual está relacionado.

1 Sistema de controle determinísticos: a resposta à entrada é prognosticável e repetível.

${ }^{2}$ Sistema de controle estocástico: a resposta à entrada é não prognosticável e não é repetível 


\subsection{Sistemas de Controle}

Um sistema de controle comanda ou regula um processo para que seja obtida a saída desejada. Como pode ser visto na FIGURA 5.1, um sistema de controle básico é formado por três componentes prinqipais: sensores, atuadores e controlador. Os sensores medem o comportamento do processo e retroalimentam o controlador. Alguns sensores utilizados na prática são: encoders, sensores de corrente, de temperatura, de pressão, dentre outros. Os atuadores fornecem as forças corretivas para que se obtenha a saída desejada. Exemplos de atuadores são: motores $\mathrm{A}$ C / DC, válvulas e reles.

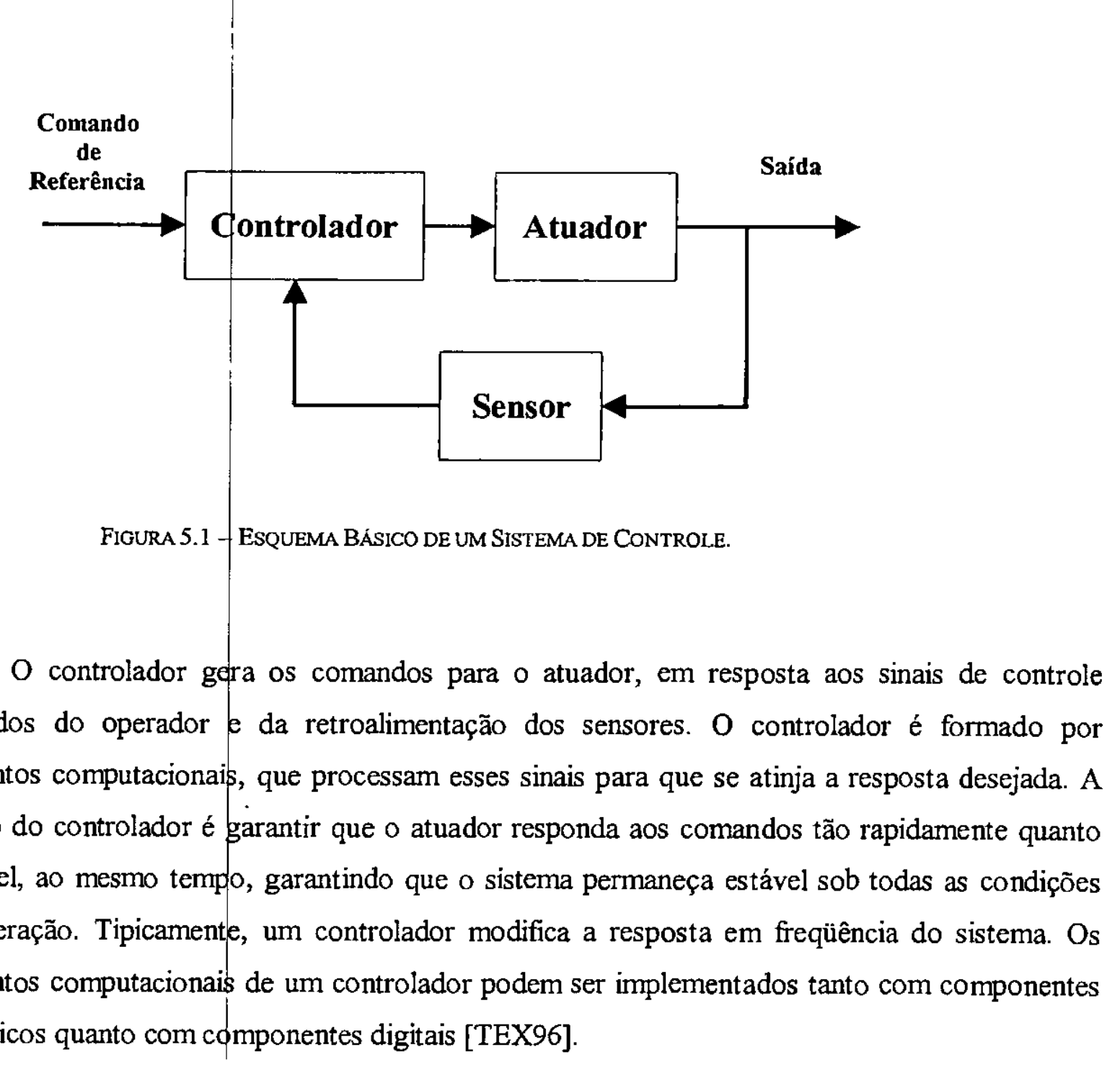




\subsubsection{Funções de Transferência}

Em sistemas de controle, funções denominadas funções de transferencia são normalmente utilizadas para caracterizar as relações de entrada e saída de componentes.

A função de tranşferência de um sistema de equações diferenciais lineares invariantes no tempo é definida como a relação da transformada de Laplace da função de saída (função resposta) para a transformada de Laplace da função entrada (função excitação) sob a hipótese de que todas as condiçðes iniciais são nulas.

\subsubsection{Diagrama de Blocos}

Um sistema de controle pode ser constituído de vários componentes. Para mostrar as funções desempenhadas ppr cada componente, normalmente utiliza-se diagramas de blocos.

Um diagrama de blocos de um sistema é a representação gráfica das funções desempenhadas por cada um dos componentes, juntamente com o fluxo de sinais, indicando as inter-relações existentes entire vários os componentes do sistema.

Em um diagrama de blocos, todas as variáveis do sistema são ligadas umas as outras através de blocos funcionais. O bloco funcional é um símbolo da operação matemática realizada no sinal de entrada, produzindo o sinal de saída (FIGURA 5.2). As funções de transferência dos componentes são geralmente introduzidas nos blocos correspondentes, sendo conectados por setas para indicar o sentido dos sinais.

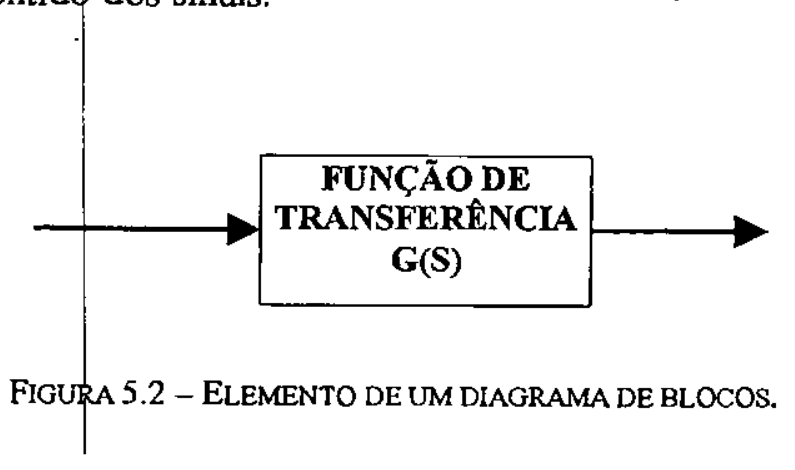




\subsubsection{Sistema de Cpntrole em Malha Aberta}

Em um sistema de controle em malha aberta, a saida não tem nenhum efeito sobre a ação do controle, ou seja, a saída não é medida nem realimentada para comparação com a entrada.

Em qualquer sistema de controle em malha aberta, a saída não é comparada com a entrada de referência, desse modo, a cada entrada de referência corresponde uma condição de operação fixa. Em conseqüência, a precisão do sistema depende de uma calibração. Ocorrendo perturbações, o sistema de controle em malha aberta não executará a ação desejada.

Sendo a função de transferência de um sistema qualquer denominada por $G(S)$, pode-se representar um sistema de controle em malha aberta, com entrada $\mathrm{R}(\mathrm{s})$ e saída $\mathrm{C}(\mathrm{s})$ pelo diagrama de blocos da Figura 5.3.

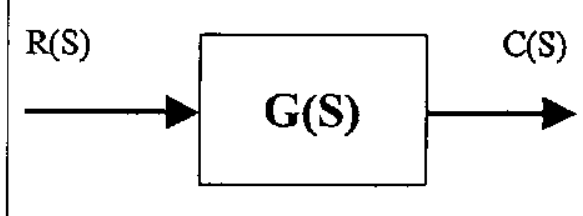

\subsubsection{Sistema de Controle em Malha Fechada}

Nos sistemas de controle em malha fechada, também conhecidos como sistema de controle realimentado, o sinal de erro atuante, que é a diferença entre o sinal de entrada e o sinal realimentado (que pode ser o próprio sinal de saída ou uma função do sinal de saída e suas derivadas), é introduzida no controlador de modo a reduzir o erro e trazer a saída do sistema a um valor desejado. O termo controle em malha fechada sempre implica no uso de ação de controle realimentado a fim de reduzir o erro do sistema.

Na FigurA 5.4, é representado um diagrama de blocos de um sistema de controle em malha fechada. Neste diagrama, $\mathrm{R}(\mathrm{s})$ representa ao sinal de referência ou entrada, $\mathrm{E}(\mathrm{s})$ representa o erro (entrada - saida) e C(S) representa a saída do sistema. 


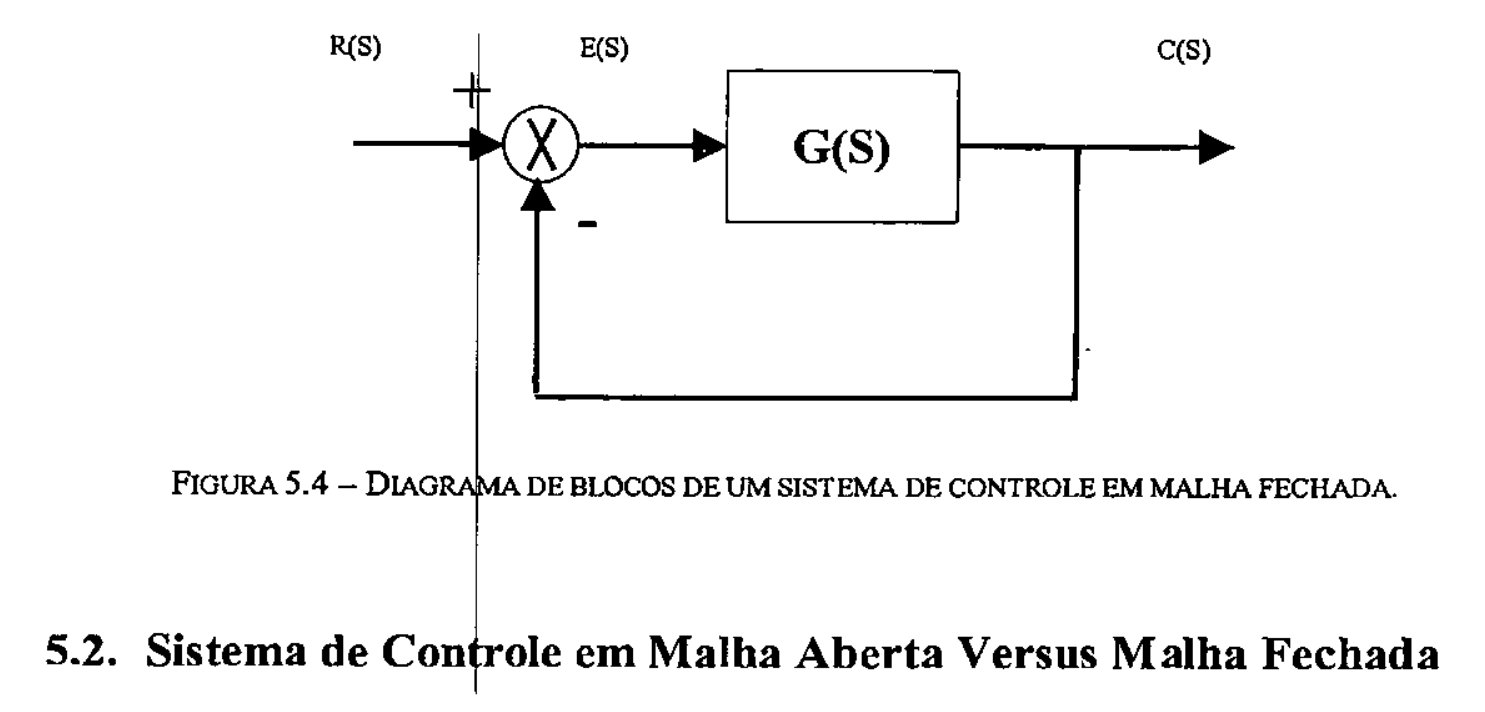
resposta do sistema relativamente insensível a distúrbios externos e a variações internas dos parâmetros do sistema. Dessa forma é possível utilizar componentes mais baratos e sem muita precisão para obter o controle preciso de um dado processo, o que não é possivel em um sistema de controle em malha abefta.

No caso da estabilidade, um sistema de controle em malha aberta é mais fácil de ser projetado, pois a estabilidade do sistema não constitui um problema significativo. Já no caso dos sistemas de controle em malha fechada, a estabilidade é sempre um problema fundamental, pois este tende a corrigir erros, o que pode causar oscilações de amplitude constante ou variável na saída do sistema.

\subsubsection{Controladores Analógicos e Digitais}

Os sistemas de controle analógicos são normalmente implementados com componentes analógicos tais como amplificadores operacionais, resistores e capacitores. Estes componentes analógicos são dispostos de maneira a formar estruturas do tipo filtro, que modificam a resposta em freqüência do sistema. Na FIGURA 5.5 está ilustrada uma implementação de controlador analógico. 


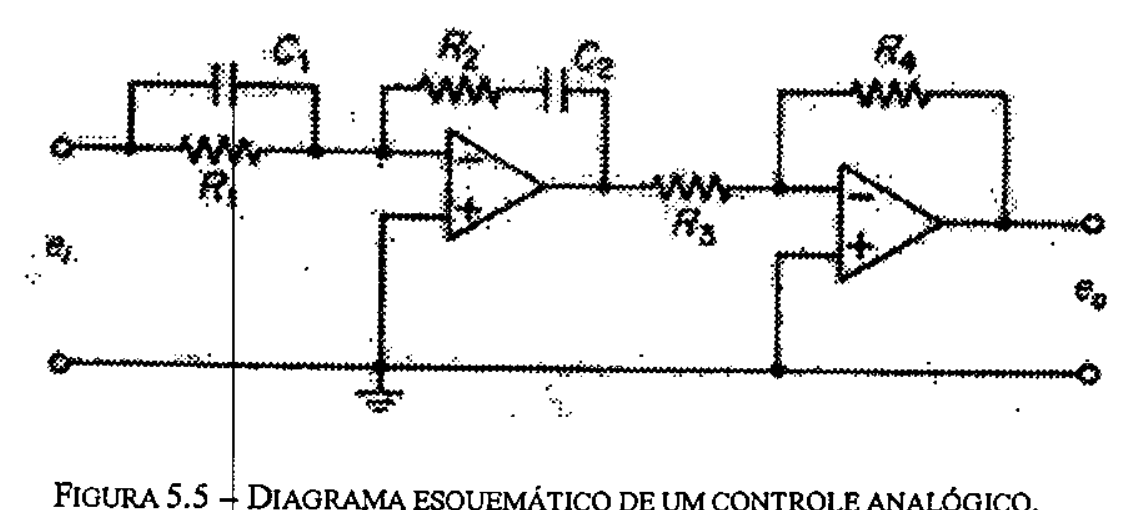

Figura 5.5 - Diagrama ESQUEMÁTICO DE UM CONTROLE ANALÓGICO.

Com o aumento do desempenho e da qualidade dos microprocessadores os controladores digitais estão tomando $o$ lugar dos controladores analógicos em diversas situações. Como vantagens dos controladofes digitais, pode-se citar:

- Pode ser proguamável:

- Permite a programação de diferentes modos de controle os quais podem ser ativados pelo operador.

- Insensivel a mudanças ambientais:

- A ausência de componentes tais como resistores e capacitores, elimina o problema causado por envelhecimento associado a estes componentes.

- Apresenta comportamento preciso

- Capaz de implementar algoritmos complexos

Um controlador dfgital é formado basicamente por um controlador, que processa o sinal de erro/realimentação $\left(P Y^{3}\right)$ em relação à entrada/sinal de referência $\left(\mathrm{SP}^{4}\right)$. Um conversor digital para analógico (D/A) é necessário para converter a saída digital do processador em um sinal analógico e acionar $o$ amplificador de potência (AP) e o atuador. Para possibilitar a realimentação ao processador, é necessário um conversor analógico para digital (A/D), como interface do sinal do sensor para o processador. Um diagrama básico de um sistema de controle digital pode ser visto na F.GURA 5.6.

${ }^{3}$ PV (Process variable) ou variâvel de processo.

${ }^{4} \mathrm{SP}$ (Setpoint) ou ponto de ajuste do processo. 


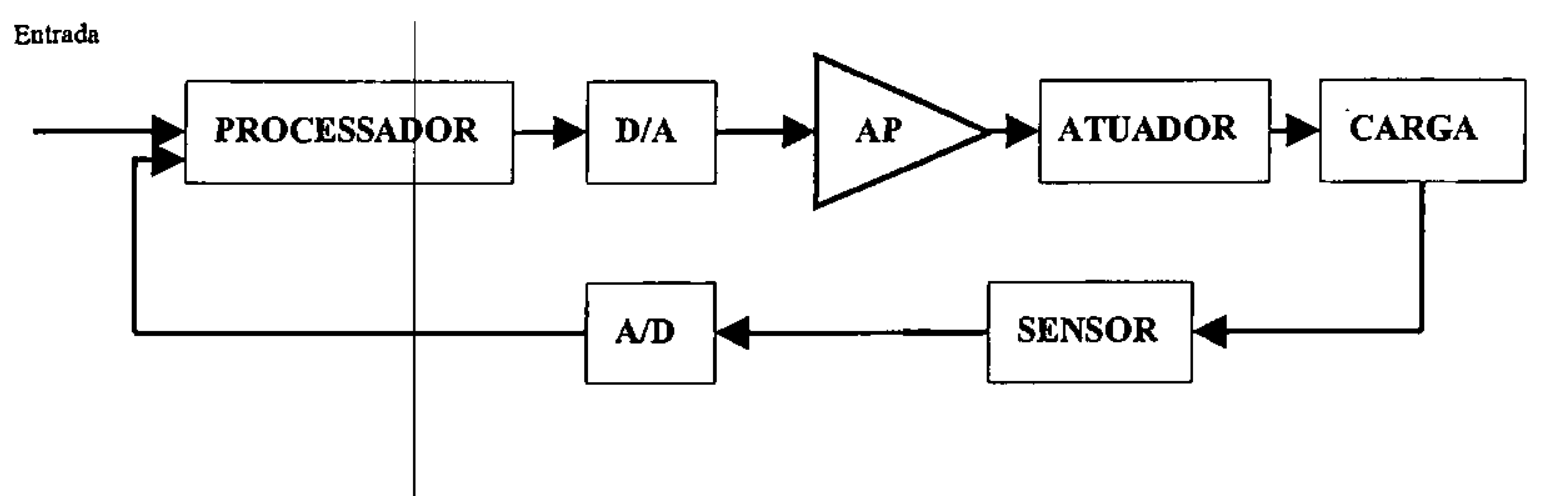

FIGURA 5.6 - DLAGRAMA DE UM SISTEMA DE CONTROLE digtTAL.

\subsection{Ações Básicas de Controle}

A FIGURA 5.7 representa um sistema de controle de temperatura de um forno elétrico. Para completar o sistema de controle, existe um sensor de temperatura com acesso a cavidade do forno, um atuador que fornece potência a resistência elétrica e um controlador que compara a temperatura medida à temperatura desejada. $\mathrm{O}$ controlador pode assumir qualquer uma das formas básicas que serão descritas a seguir.

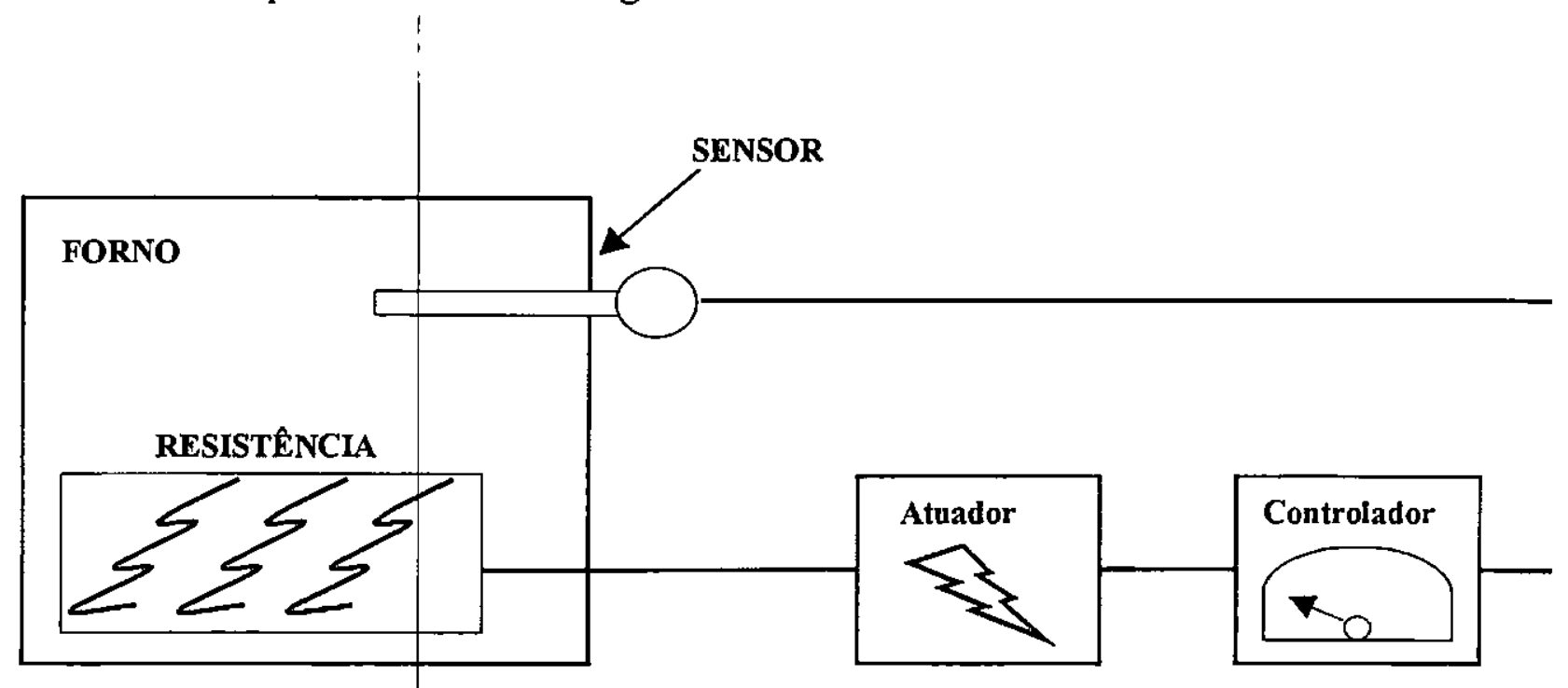

FIGURA 5.7 - ESQUEMA DE UM CONTROLE DE TEMPERATURA DE UM FORNO ELÉTRICO. 


\subsubsection{Controlador de Duas Posições ou ON-OFF}

Esta é a forma mais simples de controle, sendo utilizada pela maioria dos aparelhos domésticos que contém termostatos. Neste tipo de controle, o atuador oscila entre duas posições: ligado e desligado.

Se o propósito do sistema for aquecimento, como por exemplo, o forno elétrico representado na FIGURA 5.7, as duas posições do controlador são a potência máxima $(O N)$ e a potência mínima $(O F F)$. Para um bom funcionamento deste tipo de controlador, deve-se ter cuidado de programar a temperatura de ligar o aquecedor ligeiramente diferente da temperatura de desligá-lo. Este recurso é conhecido por histerese. A aplicação de histerese previne que ruídos liguem e desliguem o aquecedor de uma maneira rápida e desnecessária, quando a temperatura estiver próxima da temperatura de operação ou setpoint.

A FIGURA 5.8 mostra o comportamento de um controlador ON-OFF. Pode-se observar na figura, a saida oscilando em torno da temperatura desejada (setpoint) de processo. A forma de onda na parte inferior do gráfico representa a potência oferecida ao sistema.

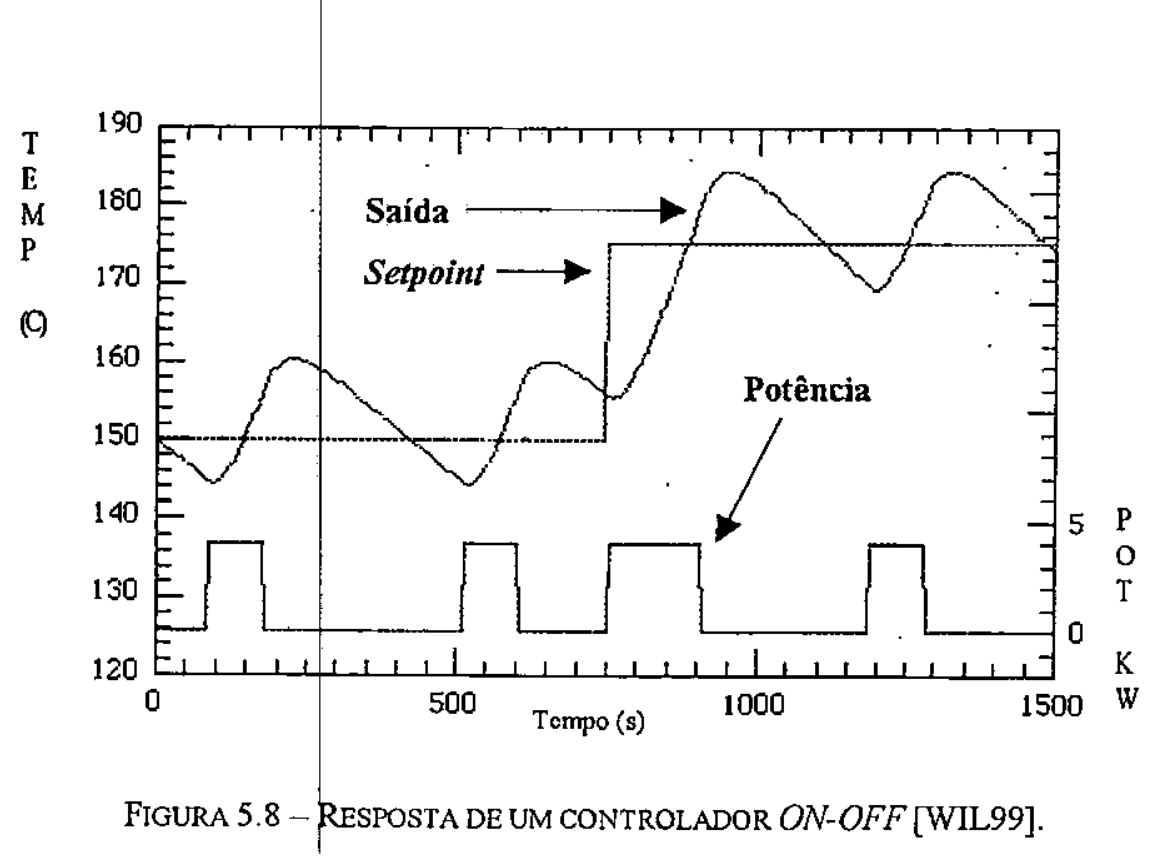


Tomando-se como exemplo a FIGURA 5.8, no instante 750 segundos há uma mudança no ponto de operação de $150^{\circ} \mathrm{C}$ para $175^{\circ} \mathrm{C}$. Neste instante nota-se que a potência (representada em cor azul) passa para o valor máximo até que a temperatura alcance o valor de operação desejado mais o valor da histerese. Após este instante a potência volta a zero, onde ficará até que a temperatura caia até da temperatura de operação menos o valor da histerese.

Neste tipo de controlador a saída jamais acompanha o valor desejado sem que haja um erro significativo.

\subsubsection{Controlador Proporcional}

Um controlador proporcional é essencialmente um amplificador com o ganho ajustável. No controle proporcional, o sinal de erro (setpoint - variável de processo) é multiplicado por uma constante antes de sef alimentar o atuador.

Continuando-se com o exemplo do forno elétrico do item 5.2.1, a potência $\mathbf{W}$ aplicada ao atuador (resistência de aquecimento) é proporcional à diferença de temperatura ajustada (setpoint), Ta e a temperatura do forno, Tf. A equação 5.1 representa de maneira simplificada a ação proporcional.

$$
\mathbf{W}=\mathbf{P} *(\mathbf{T a}-\mathbf{T} \mathbf{f})
$$

Equação 5.1

O fator $\mathbf{P}$ é conhecido como ganho proporcional do controlador. Com o aumento do ganho $\mathbf{P}$, o sistema responde mais rapidamente às mudanças de setpoint, mas pode, eventualmente, tornar-se instável sob a forma de oscilações.

A FIGURA 5.8 mostra o comportamento de um controlador proporcional para o exemplo do forno elétrico. O setpoint representa a ponto de ajuste desejado para o sistema. As outras três curvas do gráfico representam a saída do sistema. Pode ser observado, que a medida em que o ganho aumenta, há uma diminuição do tempo de resposta e uma redução do erro de regime 
estacionário $^{5}$. Nota-se também, que dependendo do aumento no ganho, pode haver a formação de sobre-sinal ${ }^{6}$.

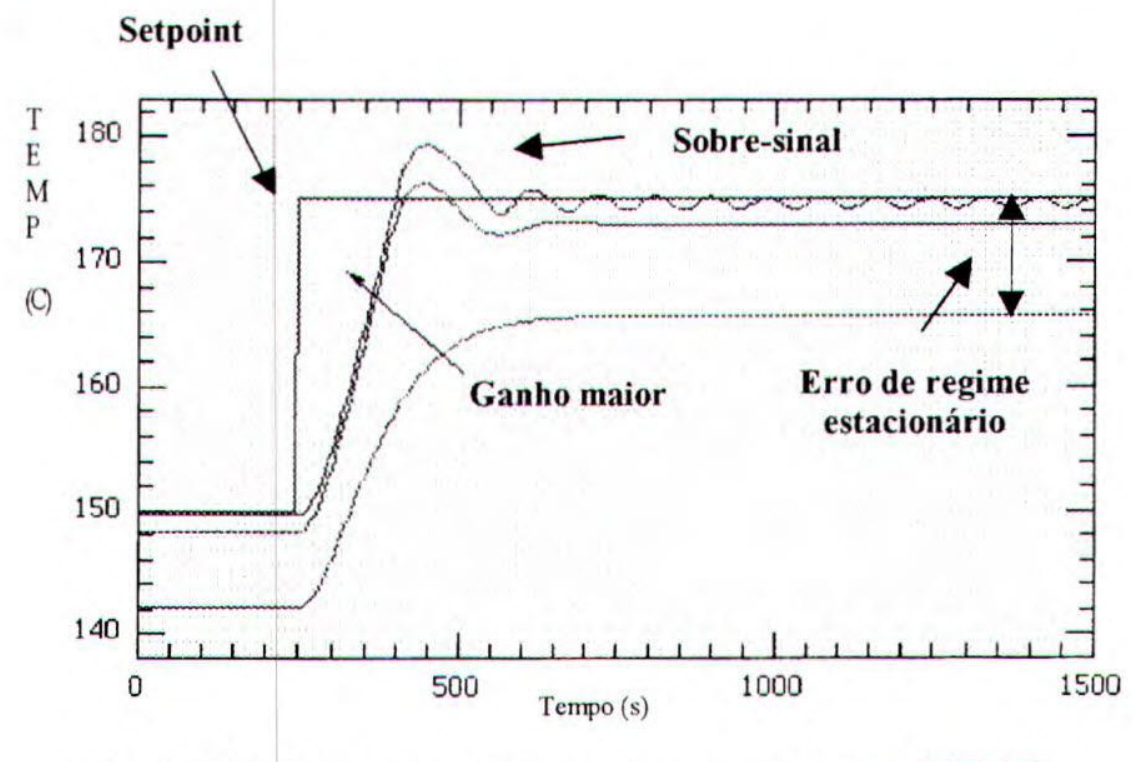

FIGURA 5.9 - RESPOSTA DO CONTROLADOR PROPORCIONAL [WIL99].

\subsubsection{Controlador Proporcional Mais Derivativo}

Os problemas de estabilidade e de sobre-sinal apresentados por controladores proporcionais com alto ganho, podem ser minimizados com a adição de um termo derivativo. $\mathrm{O}$ termo de amortecimento D age no tempo de resposta do sistema causando um amortecimento. Como no caso anterior do controlador proporcional, o termo derivativo também atua sobre o sinal de erro (entrada - saída), como pode ser visto na equação 5.2.

$$
W=P *[(T a-T f)+D * d / d t(T a-T f)]
$$

Equação 5.2

A Figura a 5.9 mostra a resposta (temperatura) de um sistema PD utilizado no exemplo de controle de um forno elétrico. A saída de maior sobre-sinal mostra uma resposta do sistema praticamente sem a ação derivativa. A medida em que o fator $\mathbf{D}$ for aumenta, também aumenta o amortecimento do sistema, o que pode ser observado nas outras saídas do sistema. Como nos exemplos anteriores, o sinal de setpoint representa o valor de operação ajustado para o sistema.

\footnotetext{
${ }^{5}$ Erro de regime estacionário: diferença entre o sinal de entrada e o sinal de saída com o sistema em regime permanente.
} 


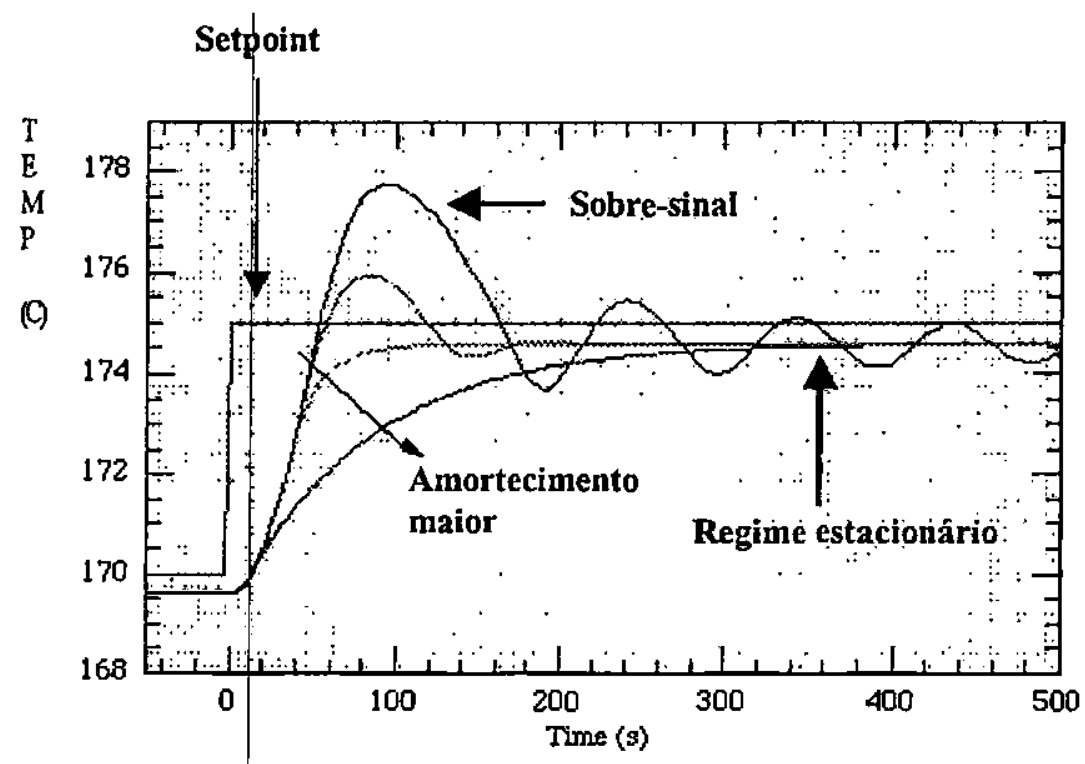

FIGURA 5.10 - RESPOSTA DO CONTROLADOR PROPORCIONAL MAIS DERIVATIVO [WIL99].

\subsubsection{Controlador Proporcional Mais Integral}

Quando o sensor de um sistema é susceptivel a ruídos ou à interferência elétrica, ações de controle derivativas podẹm causar grandes flutuações de saída do sistema. Nestas circunstâncias, a melhor escolha de controlador seria o do tipo PI (proporcional mais integral).

\subsection{Controlador Integral mais Proporcional mais Derivativo (PID)}

Apesar do controlador PD atuar de maneira satisfatória no sobre-sinal do sistema, este não minimiza o efro de estado estacionário. Felizmente, pode-se eliminar este erro aplicando-se ganhos de baixos valores e adicionando-se um termo integral a função de controle PD. A equação 5.3 mostra a função completa do controlador PID.

$$
W=P *\left[(T a-T f)+D * d / d t(T a-T f)+I * \int(T a-T f) d t\right.
$$

\footnotetext{
${ }^{6}$ Sobre-sinal: máximo valor de pico apresentado pela curva de resposta.
} 
Na equação 5.3, o termo I representa o ganho integral. O efeito do termo integral é alterar a potência de saída até que a média temporal do valor do erro de saída seja zero, ou seja, o termo integral aumenta a precisão do sistema.

A FigURA 5.10 mostra o comportamento de um controlador PID para o exemplo do forno elétrico. No gráfico somente estão representados o setpoint, a saída e a potência fornecida ao sistema. Como pode ser фbservado na curva de saída, não há mais sobre-sinal e o erro de regime estacionário é praticamente nulo. A curva na parte inferior do gráfico representa a potência oferecida pelo controlador. Note que a máxima potência é utilizada apenas no inicio quando há uma variação brusca de setpoint, depois de estabilizado, o sistema apenas utiliza potência de "manutenção".

\subsection{Controlador PID Digital}

A FIGURA 5.12 mostra o diagrama de blocos de um sistema de controle analógico ou contínuo, contendo uma planta (processo) Gp(s) e um controlador PID Gc(s). A entrada do sistema é representada por $\mathrm{R}(\mathrm{s})$ e a saída por $\mathrm{C}(\mathrm{s})$. $\mathrm{E}(\mathrm{s})$ é o erro ou diferença entre o sinal de entrada e o de saída e U(s) representa a saída do controlador PID. 


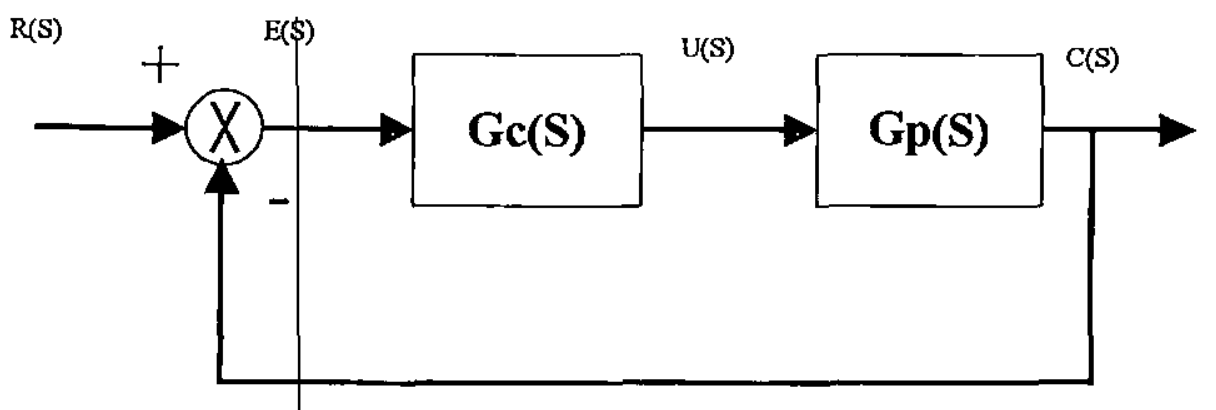

FIGURA 5.12- DIAGRAMA DE BLOCOS DE UM SISTEMA DE CONTROLE COM PID NA FORMA CONTfNUA.

A forma temporal da função de transferência do controlador PID, Gc(s), é dada pela Equação 5.4 .

$$
U(t)=K\left[e(t)+\frac{1}{T i} \int e(t) d t+T d \frac{d e(t)}{d t}\right]
$$

Nesta equação, K é o ganho do controlador, Ti é o tempo de ação integral e Td é o tempo de ação derivativo.

O cálculo dos parâmetros de um PID digital pode ser feito utilizando-se métodos bem conhecidos de projeto de sistemas contínuos. Isto significa que as regras e métodos de sintonia para sistemas analógicos podem ser aplicados sem alterações para o caso dos PIDs digitais [BEN88].

Para tempos de amostragem pequenos, $T_{0}, A$ equação 5.4 pode ser expressa de forma discreta por equações diferença. O termo derivativo é simplesmente substituído pela equação diferença de primeira ordem e o termo integral é substituído por uma soma. A integração contínua pode ser discretizada tanto por aproximação retangular quanto por aproximação trapezoidal.

Integrando-se por aproximação retangular tem-se a equação 5.5:

$$
U(k)=K\left[e(k)+\frac{T o}{T i} \sum_{i=0}^{k-1} e(i)+\frac{T d}{T o}(e(k)-e(k-1))\right]
$$


Esta equação repłesenta o algoritmo não recursivo de controle. Para a programação do controlador PID um algoritmo recursivo seria mais apropriado. O algoritmo recursivo se caracteriza por calcular a variável atual, $\mathrm{U}(\mathrm{K})$, baseada na variável calculada no tempo anterior, $\mathrm{U}(\mathrm{K}-1)$ mais os termos de correção [ISE89].

Para se derivar \& equação recursiva deve-se subtrair da Equação 5.5 a Equação 5.6 representada a seguir.

$$
U(k-1)=K\left[e(k-1)+\frac{T o}{T_{i}} \sum_{i=0}^{k-2} e(i)+\frac{T d}{T_{o}}(e(k-1)-e(k-2))\right] \quad \text { Equação } 5.6
$$

Como resultado obtém-se a Equação 5.7 para o algoritmo recursivo do controlador PID.$$
U(k)=U(k-1)+q 0 \cdot e(k)+q 1 \cdot e(k-1)+q 2 \cdot e(k-2)
$$

Os parâmetros q0, q1 e q2 podem ser calculados pelas seguintes relações:

$$
\begin{aligned}
& q 0=K\left(1+\frac{T d}{T o}\right) \\
& q 1=-K\left(1+2 \frac{T d}{T o}-\frac{T o}{T i}\right) \\
& q 2=K \frac{T d}{T o}
\end{aligned}
$$

Equação 5.8

Equação 5.9

Equação 5.10

Em virtude das equações 5.7 representar quantidades em função de amostras em vez de em função do tempo, pode-se implementá-las em microcontroladores eu diretamente em hardware, como no caso dos FPGAs. 


\subsection{Sintonia de Controladores PID}

Um aspecto importante dos controladores PID é a escolha adequada dos seus parâmetros $\mathrm{K}$, Ti e Td. A determinação destes parametros é conhecida como sintonia do controlador PID. Somente com um corret $\phi$ ajuste destes parâmetros pode-se garantir que o sistema satisfaça as especificações de desempenho exigidas pelo sistema.

Uma das formas utilizadas para se fazer a sintonia dos parâmetros PID é por ajuste manual de cada parâmetro. Variam-se os parâmetros $\mathrm{K}$, Ti e Td e ao mesmo tempo observa-se a resposta do sistema até que esta esteja dentro dos padrões especificados. Este método, no entanto, é demorado e depende muito da experiência do operador, sendo que operadores diferentes produzem parâmetros diferentes para o mesmo processo [CAO99].

Uma outra forma para determinação doas parâmetros de um controlador PID são as regras de Ziegler e Nichols. Estas regras são baseadas nas características da resposta transitória de uma dada planta e são muito convenientes quando os modelos matemáticos das plantas não são conhecidos.

Há dois métodos de determinação dos parâmetros de um controlador PID pelas regras de Ziegler e Nichols.

O primeiro método consiste em obter experimentalmente a resposta da planta a uma entrada degrau unitário. Se a resposta apresentar uma curva em forma de " $\mathrm{S}$ " a da Figura 5.13, os parâmetros do controlador podem ser calculados pelas seguintes relações:

$$
\begin{aligned}
& K=1.2 \frac{T}{L} \\
& T i=2 \cdot L \\
& T d=0.5 \cdot L
\end{aligned}
$$




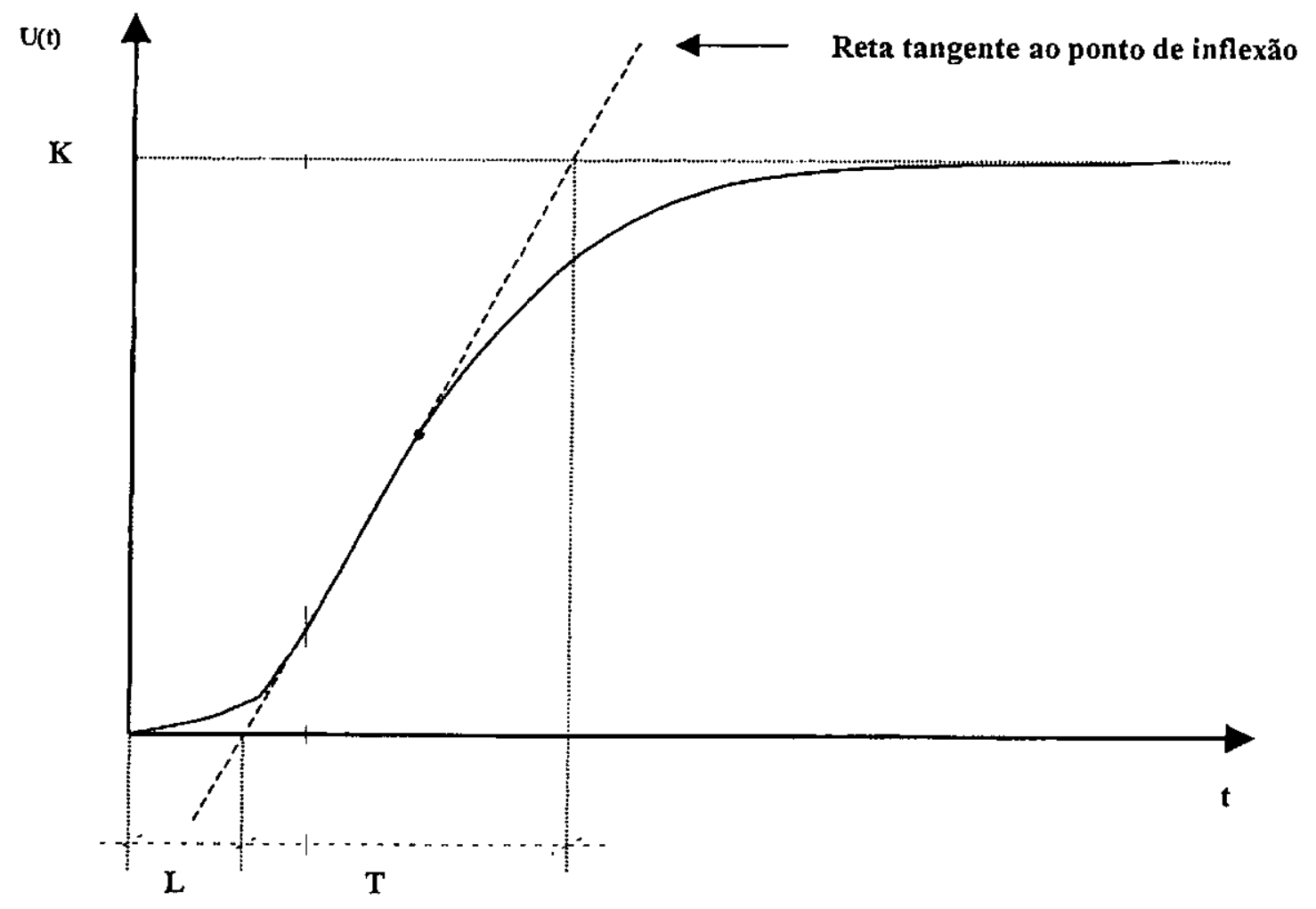

FigURA 5.13 - CURVA DE RFSPOSTA EM FORMA DE "S".

O segundo método consiste em aumentar o ganho $\mathrm{K}$ do controlador até que a saida do sistema exiba oscilações mantidas, conforme a Figura 5.14. O valor do ganho que causa estas oscilações será representado por Kcr e o período destas oscilações será Pcr. 
$\mathrm{U}($

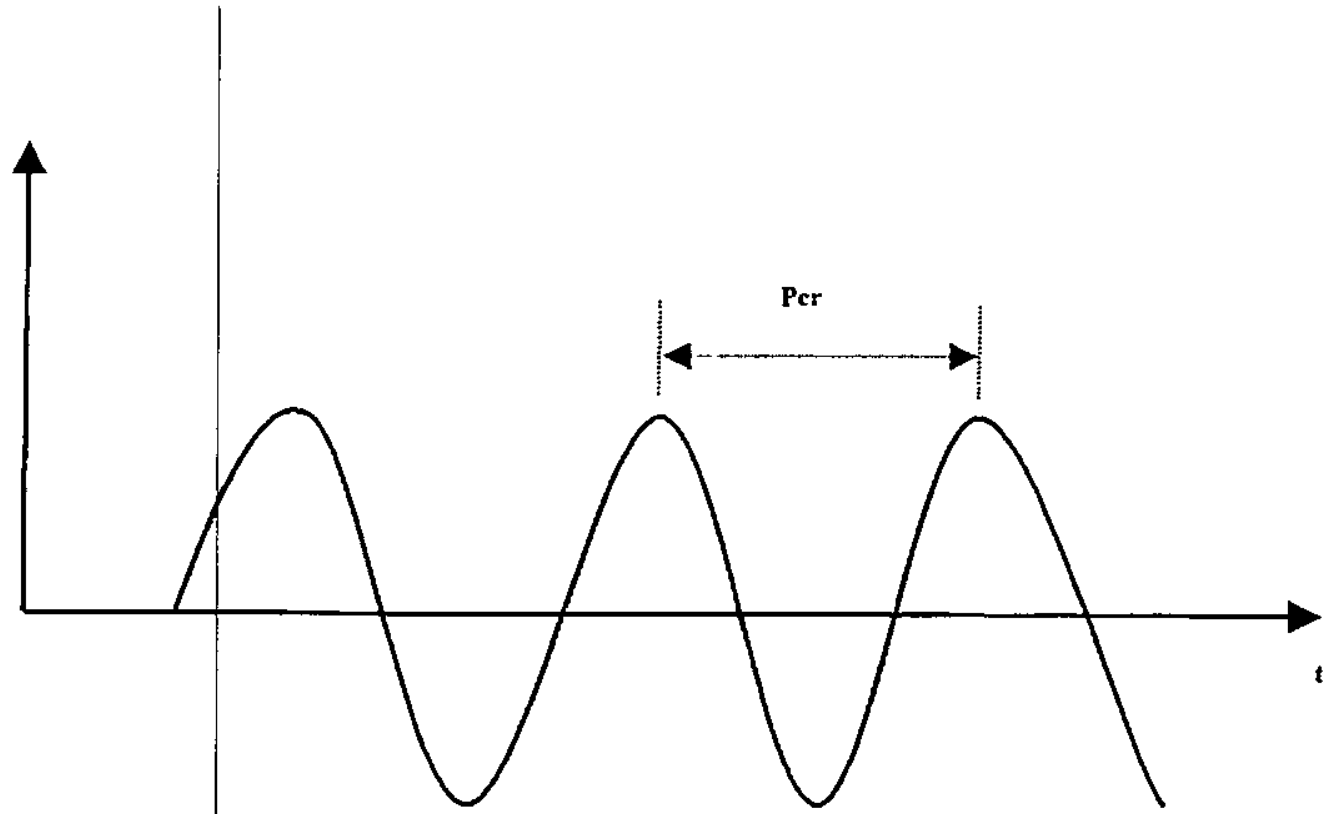

FIgura 5.14 - CuRVA DE RESPOSTA OSCILANTE, COM PERIODO PCR.

Por este método, фs parâmetros $\mathrm{K}$, Ti e Td do controlador PID são dados pelas Equações $5.14,5.15$ e 5.16 .

$$
\begin{aligned}
K & =0.6 \cdot \mathrm{Kcr} \\
T i & =0.5 \cdot \mathrm{Pcr} \\
T d & =0.125 \cdot \mathrm{Pcr}
\end{aligned}
$$

Equação 5.14

Equaçãd 5.15

Equação 5.16

As regras de determinação dos parâmetros de Ziegler e Nichols fornecem um bom ponto de partida para a determinação fina dos parâmetros [OGA93].

Além dos método\$ descritos anteriormente, atualmente já existem sistemas que fazem a sintonia automática dos parâmetros PID. A sintonia automática mostra-se muito útil, pois proporciona um tempo menor de sintonia e garante a repetibilidade dos parâmetros, já que não 
depende da experiência de cada operador ou de analise das curvas de resposta de um determinado sistema.

Para a auto-sintonia dos parâmetros de controladores como o PID, vários autores propōem métodos distintos, que requerem informações variadas sobre as características do sistema, tais como caracteristicas da resposta ao degrau unitário de malha aberta, constantes de tempo de malha fechada, dentre outros. Os detalhes deste tipo de sintonia estão fora do escopo deste trabalho e, portanto não serão descritos aqui.

\subsection{PID NA ROBÓPICA}

Robôs $^{1}$ são dispositivos mecânicos, geralmente equipados com sensores e atuadores, que operam automaticamente, controlados por um sistema computacional. Os robôs podem realizar uma grande variedade de tarefas e o seu uso é particularmente interessante nas tarefas que são repetitivas, dificeis ou muito perigosas para um ser humano realizar.

No caso dos robôs industriais, predominam as ações de manipulação, que são geralmente tarefas repetitivas tais como furação, soldagem, pintura e empacotamento de objetos [FER87].

Um outro exemplo de aplicação de robôs é na área militar, onde um robô pode ser utilizado para percorrer túneis, campos minados ou qualquer outro tipo de ambiente hostil. Um robô como este pode ser equipado com uma câmera e microfones para fazer uma varredura em locais perigosos, com bombas, armadilhas e inimigo [BRU00].

Os robôs podem ser móveis e, ao mesmo tempo, dotados de membros articulados. Nestes dois casos, a propulsão do robô e a movimentação dos membros articulados são feitas, na maioria das vezes, por servo-motores do tipo CC (Corrente Contínua). Neste contexto, o algoritmo PID é o mais amplamente utilizado para o controle de servo-motores por ser fácil de se entender e de sintonizar seus parâmetros [BOW99].

\footnotetext{
'A palavra robô é derivada da palavra Tcheca "ROBOTA" que significa trabalho monótono, árduo.
} 
O controlador PID elaborado neste trabalho será uma das partes integrantes de um projeto mais abrangente, chamado ARMOSH, do Laboratório de Computação Reconfigurável (LCR), do LABIC (Laboratório de Inteligência Computacional), ambos do ICMC-USP, em conjunto com o e Camegie Mellon Univesity, EUA.

O projeto ARMOSH (Aprendizado em Robôs Móveis via Software e Hardware) visa o estudo e implementação de algoritmos de aprendizado de robôs móveis (navegação, reconhecimento de objetps, etc.), tanto em nível de software quanto em nível de hardware, visando uma comparação de desempenho dos principais algoritmos de aprendizado na versão de software e hardware. Este projeto também visa, em longo prazo, a construção de um robô completo, com uma arquitetura reconfigurável.

Como uma primeipa implementação do projeto ARMOSH, pretende-se utilizar a solução Excalibur da Altera. A linha Excalibur oferece soluções tanto com softcores quanto com hardcores de processadores, otimizados especialmente para lógica programável.

O processador embutido NIOS é um softcore de processador RISC configurável com um conjunto de instruções de 16 bits e um datapath selecionável de 16 ou 32 bits. Este core é inicialmente destinado para a família de dispositivos APEX da Altera, ocupando apenas 12\% da área de um dispositivo de 200.000 portas. As soluções Excalibur, da Altera, para hardcores são baseadas nos processadores da ARM Limited e MIPS Technologies.

Uma configuração inicial do sistema de controle do robô está representada na Figura 5.15. Nesta configuração o controlador PID fará parte de uma rede de FPGAs, cada um executando uma tarefa específica, sendo controlados por um processador central.

Para a comunicação e interfaceamento dos diversos componentes desta arquitetura, estuda-se adotar uma solução do tipo CAN (Controller Area Network) ou AMBA (Advanced Microcontroller Bus Architecture). O AMBA é uma especificação aberta de barramento on-chip, que detalha uma estratégia para interconexão e gerenciamento de blocos funcionais que compõem um System-On-Chip (SOC). 


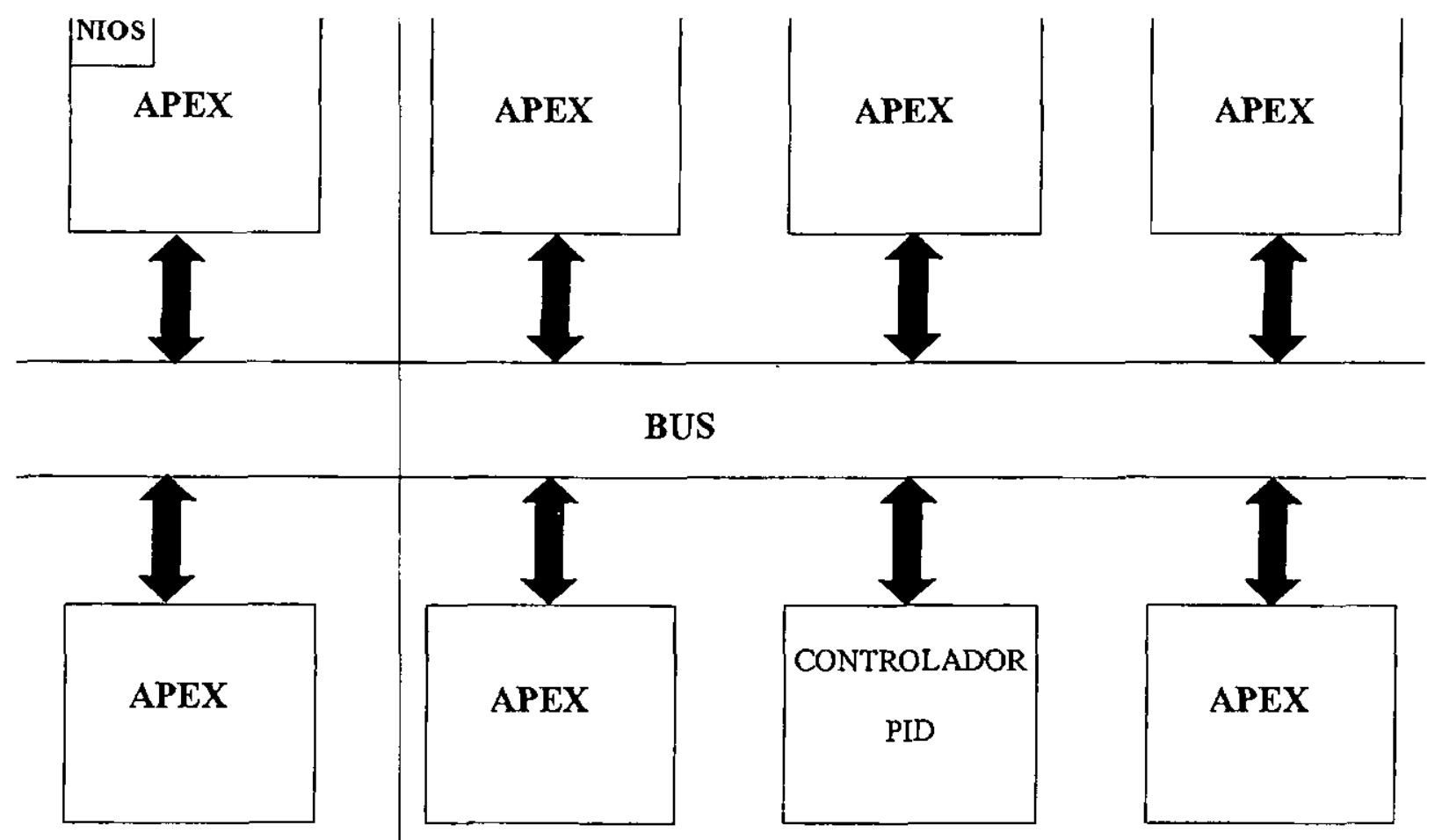

FIGURA 5.15- REPRESENTAÇÃO DO SISTEMA DE CONTROLE DO ROBÔ.

\subsubsection{Driver PWM (Pulse Width Modulation)}

Para que um cohtrolador PID digital possa controlar propriamente um motor CC (Corrente Contínua), há a necessidade de se utilizar algum tipo de interface entre o mundo digital do PID e o motor, que além de ser analógico, demanda uma potência muito além da que pode ser oferecida por um dispositivo como um conversor D/A ou diretamente um por FPGA.

Um dos modos de se fazer o controle da velocidade de um motor $\mathrm{CC}$ é através da variação da tensão de alimentação do mesmo. Utilizando-se um driver apropriado, como por exemplo, um amplificador de potência, pode-se fazer a variação da tensão contínua de entrada do motor. No caso de um sistema de controle digital, o sinal analógico de controle do motor deve vir de um conversor digital para analógico, D/A. Uma desvantagem deste sistema é que com a inclusão de um conversor D/A, o número de CIs do sistema aumenta o que naturalmente causa aumento de custo e de consumo de potência [MOD88]. A Figura 5.16 esquematiza este tipo de controle. 


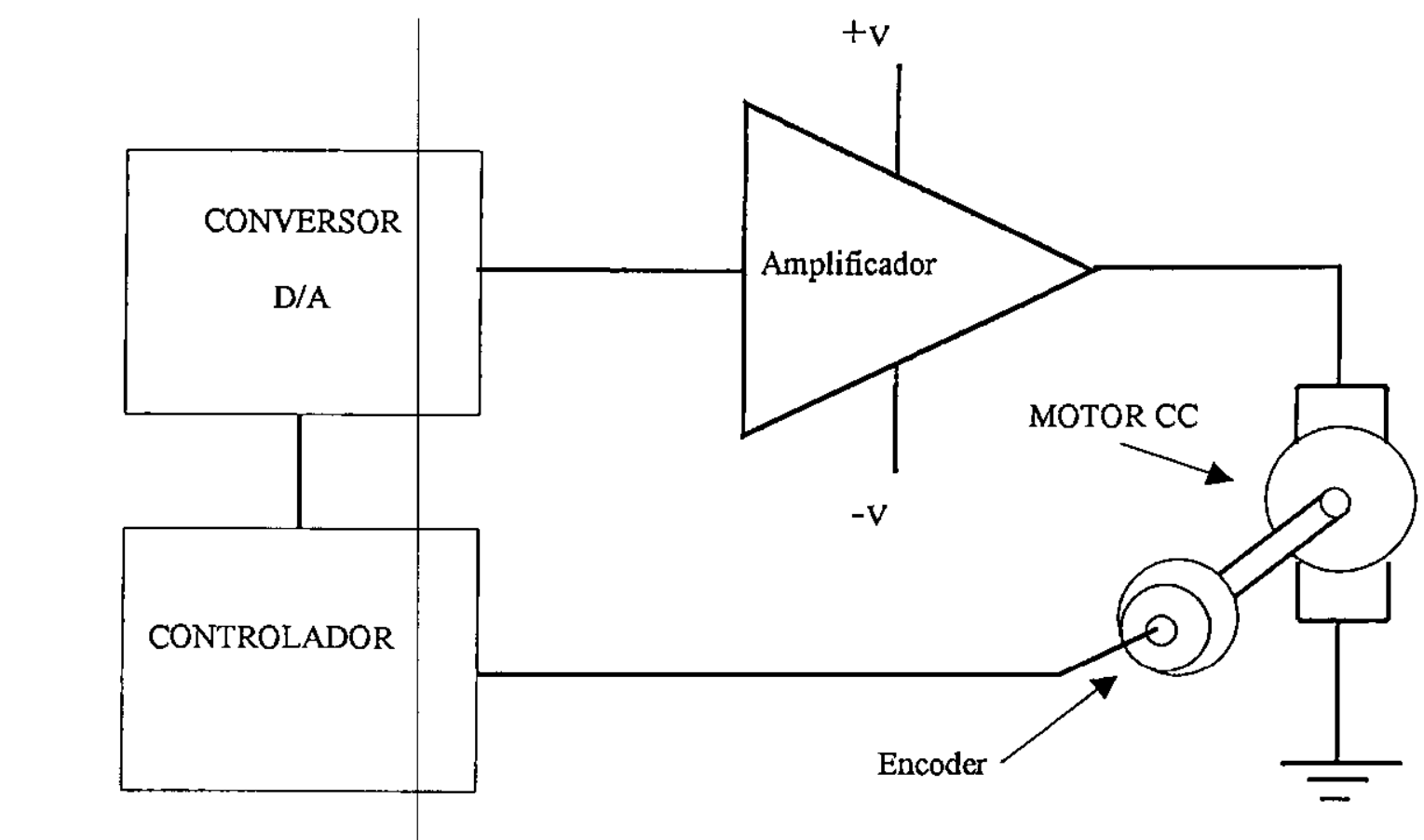

FiguRA 5.16- CONTROLE DE MOTOR CC POR VARIAÇÃO DA TENSÃO DE ALIMENTAÇÃO.

Na configuração mostrada na Figura 5.16, o controlador envia sinais digitais ao conversor D/A e este faz a conversắo do sinal para analógico para alimentar um amplificador de potência. O amplificador de potência, por sua vez, tem a capacidade de manter uma tensão de alimentação no motor mesmo com a exigência, em muitos casos, de altas correntes elétricas. O encoder ${ }^{1}$ indicado na figura é um exemplo de como se pode fazer a realimentação da velocidade do motor para o controlador.

Uma segunda alternativa para o controle de motores CC é o PWM ou do Inglês, Pulse Width Modulation ou modulação por largura pulso. Nesta abordagem, ao invés de variar a tensão DC de alimentação do motor, o controle é feito pela variação da largura de um trem de pulsos de fieqüência constante. Apesar de o motor ser alimentado por uma tensão pulsante, o que é realmente "sentido" pelo motor é uma tensão média equivalente. A Figura 5.17 ilustra um conjunto de ondas no formato PWM.

\footnotetext{
${ }^{1}$ Encoder - Dispositivo que converte a rotação do motor em pulsos elétricos, geralmente utilizado em medidas de posição e velocidade de motores.
} 
a)

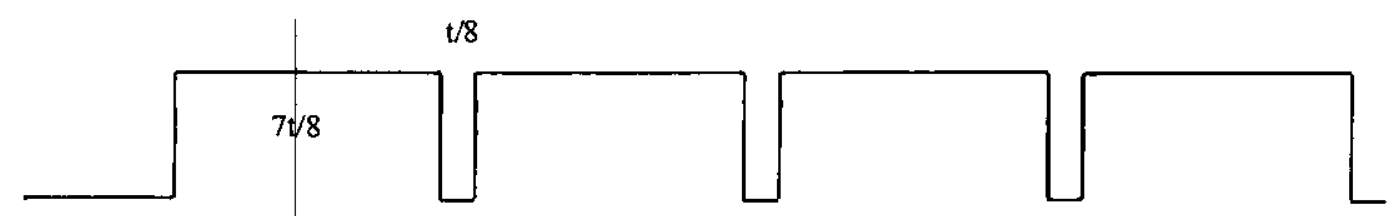

b)

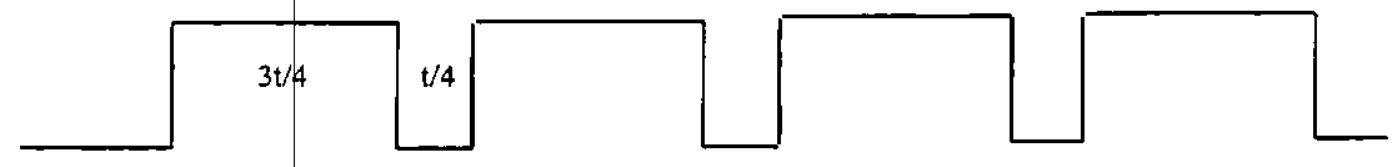

c)

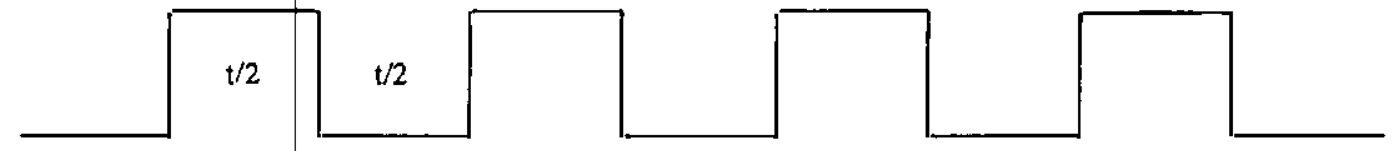

d)

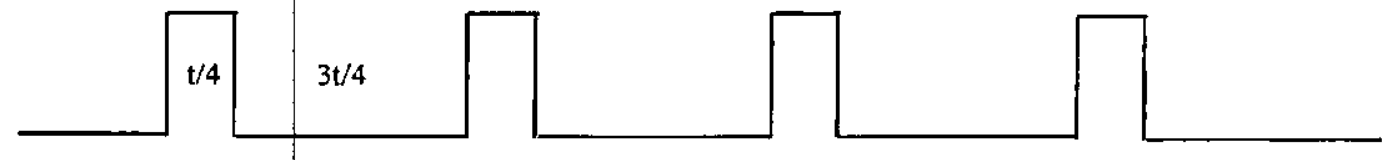

e)
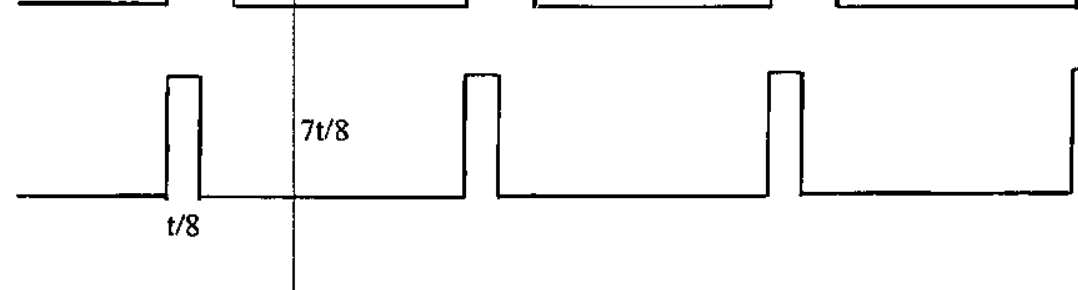

FIGURA 5.17- FORMAS DE ONDA NO FORMATO PWM.

Nas formas de onda da Figura 5.17, a tensão média equivalente diminui da onda "a" para a onda " $\mathrm{e}$ ". A forma de onda "c", por exemplo, representa um PWM com 50\% de ciclo de trabalho ou do Inglês duty cycle. Respectivamente, os ciclos de trabalho das ondas representadas nesta figura são os seguintes: a) $87,5 \%$; b) $75 \%$; c) $50 \%$; d) $25 \%$ e d) $12,5 \%$.

Mesmo com a utilização do PWM, ainda é necessário se utilizar um driver para que se possa fornecer potência suficiente ao acionamento do motor. Uma das soluções que podem ser empregadas é a utilização de uma configuração chamada de Ponte $\mathrm{H}$, como esquematizado na Figura 5.18. Uma ponte tipo $\mathrm{H}$ é formada por quatro transistores bipolares de junção (BJT) ou quatro transistores de efeito de campo tipo MOSFET de potência que atuam como chaves. Estes transistores são utilizadọs em uma configuração H. O motor é acoplado no centro da configuração $\mathrm{H}$ e o controle é feito permitindo se que a corrente elétrica flua sempre entre dois transistores. Com o acionamento dos transistores Q1 e Q4 o motor gira em um sentido e com o acionamento dos transistores Q2 e Q3, o motor gira no sentido oposto [ZIL01]. 


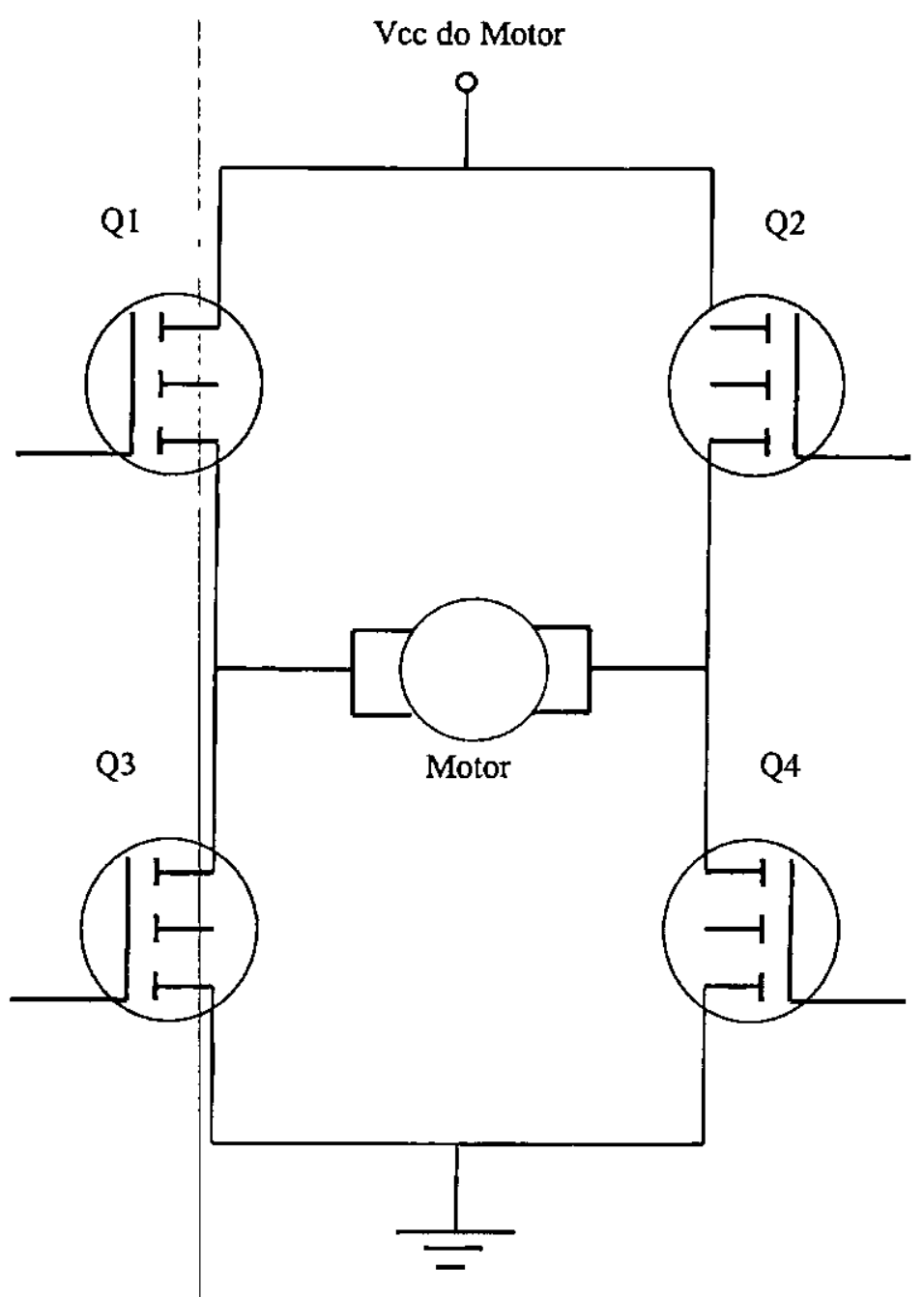

Figura 5.18- CiRCUITO BÁSICO DE UMA PONTE H.

As pontes $\mathrm{H}$ são tradicionalmente implementadas com transistores discretos, no entanto, atualmente, soluções totalmente integradas são comuns em impressoras, plotters, robôs e em controle de processos. Um exemplo de solução completamente integrada é o circuito integrado LMD18200 da National Semiconductor. Este componente é uma ponte H integrada, capaz de oferecer a um motor, uma corrente de até 3A e uma tensão de até $55 \mathrm{~V}$ [REG99].

A Figura 5.19 mostra um esquema de ligação entre este componente e um motor. 


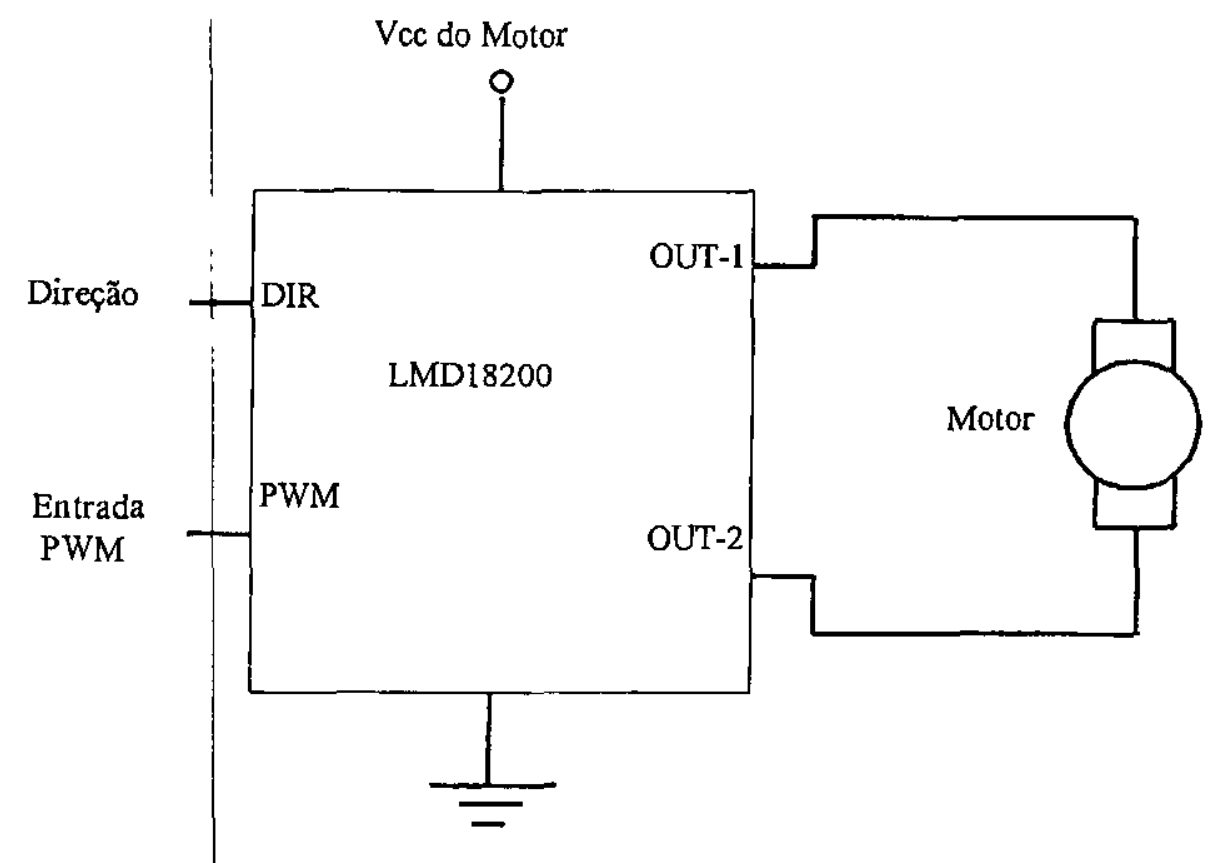

FiguRA 5.19- ESQUEMA DE LIGAÇÃo DE LMD18200.

Um fator interessante deste circuito integrado é o fato de haver uma entrada para controle sinal ou reversão do motor. Há apenas uma entrada PWM e de acordo com o nível lógico do pino de controle de direção o sinal PWM é repassado a saída OUT-1 ou OUT-2. A Figura 5.20 mostra as formas de onda da entrada PWM, do controle de direção e das saídas OUT-1 e OUT-2.

Direção

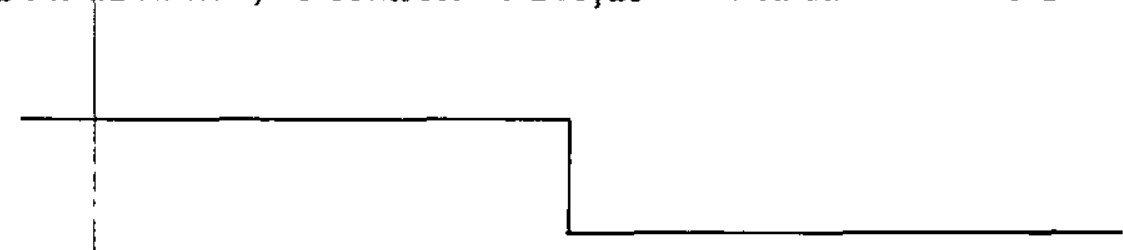

PWM

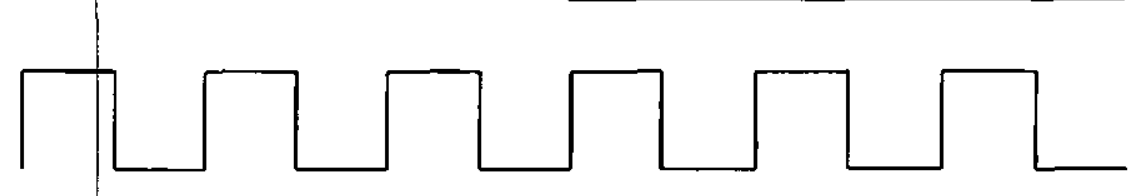

OUT-1

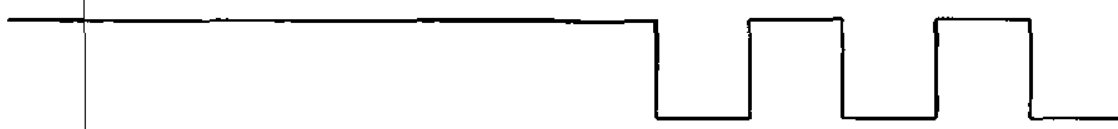

OUT-2

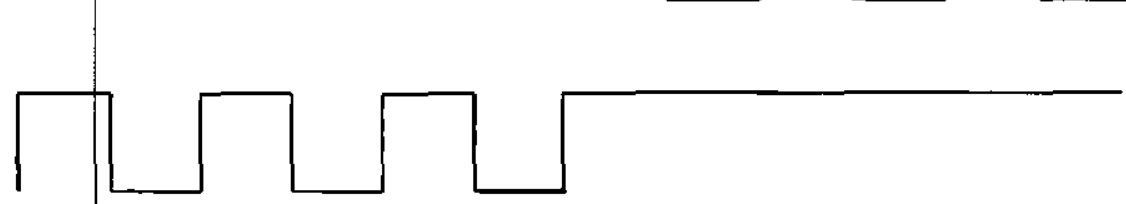

FIGURA 5.20- FORMAS DE ONDA DE ENTRADA E SAIDA DO LMD18200. 


\section{Desenvolvimento do Projeto}

Neste capitulo serão apresentadas duas versões de arquitetura de controlador PID digital com saída PWM. As duas soluções de arquitetura visam o cálculo da Equação 5.7 do controlador PID descrita no capítulo 5 desta dissertação.

Como mencionado anteriormente, o controlador PID será parte integrante de um sistema mais complexo, o qual conterá um ou mais processadores e outros subsistemas de apoio para a finalidade de controle de um robô. Neste trabalho não é levada em consideração a interface de comunicação entre controlador PID e o restante do sistema de controle do robô, pois estes detalhes do projeto ARMOSH ainda não estão definidos e serão assunto de outro trabalho de pós-graduação.

A primeira versão de arquitetura do controlador PLD explora os elementos de hardware de forma que o cálculo da rotina PID é feito de modo seqüencial, desta forma, a cada ciclo de clock, é calculado um produto parcial da equação. Nesta arquitetura, por haver reutilização do circuito para o cálculo dos produtos parciais, são necessários seis ciclos de $c l o c k$ para o completo cálculo da rotina PID.

A segunda versão de arquitetura opera de modo paralelo e foi elaborada de forma a permitir que o cálculo de todas as etapas ou produtos parciais da equação do controlador PID fossem executadas em apenas um ciclo de clock. Em oposição ao caso anterior, é um hardware capaz de processar dados mais rapidamente, mas com uma maior ocupação da área do FPGA.

As duas arquiteturas propostas foram projetadas e validadas por simulação utilizando-se o MAX+PLUS II versão 10,0, que é a ferramenta de projeto de hardware digital da empresa norte americana ALTERA Corparation.

Nos próximos tópicos serão discutidos os detalhes de operação e de implementação das arquiteturas propostas. 


\subsection{Considerações Gerais Sobre as Arquiteturas}

As duas arquiteturas de controlador PID descritas neste trabalho apresentam a mesma estrutura geral, contendo três módulos principais descritos a sequir:

- Módulo CE2PROM:

Este módulo tem a função e obter os parâmetros q0, q1 e q2 que serão utilizados durante o cálculo da rotina PID, de acordo com a Equação 5.7 do capítulo 5. Este módulo faz a comunicação com uma memória EEPROM (Electricaly Erasable and Programmable Read Only Memory) serial por meio de uma interface Microwire ${ }^{i m}$.

- Módulo PID

Este módulo é responsável pelo cálculo da rotina PID, assim como o devido condicionamento dos dados para que sejam utilizados pelo módulo PWM.

\section{- Módulo PWM:}

Este módulo se encarrega da conversão dos valores calculados pelo módulo PID em um conjunto de pulsos no padrão PWM.

A Figura 6.1 esquematiza a configuração geral do FPGA, com a indicação dos pinos de entrada e saída. A tabela 6.1 resume a função dos pinos do controlador. 


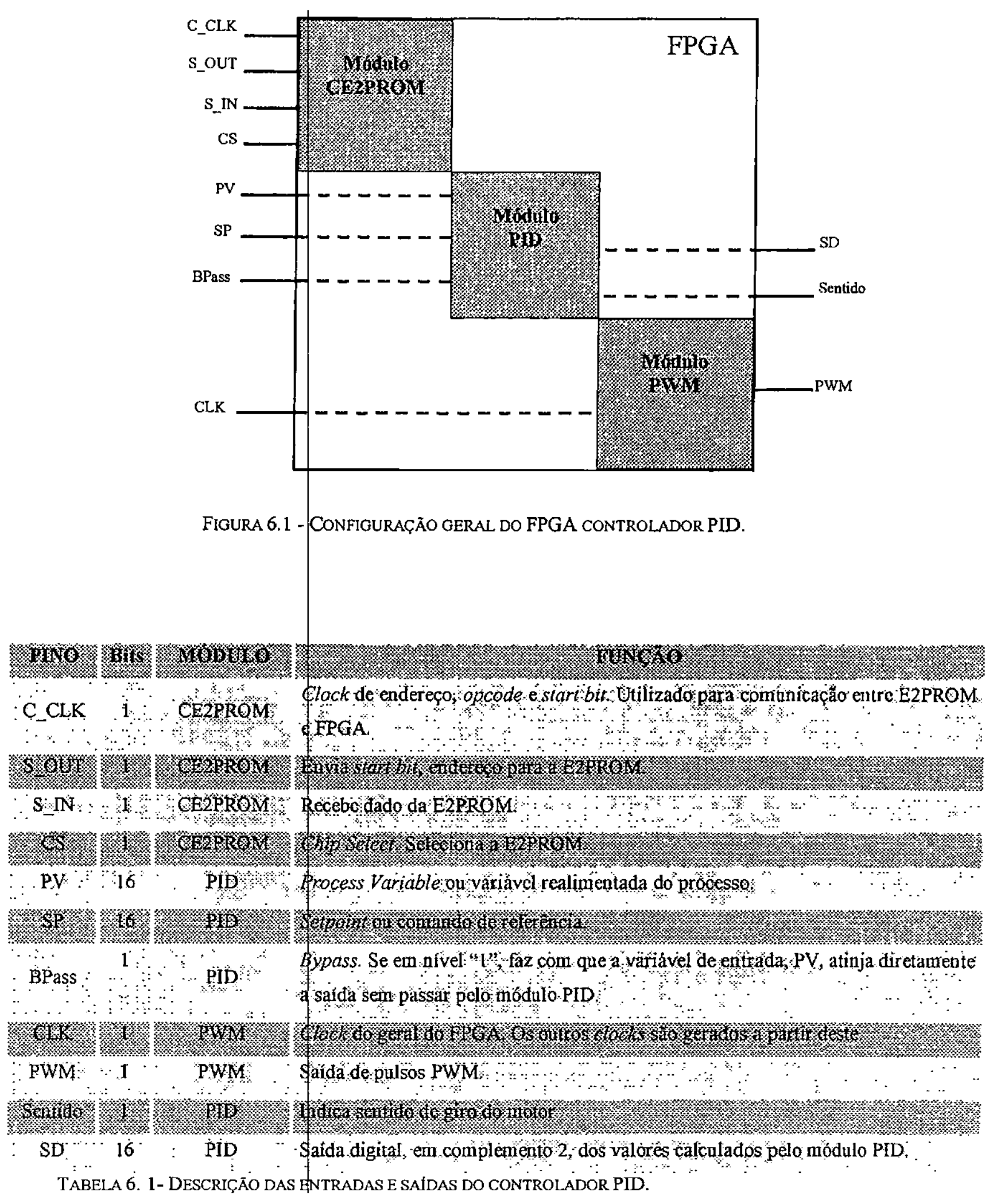


O que diferencia|as duas arquiteturas de controlador PID é o modo de implementação do módulo PID, pois os outros dois módulos, CE2PROM e PWM são idênticos nos dois casos. De forma geral, durante a sua operação, o controlador PID executa as tarefas descritas no diagrama da Figura 6.2.

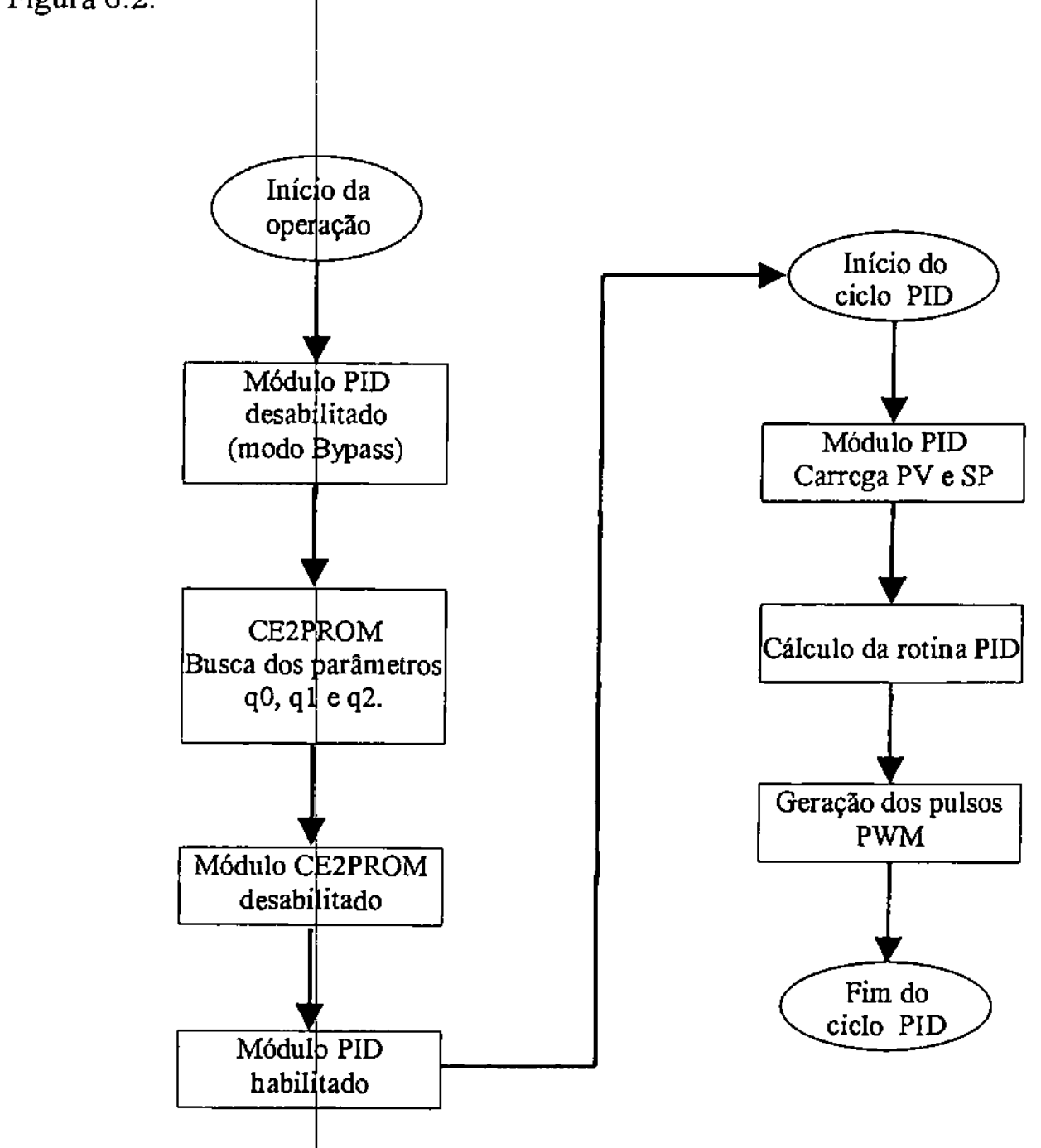

Figura 6.2- TAREFAS EXEEUTADAS PELO CONTROLADOR PID DURANTE UM CICLO.

Como mencionado anteriormente, no início da operação do controlador PID, o módulo CE2PROM faz a busca dos parâmetros q0, q1 e q2. Enquanto esta busca ocorre, a rotina PID não deve ser calculada, sendo o valor do comando de referência, $\mathrm{SP}$, diretamente repassado às saídas PWM e SD de 16 bits. Aq término da busca dos parâmetros, o módulo CE2PROM é desabilitado e o módulo PID inicia autфmaticamente o seu ciclo de operação. 
Nos próximos tópicos serão descritos mais detalhadamente os aspectos de implementação de cada módulo do controlador PID.

\subsection{Projeto do Módulo CE2PROM}

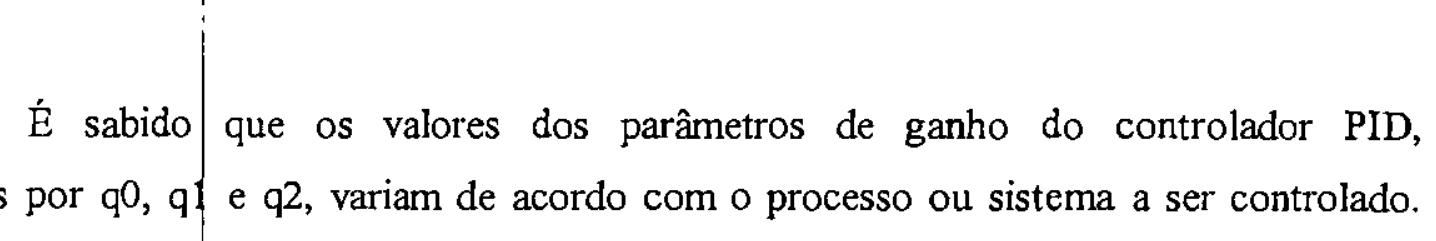
representados por q0, q1 e q2, variam de acordo com o processo ou sistema a ser controlado. Igualmente, é comum que o envelhecimento de componentes cause alteração das características, e, portanto, da função de transferência de um determinado sistema. Por estes motivos, os valores dos parâmetros do controlador não podem ser fixos, sendo importante haver um modo prático e simples de alterá-los.

A solução escolhida para tornar a alteração dos parâmetros mais flexível consiste em um módulo, nomeadp de CE2PROM, que faz a busca automática dos parâmetros de uma memória serial EEPROM, através de uma interface Microwire. Nesta solução, quando for necessário alterar os parâmetros do controlador PID, deve-se atualizar os dados da EEPROM, tarefa que pode ser realizada facilmente por um operador de sistema ou por um processador de gerenciamento do sistema, como existente no projeto ARMOSH.

\subsubsection{Interface Microwire e memórias EEPROM}

A interface Microwire, da empresa National Semiconductor Corporation, não define especificamente nenhum protocolo, determinando somente um conjunto básico de pinos de sinal para se fazer a interconexão de dois ou mais dispositivos. De uma maneira geral, a interface em EEPROMs da National é composta por quatro pinos de entrada e saída principais: CS (Chip Select), SK (Serial Clock), DI (Data In) e DO (Data Out). A seguir faz-se uma breve descrição de cada pino [LUB91].

- Chip Select (CS): utilizado para diferenciar ou selecionar vários dispositivos em um barramento Microwire. No caso de memórias EEPROM, CS não pode ser mantido em nível alto indeffinidamente, pois executa outras funções internas.

- Serial Clock (SK): é a entrada de clock utilizada para sincronizar dados, endereços, códigos de operação e start bits da EEPROM. 
- Data In (DI): | a entrada Data In recebe de forma serial, os start bits, endereços e dados. Cada bit é transferido na borda de subida de SK.

- Data Out (DO): A saída Data Out dispõe os dados no barramento microwire também na borda de subida de SK.

A National Semiçonductor disponibiliza uma ampla variedade de memórias EEPROM com interface Microwire variando de 256 bits a 4906 bits, todas com palavias de 16 bits. A família NM93Cxx, por exemplo, opera com sete instruções que controlam operações de leitura, escrita e proteção de dados. Especificamente para este trabalho, como serão armazenados apenas três valores de 16 bits, pode-se utilizar a NM93C06, que é a memória de menor capacidade de armazenamento, 16 palavras de 16 bits e opera em até $1 \mathrm{MHz}$. A figura 6.3 ilustra como deve ser ligada a EEPROM ao controlador PID.

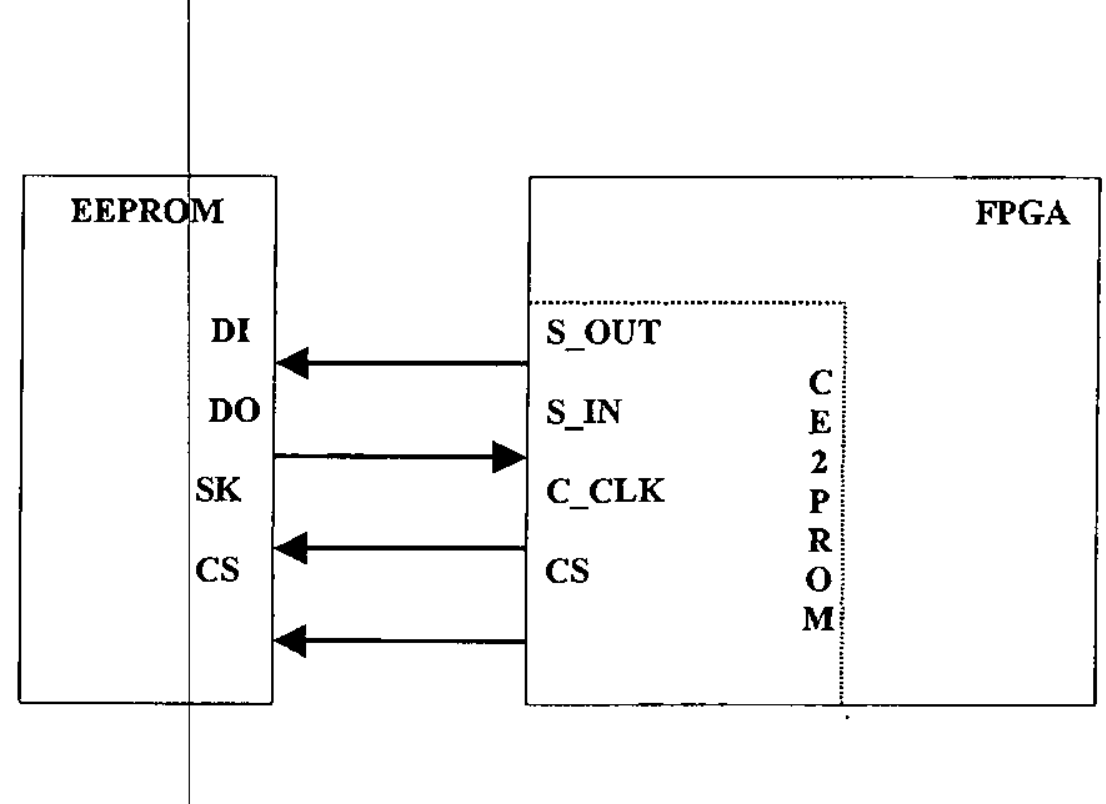

Figura 6.3 - ESQUEMA DE LIGAÇÃo ENTRE A EEPROM E O CONTROLADOR PID.

Para se fazer uma leitura em uma EEPROM com interface Microwire, deve-se enviar ao pino DI da memória uma seqüência de nove bits. O primeiro é o start bit "1", na seqüência, o "op-code" de leitura "10" e finalmente o endereço do dado que se quer ler, de A5 a A0. No clock seguinte a esta operação, o pino DO da EEPROM começa a dispor nos 17 bits seguintes, o dado requerido na operação de leitura. O primeiro destes 17 bits é um "dummy" bit " 0 " e deve ser descartado. A Figura 6.4 ilustra a operação de leitura em uma EEPROM [NAT96]. 


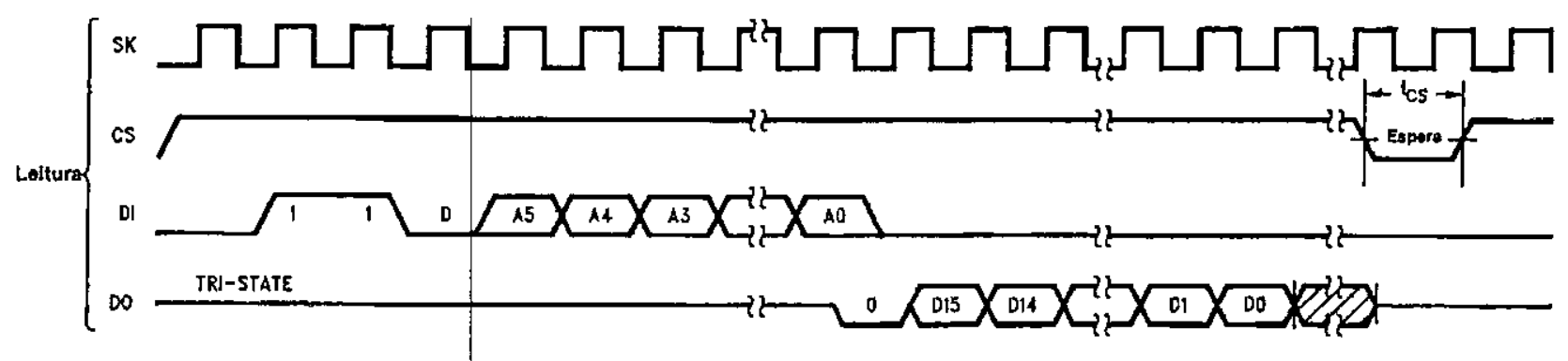

FIGURA 6.4- CICLO DE LEITURA EM UMA EEPROM MICROWRE.

\subsubsection{Detalhamento do Projeto do Módulo CE2PROM}

Para disponibilizar os parâmetros q0, q1 e q2 para o módulo PID, o módulo CE2PROM faz três leituras à memória EEPROM. Este módulo não é uma interface genérica Microwire, capaz de executar comandos de leitura, escrita e apagamento de dados. O módulo CE2PROM somente realiza a tarefa especifica de ler seqüencialmente três valores da EEPROM.

O módulo CE2PROM possui quatro pinos de entrada e saída para comunicação com uma EEPROM. O pinos C_CLK, CS e S_OUT geram respectivamente os sinais SK, CS e DI mostrados na Figura 6.4. O pino $S_{-} I N$ do módulo CE2PROM recebe sinais do pino DO da memória.

Os valores das constantes q0, ql e q2 de 16 bits, devem ser gravados nas posições 0,1 e 2 respectivamente, da EEPROM. Para acessar estes dados, o módulo CE2PROM deve enviar a EEPROM um start bit, um op-code e um endereço em um total de nove bits. Para se fazer a leitura das três primeiras posições de memória, a seqüência de bits que deve ser enviada pelo módulo CE2PROM a mernória deve ser como indicada na Tabela 6.2.

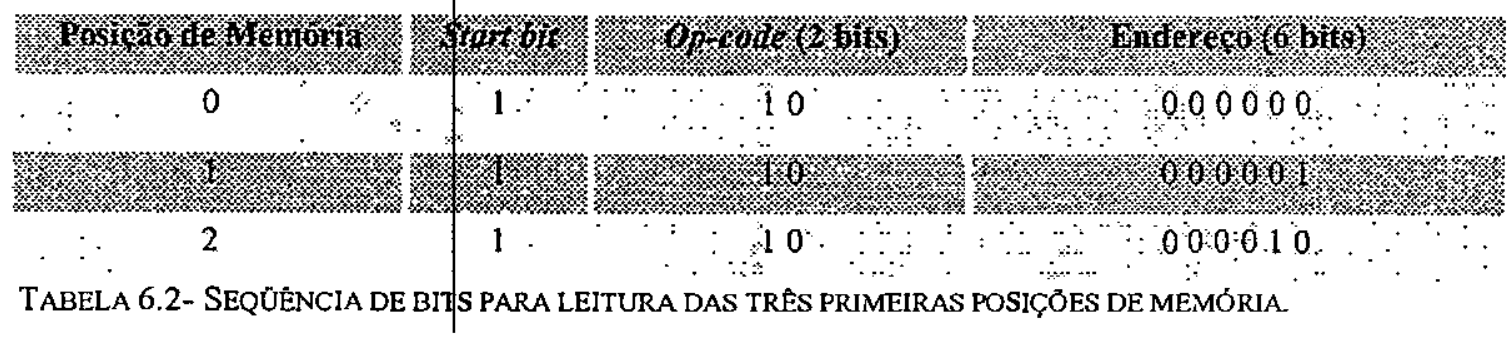


O fluxograma da Figura 6.5 ilustra a sequêencia de operações realizadas pelo módulo CE2PROM. Neste fluxograma, C1, C2, C3, Dado e IL são variáveis auxiliares utilizadas somente para ilustrar a operação lógica deste módulo.

Antes de começar as operações de leitura na EEPROM, o módulo CE2PROM gera um sinal de "bypass" para o módulo PID, fazendo com que o sinal de entrada SP seja transferido diretamente a saída, sem haver o processamento PID. O módulo PID somente entra em operação após o último dado ser transferido da EEPROM para o FPGA.

Basicamente, depois de carregar a seqüência de bits de leitura em um registrador, os nove bits são deslocados para o pino de saída S_OUT (Loop-1 do fluxograma). Após esta operação, um outro registrador recebe, 16 bits do pino de entrada $S \_I N$. O $1^{\circ}$ bit da sequêencia, dummy bit, não é recebido (Loop-2 dp fluxograma). No próximo passo, há o incremento da sequuência de bits de leitura, passado a "110000001" e novamente ocorre o envio de bits por S_OUT e o recebimento de bits por S_IN. A seqüência é repetida com mais um incremento dos bits de leitura para "110000010". Ao final de toda a seqüência, os dados vindos da EEPROM ficam disponiveis no barramento de saida de três registradores, sob os nomes de q0, q1 e q2. 


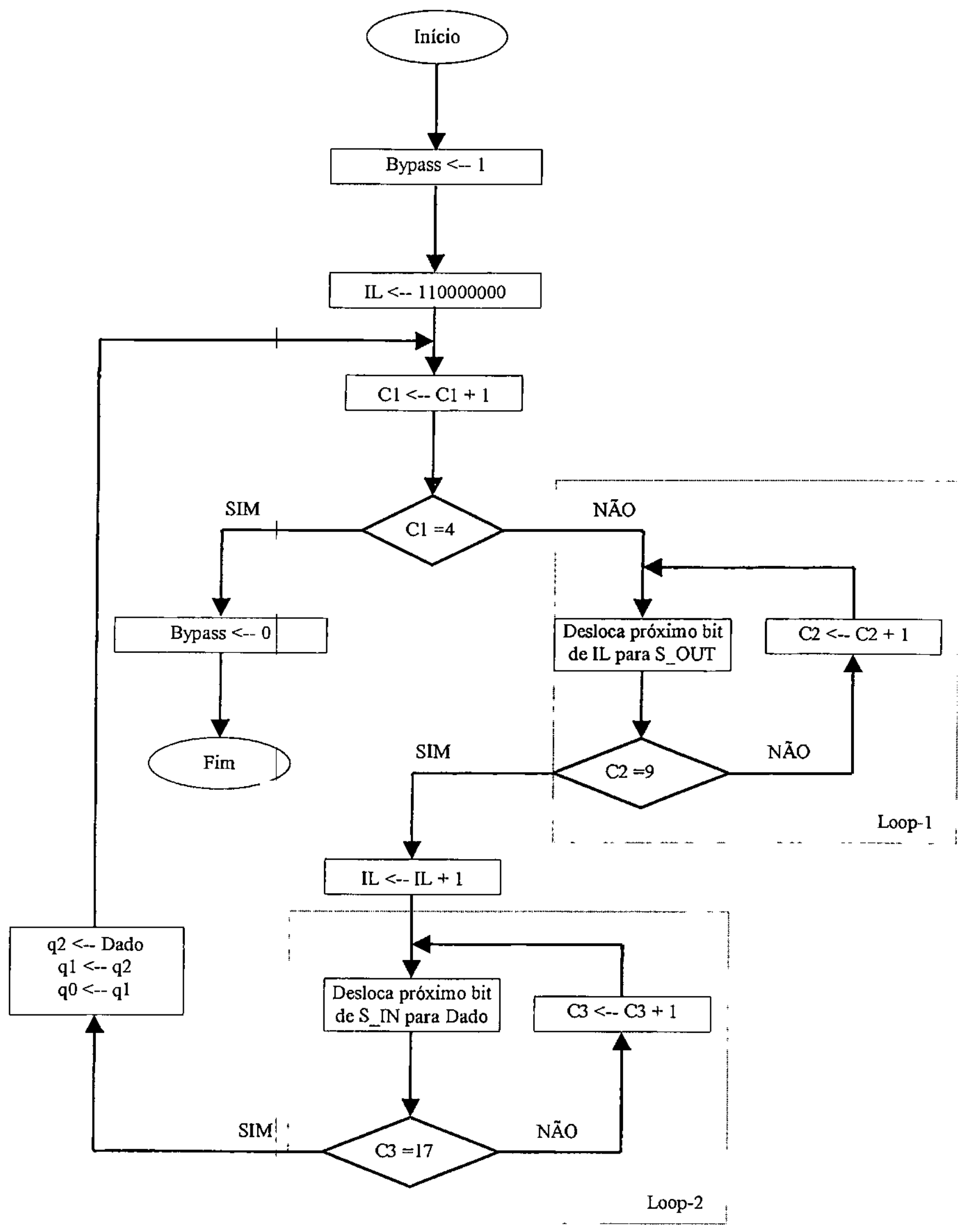

Figura 6.5- FLUXOGRAMMA REPRESENTATIVO DO MÓDULO CE2PROM. 


\subsection{Projeto do Módulo PWM}

Mesmo podendo ser utilizado em outras aplicações, o controlador PID desenvolvido neste trabalho tem a finalidade de servir a um sistema de controle de robô. Como discutido no capítulo anterior, o controlador PID para esta aplicação deverá ser capaz de controlar um motor de corrente contínua. Para tal, um módulo PWM já embutido no FPGA do controlador PID tem grande utilidade por tornar a interface entre o controlador e o motor mais simples, não havendo necessidade de se utilizar um conversor D/A.

Como o módulo do controlador PID, em ambas as arquiteturas, disponibiliza resultados com palavras de 16 bits em lógica de complemento dois, optou-se por desenvolver um módulo de saída PWM de 15 bits, pois este é o tamanho da palavra digital fornecida pelo módulo PID descartando-se o bit de sinal.

Ao término de um ciclo de processamento, o valor resultante do módulo PID é encaminhado a um bloco de cálculo do valor absoluto. Se o número a ser processado por este bloco for positivo, não ocorre nenhuma alteração e o número é apenas repassado a saída. No entanto, se o número tesultante do módulo PID for negativo, ocorre uma conversão de complemento dois para nưmero binário convencional, e este é encaminhado ao módulo PWM.

Para a formação dos pulsos de saída PWM o bit de sinal não é utilizado, sendo importante apenas o valor absoluto do dado disponibilizado pelo módulo PID. A distinção de sinal é feita antes do dado atingir o bloco de cálculo do valor absoluto, por seleção do bit mais significativo. Este bit de sinal é separado e encaminhado a um pino de saída do FPGA, o que propicia a integração com uma ponte H como, por exemplo, o LMD18200 da National Semiconductor Corporation. Como explicado no capítulo anterior, este CI apresenta, além da entrada PWM, uma entrada para controle de direção do motor. A Figura 6.6 ilustra o fluxo de dados entre a saída do módulo PID e o módulo PWM. 


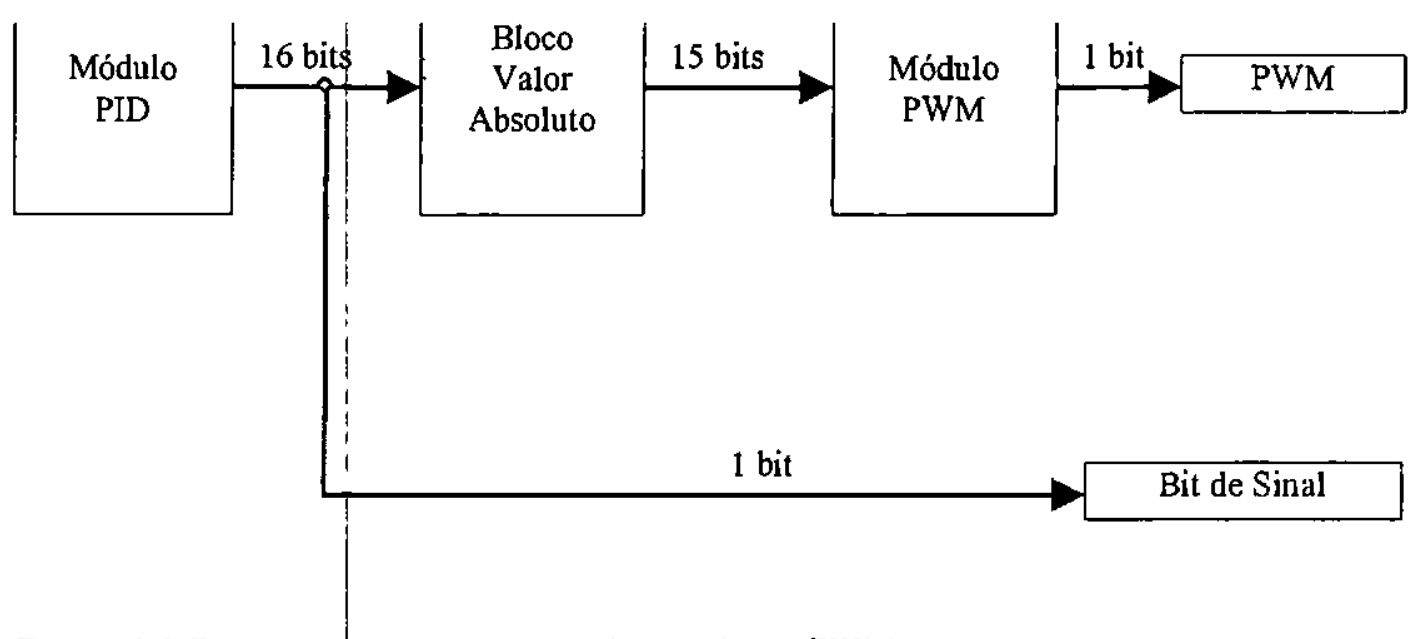

Figura 6.6- FluXo de dADOS ENTRE os MÓdUlos PID E PWM.

\subsubsection{Detalhamento do Projeto do Módulo PWM}

Para o desenvolvimento de um PWM digital, utilizou-se como base uma arquitetura sugerida pela empresa Adtel Corporation, que utiliza um contador, um comparador, um latch e um flip-flop tipo JK [DEL96]. A Figura 6.7 ilustra a arquitetura básica de um PWM digital.

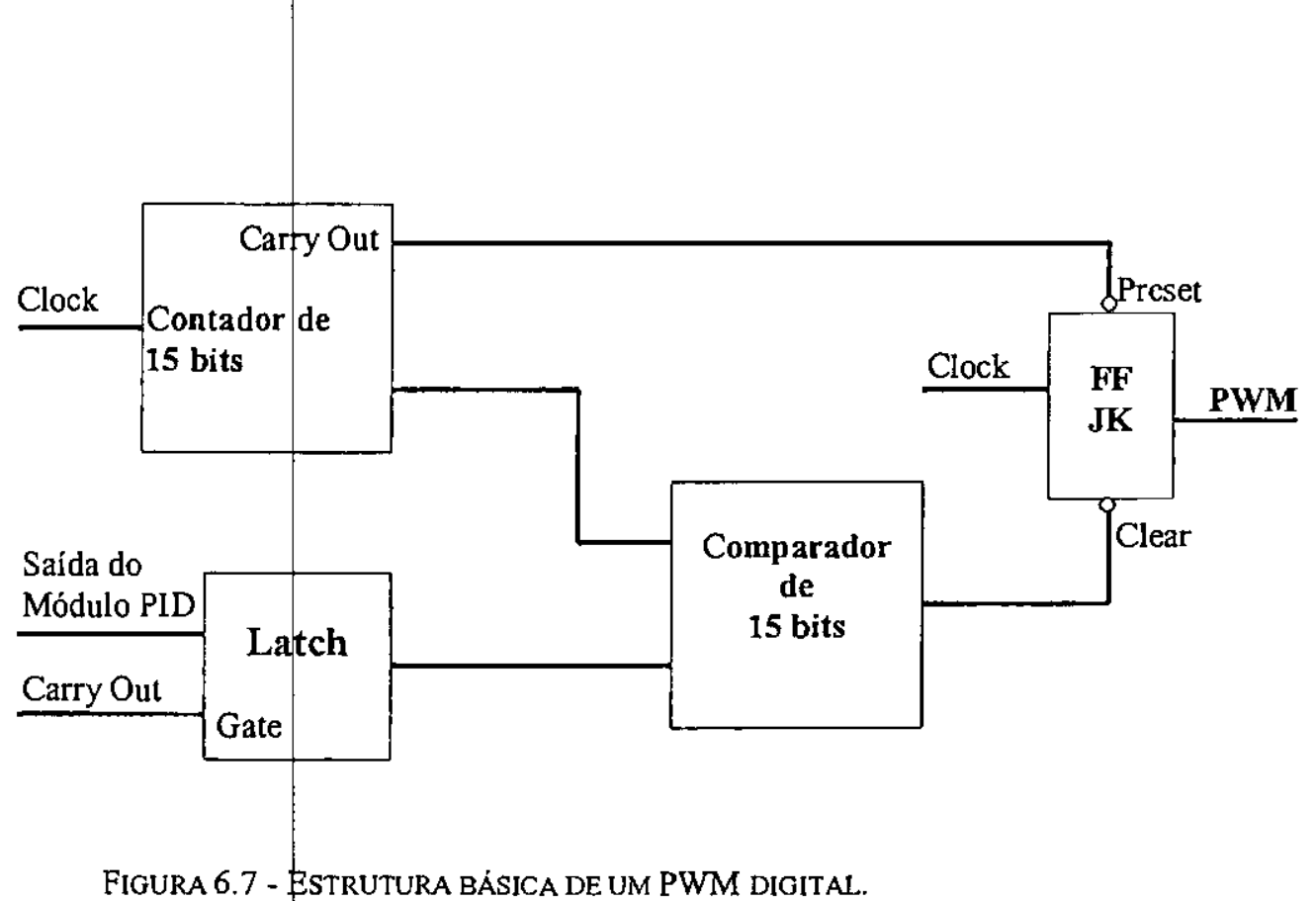


Na geração dos pulsos PWM, a cada ciclo de clock, o dado proveniente do módulo PID é comparado ao valor de contagem do contador. Quando estes valores forem iguais o flip-flop é "resetado". Ao final do ciclo de contagem, o flip-flop é "setado" pelo sinal de carry out do contador e o ciclo recomeça. Desta forma, o tempo em que um pulso PWM fica em nível alto é proporcional ao valor de saída do módulo PID. A Figura 6.8 ilustra a dinâmica de geração dos pulsos PWM. É importante a inclusão de um latch para o funcionamento do PWM, pois este garante que o dado que alimenta o comparador não seja alterado antes do termino do ciclo PWM.

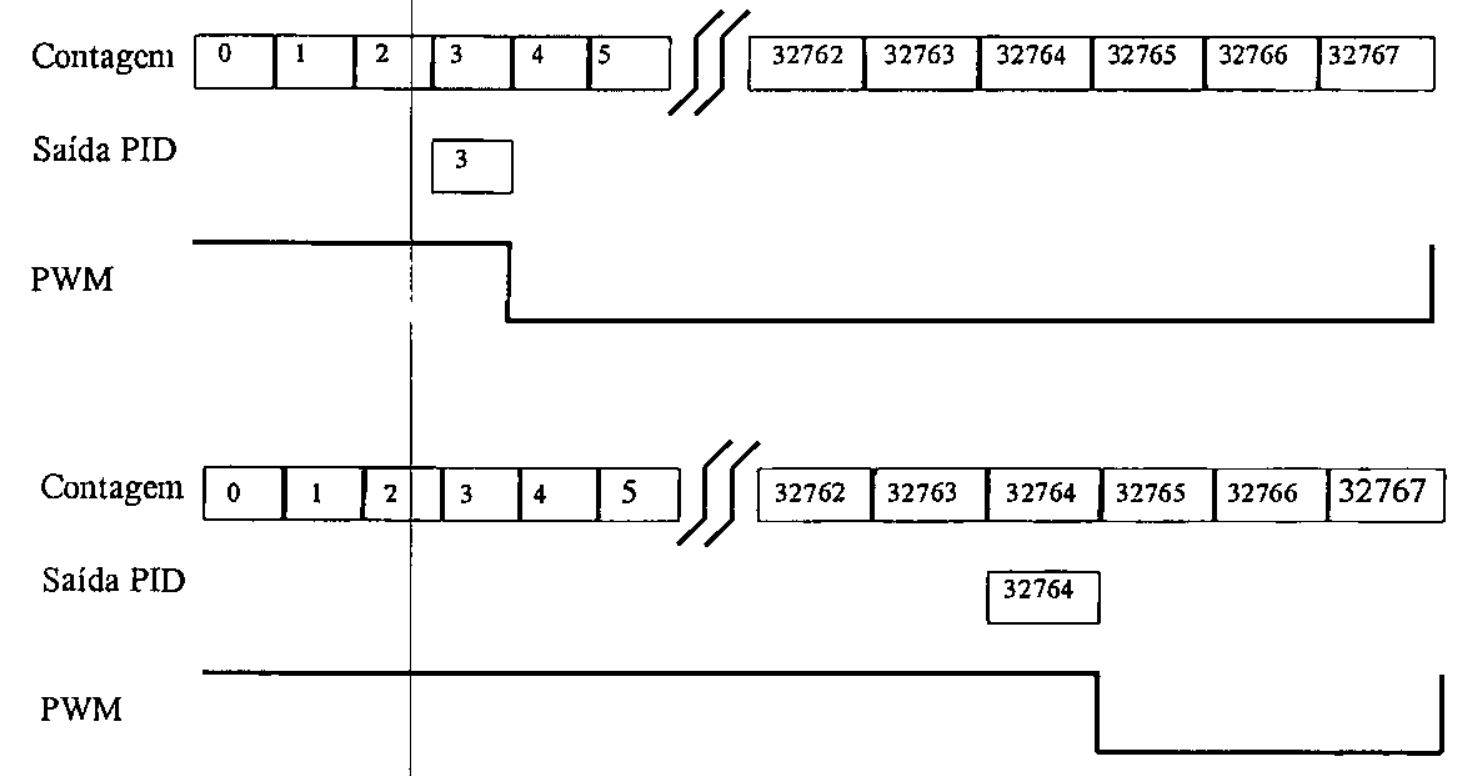

\subsection{Módulo PID - Considerações gerais}

O módulo PID tem a função de calcular a Equação 6.1, já apresentada no capítulo 5 . A função descrita por esta equação é recursiva, sendo o seu resultado dependente do resultado calculado no periodo de amostragem anterior. Os termos $\mathrm{e}(\mathrm{k}), \mathrm{e}(\mathrm{k}-1)$ e $\mathrm{e}(\mathrm{k}-2)$ são os valores de erro calculados, respectivamente, no período atual t, período passado $t-1$ e período passado $t-2$. Esta equação representa um filtro digital do tipo IIR (Infinite Impulse Response), estudado na teoria de processamento digital de sinais DSP (Digital Signal Processing).

$$
U(k)=U(k-1)+q 0 \cdot e(k)+q 1 \cdot e(k-1)+q 2 \cdot e(k-2) \quad \text { Equação } 6.1
$$


A equação 6.1 pode ser representada por uma arquitetura baseada em uma configuração de registradores de deslocamento, como representada na Figura 6.9 [ALT98].

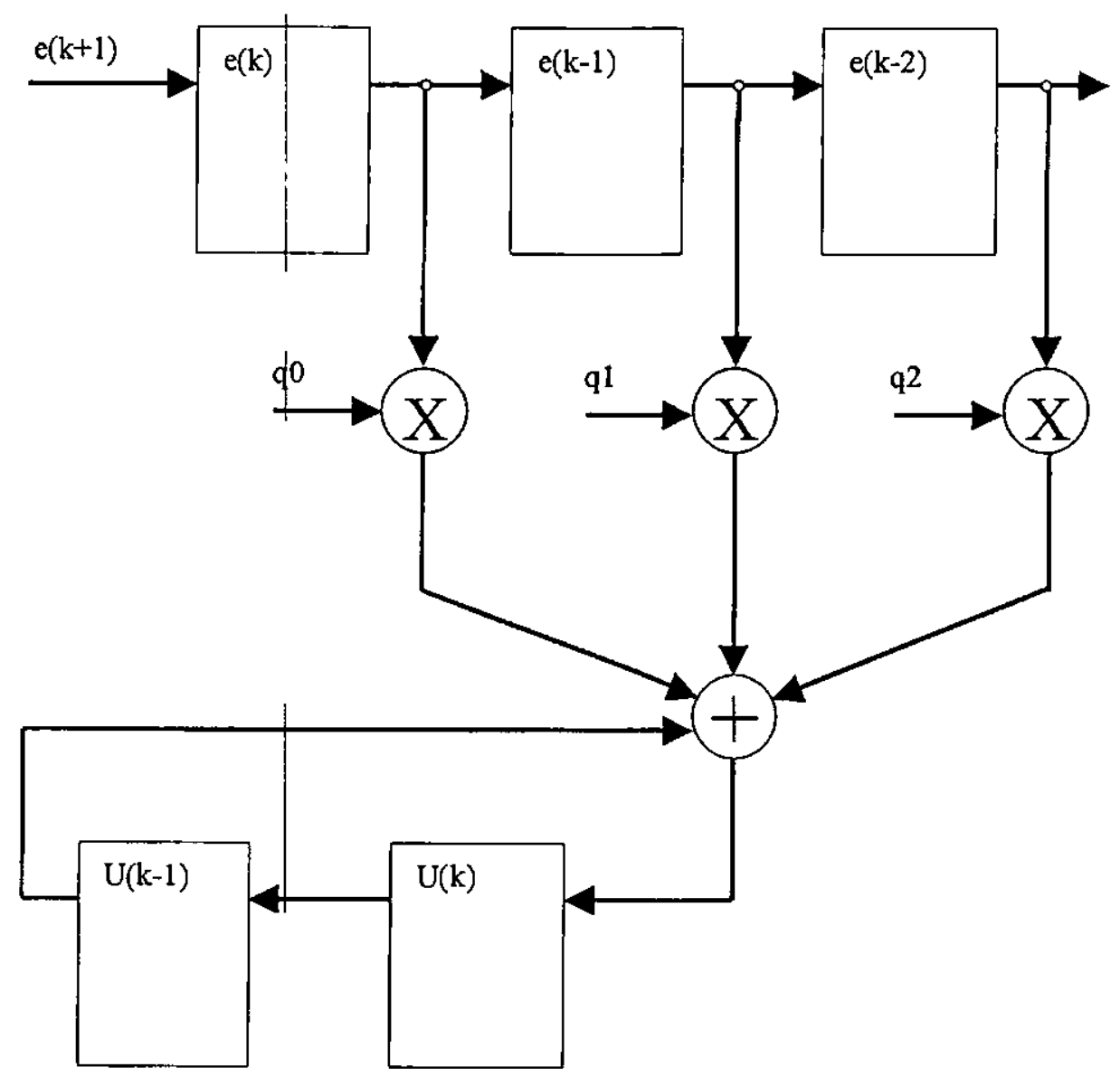

Figura 6.9- ARQuTteTUkạ uU Módulo PID BASEAdA EM REGISTRADORES DE DESLOCAMENTo.

Para tornar o hardware mais simples e compacto, foi decidido utilizar lógica de inteiros, com sinal na representação de complemento dois. Certamente, um dos tópicos de maior importância para a implementação do controlador são os efeitos de se utilizar lógica de pontofixo.

A maioria dos controladores digitais utiliza aritmética de ponto-fixo. Em um processador que utiliza aritmética de ponto-fixo, apenas uma quantidade limitada de espaço no byte (de 4, 8 ou 16 bits) está disponíyel para o armazenamento de um sinal ou constante. Os efeitos do tamanho limitado da palavra digital aparecem no sistema como ruido e podem causar 
instabilidade do sistema Estes efeitos são também conhecidos como ruidos de quantização [TEX96].

Em processamento digital de sinais (DSP), a maior parte dos algoritmos, incluindo-se os algoritmos de controle, pode ser representada por equações diferenças, consistindo de multiplicações e somas (multiplicar e acumular). Neste contexto, outro efeito causado pelo tamanho limitado da palavra digital surge durante o processamento ou cálculos intermediários. É sabido que para se realizar cálculos intermediários, uma maior precisão é necessária. Por exemplo, quando uma multiplicação de 16 bits por 16 bits é realizada, é necessário um registrador de 32 bits para armazenar o resultado. Se o processador apenas apresenta registradores de 16 bits, os 16 bits menos significativos devem ser descartados, o que resulta em perda de precisão do resultado final. Este fato é também conhecido como erro de arredondamento e este se acumula a medida em que cálculos sucessivos se realizam.

Um outro fator gerador de erros na lógica de ponto fixo é o overflow de registradores. O Overflow ocorre quando uma operação aritmética é executada e o resultado extrapola os limites que a quantidade de bits da palavra permite. Neste caso, o resultado pode ficar oscilando entre valores positivos e negativos. Para sanar este problema, é necessário que haja algum tipo de controle, fazendo com que o resultado seja saturado para o maior valor positivo ou o menor valor negativo [STO96].

Portanto, para minimizar os efeitos da aritmética de ponto-fixo, é recomendável se utilizar uma palavra de no mínimo 16 bits, com registradores de 32 bits para armazenar resultados intermediários [TEX96].

As duas arquiteturas de controlador PID foram desenvolvidas em lógica de ponto-fixo com representação numérica em complemento dois. As entradas PV e SP são de 16 bits e arquitetura interna possui operadores e registradores de 32 bits para armazenar valores intermediários. As saídas, tanto a PWM quanto a digital, são de 16 bits, descartando-se os 16 bits menos significativos da saída U(k) do módulo PID. Apenas para a saída ocorre o truncamento do sinal em 16 bits, no entanto, para os cálculos internos não há perda de precisão, pois são utilizados os valores de 32 bits [BOW99]. 


\subsubsection{Bloco Limitador}

O bloco limitador tem a função de verificar a ocorrência de overflow durante as operações aritméticas de 32 bits. Este bloco é utilizado nas duas arquiteturas do módulo PID, sempre após um bloco somador. A figura 6.10 ilustra a estrutura de um limitador.

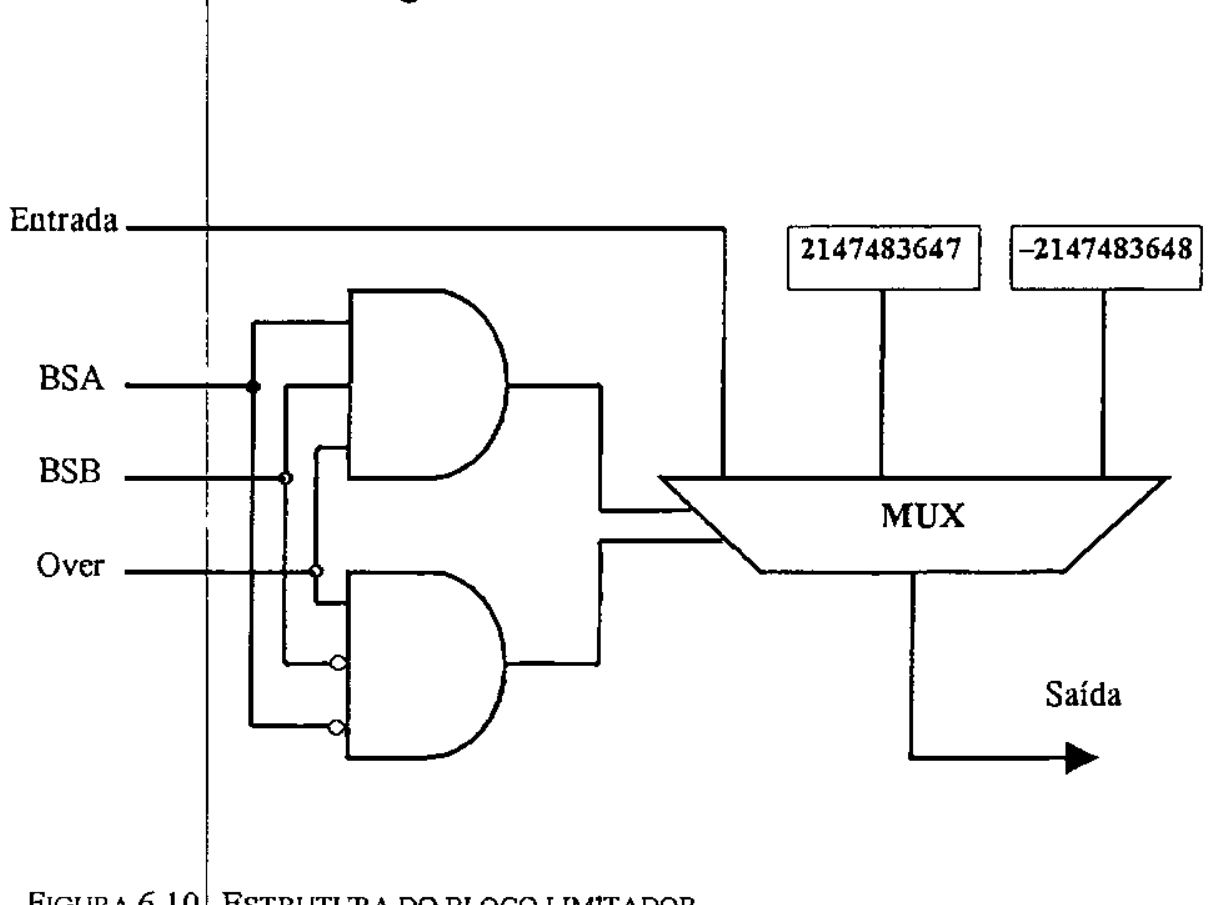

Os blocos somadores existentes na ferramenta de desenvolvimento Max+Plus II, apresentam um sinal de saída que indica quando ocorre overflow da soma. Quando ocorre overflow (bit OVER= "1"), o bloco limitador verifica o bit de sinal do operando A (BSA) e o bit de sinal do operando B (BSB). Se os sinais "Over", "BSA" e "BSB" estiverem todos em nivel " 1 " isto indica que ouve overflow em uma soma de dois números negativos e, portanto, deve-se limitar o valor da soma em -2147483648. Quando "Over" estiver em nível "1" e BSA e BSB estiverem em nível " 0 " isfo indica que ouve overflow em uma soma de dois números positivos e, neste caso, deve-se limita o valor da soma em 2147483647 que é o maior número positivo de 32 bits em complemento dois. Se "Over" estiver em nível " 0 " isto indica que não houve saturação da soma e a entrada é repassada à saída. 


\subsubsection{Bloco de Bypáss e Valor Absoluto}

As arquiteturas dos módulos PID executam duas outras funções além do cálculo da Equação 6.1. Estas funções são o controle de bypass e o preparo do resultado final U(k), através da função valor absoluto, para o módulo de saída PWM.

A função Bypass foi incluída para permitir que a entrada SP de 16 bits possa ser direcionada as saídas PWM e SD (Saída Digital) sem passar pelo cálculo da rotina PID. Esta função é particularmente útil quando o módulo CE2PROM está buscando os valores dos parâmetros q0, q1 e q2 do controlador PID. O módulo PID deve aguardar até que a busca dos parâmetros termine para começar sua operação. A função de bypass também pode ser controlada externamente pelo operador. Ao se aplicar o nível lógico "1" ao pino "Bpass", o módulo do controlador PID deixa de ser utilizado.

Como mencionadф anteriormente, o módulo PWM opera apenas com o valor absoluto do resultado, $\mathrm{U}(\mathrm{k})$, da rotina $\mathrm{PID}$. Para a geração dos pulsos PWM, apenas interessa a magnitude do valor $\mathrm{U}(\mathrm{k})$, sendo o sinal (direção de rotação do motor) fornecido pelo bit mais significativo de $\mathrm{U}(\mathrm{k})$. O diagrama da figura 6.11 exemplifica o modo de operação do bloco de bypass e de valor absoluto.

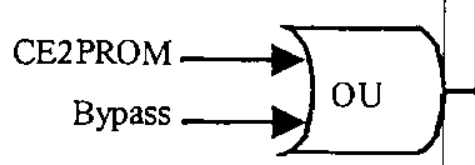

Figura 6.11- BLOCO DE BYPASS E DE VALOR ABSOLUTO. 


\subsubsection{Módulo PID - Versão I}

Como mencionado anteriormente, esta primeira versão do módulo PID reutiliza porções do hardware para o cálculo dos produtos parciais da rotina PID. Nesta arquitetura há apenas um multiplicador, de modo que a representação desta arquitetura por registradores de deslocamento difere consideravelmente da arquitetura geral ilustrada na Figura 6.9. A figura 6.12 mostra um diagrama representativo desta arquitetura.

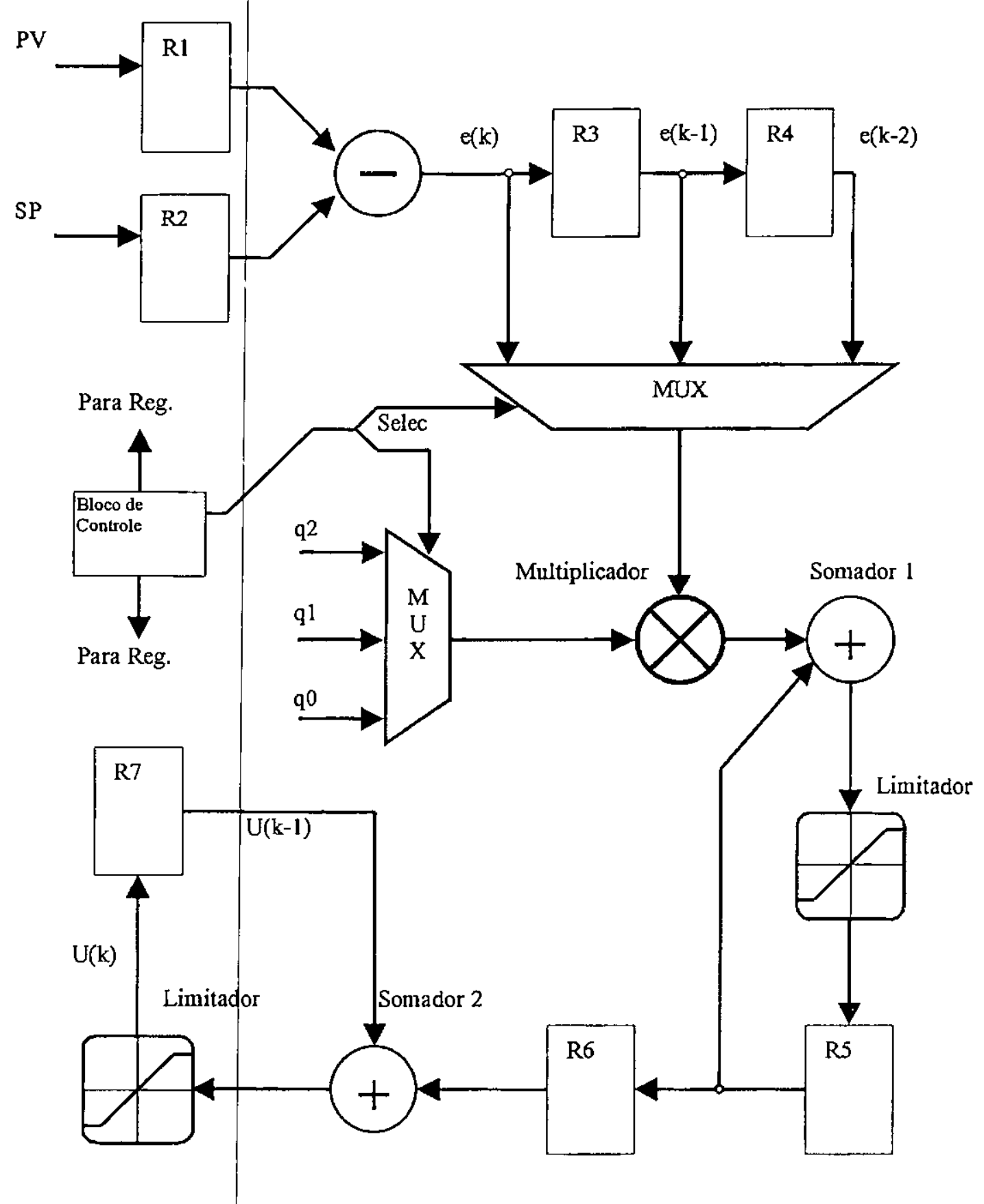

FIGURA 6.12- ARQUITETURA SIMPLIFICADA DO CONTROLADOR PID. 
Após os parâmetros q0, q1 e q2 do controlador PID serem carregados pelo módulo CE2PROM, o módulo PID entra em operação. Inicialmente, os valores de SP (Setpoint) e PV (Process Variable) são carregados (registradores 1 e 2) e o valor do erro atual $\mathbf{e}(\mathbf{k})$ é calculado como a diferença entre SP e PV. Calculado $e(k)$, os valores de $e(k)$, e(k-1) e e(k-2) são respectivamente multiplicados por $q 0, q 1$ e $q 2$ e a soma é acumulada em R5. Esta etapa é realizada pelo Multiplicador e pelo Somador 1. Durante cada soma realizada pelo Somador 1, o valor gerado é analisado pelo limitador para verificação de overflow. Depois desta etapa, o valor acumulado até o momento é representado pela Equação 6.2 .

$$
U(k)^{\prime}=q 0 \cdot e(k)+q 1 \cdot e(k-1)+q 2 \cdot e(k-2) \quad \text { Equaçăo } 6.2
$$

Após três ciclos de multiplicações e somas, o valor representado pela equação 6.2 é somado, através do somador 2 , a $\mathrm{U}(\mathrm{k}-1)$. Novamente, o valor resultante deve ser analisado por um bloco limitador. Após esta etapa, a rotina PID foi completamente calculada, de acordo com a equação 6.1 .

$\mathrm{Na}$ versão I da arquitetura do controlador PID há um bloco de controle que regula o funcionamento de todos os registradores ( $R 1$ a R7) assim como a operação dos multiplexadores. Esta arquitetura executa úm ciclo de cálculo da rotina PID a cada seis clocks. O sinal de clock que cadencia o funcionamento do modulo PID vem de um divisor de freqüência que recebe o clock geral do FPGA. A cada ciclo PWM é calculado um ciclo PID, garantindo desta forma, que um ciclo PID seja executado para cada ciclo PWM.

\subsubsection{Módulo PID - Versão II}

A segunda versão de arquitetura de controlador PID tem a estrutura totalmente paralela. Esta arquitetura permite $\mathrm{o}$ cálculo de toda a rotina PID em apenas um ciclo de clock. A figura 6.13 mostra uma representação em diagrama de blocos desta arquitetura.

Da mesma forma que a versão I da arquitetura, após os parâmetros q0, q1 e q2 do controlador PID serem carregados pelo módulo CE2PROM, o módulo PID entra em operação. Após os valores de SP e PV serem carregados (registradores 1 e 2), os valores dos erros $\mathrm{e}(\mathrm{k})$, $\mathrm{e}(\mathrm{k}-1)$ e e(k-2) são respectivamente multiplicados por $q 0, q 1$ e $q 2$. A soma $q 0^{*} \mathrm{e}(\mathrm{k})+q 1^{*} \mathrm{e}(\mathrm{k}-1)$ 
é feita pelo Somador 1. A soma $\mathrm{q}^{2 *} \mathrm{e}(\mathrm{k}-2)+\mathrm{U}(\mathrm{k}-1)$ é feita pelo Somador 2. O resultado destas duas somas passa por um novo somador (Somador 3) para finalmente ser acumulada em R5. Durante cada soma realizada nesta arquitetura, há uma analise do resultado por limitadores para verificação de overflow. Toda a seqüência descrita para esta arquitetura é realizada em apenas um ciclo de clock.

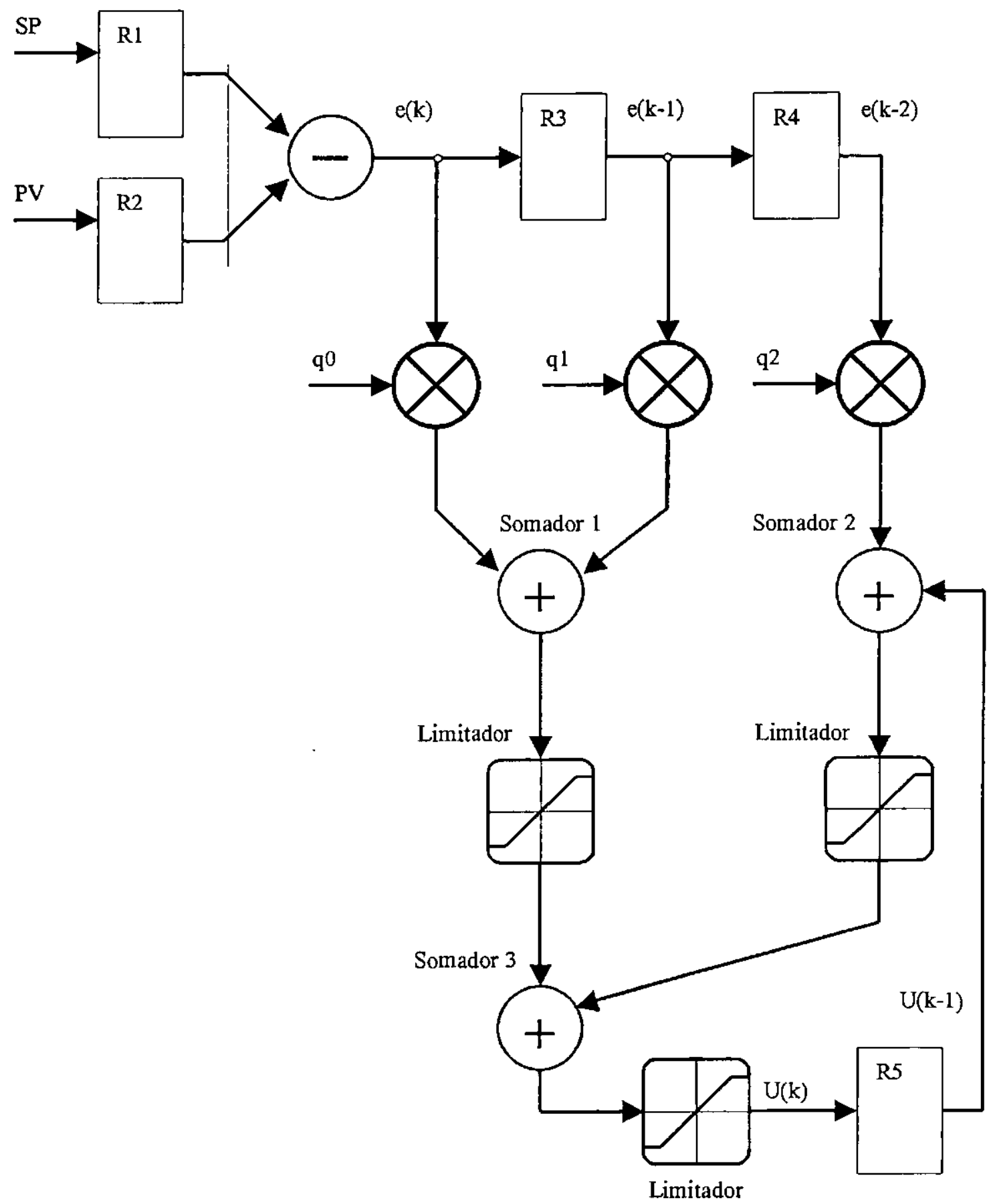

FIGURA 6.13- ARQUITETURA SIMPLIFICADA DO CONTROLADOR PID TOTALMENTE PARALFLo. 
Para esta arquitetưra, o sinal de clock que alimenta o módulo PID é gerado pelo módulo PWM. Quando o contador de 15 bits do módulo PWM atinge o final da contagem, um sinal de Carry Out é gerado. Este sinal de Carry out, que divide a frequiência do clock do FPGA por $32768\left(2^{\wedge 15}\right)$, é o sinal de clock utilizado pelo módulo PID. Desta forma pode-se garantir que para cada ciclo de geração dos pulsos PWM haja um ciclo de cálculo da rotina PID.

No próximo capítulo são descritos os detalhes da implementação das arquiteturas em FPGA e a analise dos resultados. 


\section{Implementação das Arquiteturas em FPGA e Análise dos Resultados}

Neste capítulo estão descritas as etapas realizadas durante a implementação das arquiteturas em FPGA, assim como a análise dos resultados obtidos. Ao final, é feita uma comparação com três controladores comerciais que executam a rotina PID.

As duas arquiteturas de controlador PID foram desenvolvidas com a ferramenta de projeto digital MAX+PLUS II versão 10.0 da empresa ALTERA Corporation. O software MAX+PLUS II é uma ferramenta que integra diversos módulos, com capacidade de gerenciar todas as etapas de um projeto digital, desde a entrada do projeto (esquemático e VHDL) passando pela compilação, simulação, mapeamento e finalmente a configuração dc um dispositivo. Para a implementação do projeto foi utilizada uma combinação de blocos em esquemático e linguagem VHDL.

\subsection{Simulação das Arquiteturas e Implementação em FPGA}

Após a implementação dos módulos e blocos descritos no capítulo anterior, a primeira etapa na fase de testes foi a verificação do modo de operação das arquiteturas. Para tal, utilizouse a ferramenta de simulação funcional do MAX+PLUS II. Esta ferramenta permite que se faça apenas a verificação da lógica do hardware não considerando os tempos de atraso na propagação do sinal no dispositivo.

Após a constatação da correta operação dos hardwares através da simulação funcional, houve a compilação completa das arquiteturas. Durante esta compilação, a ferramenta MAX+PLUS II realizou as etapas de síntese lógica, mapeamento, cálculo dos tempos de propagação, gerando os arquivos de configuração dos FPGAs. Os tempos de propagação do sinal são calculados durante a compilação, sendo utilizados pela ferramenta de simulação para representar com fidelidade a operação do hardware e permitir a determinação das freqüências de operação. 
A versão I da arquitetura do controlador PID foi implementada no FPGA da ALTERA EPF10K30RC208-3 da família FLEX 10K. Esta arquitetura ocupou 1044 células lógicas ou LC (Logic Cels) o que reflete em $60 \%$ da utilização do Chip.

A versão II da arquitetura por ser paralela e utilizar mais multiplicadores e somadores que a versão I, se apresentou maior, sendo implementada no FPGA, EPF10K40RC208-3 também da família FLEX 10K. Esta arquitetura ocupou 1723 LCs, o que representa $74 \%$ da capacidade deste Chip.

O processo de determinação da melhor freqüência de trabalho para as arquiteturas envolveu diversas simulações em várias freqüências, tal como sugerido pela documentação eletrônica do software MAX+PLUS II. Na primeira arquitetura, a melhor freqüência de trabalho ficou estabelecida em $33 \mathrm{MHz}$ e na segunda arquitetura, conseguiu-se bons resultados a uma frequeência de operação de $50 \mathrm{MHz}$.

\subsection{Analise dos Resultados}

As Figuras 7.1, 7.2 e 7.3 seguintes, mostram as telas de simulação temporal do MAX+PLUS II, onde estão indicadas na coluna da esquerda, os pinos de entrada, os pinos de saída e algumas variáveis internas das duas arquiteturas de controlador PID. A seguir há uma breve descrição dos pinos e variáveis utilizados para simulação.

- CLK - Clock geral do FPGA

- CLK_PID - Clock utilizado pelo módulo PID

- Bypass - Pino de Bypass, desabilita módulo PID

- S_IN, S_OUT CS e C_CLK - Pinos utilizados para comunicação com uma memória EEPROM.

- SP e PV pinos de entrada de Setpoint e Variável de processo, respectivamente.

- SD - Saída digital de 16 bits.

- UK, UKp - Resultado do cálculo da rotina PID nos tempos presente (k) e passado (k1), respectivamente. São variáveis de 32 bits.

\footnotetext{
' LC ou Logic Cell é o bloco bassico dos dispositivos da Altera, permitindo a implementação de uma ampla variedade de funções lógicas.
} 
- q0, q1, e q2 - Parâmetros do controlador PID.

- EA, EB e EC - Erros nos tempos atual (k), passado (k-1) e passado (k-2), respectivamente.

- CDIS - Sinal interno que, quando em nível "1", indica que o módulo CE2PROM está desabilitado e 0 módulo PID esta operante.

- Ccarry - sinal de controle responsável pela leitura de novos dados SP e PV (presente somente na arquitetura I).

- PWMO - Ping de saída PWM.

- Sentido - Pino que representa o sinal do valor calculado pelo módulo PID.

A Figura 7.1 mostra a etapa de busca dos parâmetros do controlador PID pelo módulo CE2PROM. Nesta figura é ilustrado o envio serial de instruções pelo pino S_OUT e o recebimento, também de modo serial, dos dados através do pino S_IN. Ao final do ciclo de buscas (entre $12 \mathrm{~ms}$ e $15 \mathrm{~ms}$ ), os registradores q0, q1 e q2 contem os valores determinados para esta simulação, que são: $q 0=10000, q 1=500$ e q2 $=3000$.

Durante o proces\$o de busca dos parâmetros nota-se que a saída SD recebe diretamente os sinais da entrada PV, isto denota que o controlador PID está em bypass. A saída PWM, indicada pelo pino PWMO também reflete o valor da entrada PV. Ao término do ciclo de buscas, o módulo CE2PROM é desabilitado, na Figura 7.1 isto é indicado pelo pino CDIS permanentemente em nívall baixo. A partir deste instante, o módulo PID entra em operação. 


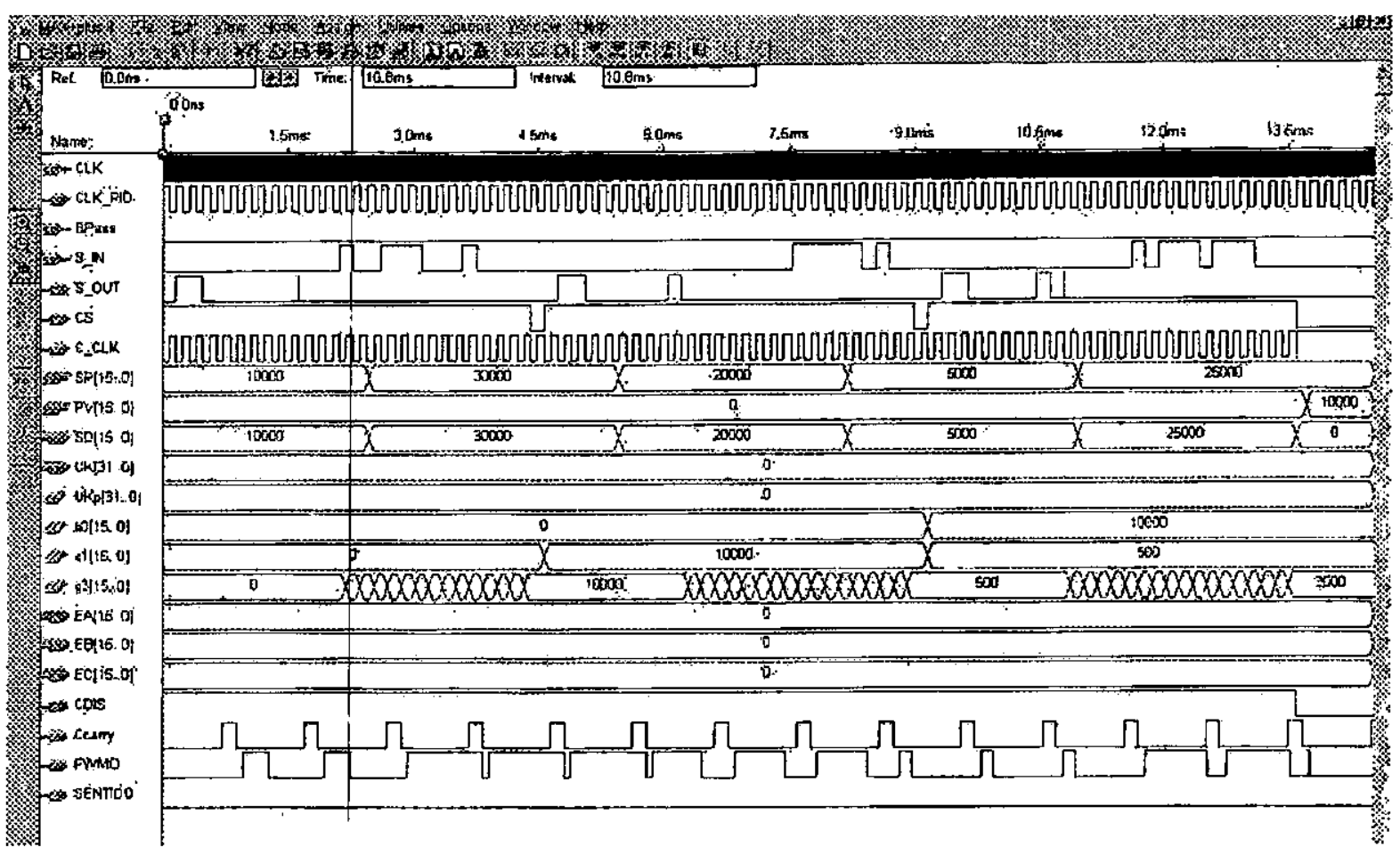

FigURA 7. I - TELA DE SIM廿LAÇĀo dURANTE O CICLO DE BUSCAS DOS PARÀMETROS PID.

A partir de 13,5 ths a rotina PID da arquitetura I começa a ser executada. Na Figura 7.2 isto pode ser observado pela seqüência de valores que aparecem no pino UK e também na variável interna UKp, que representam respectivamente o resultado do processamento atual e passado da rotina PID. Hode ser observado na figura, que na saída PWM, as larguras de pulso são proporcionais aos valores de UK ou de SD.

Os valores mostrados nas simulações estão na forma decimal, representando um número digital em complemento dois, em virtude disto, qualquer número acima do valor 32.767 representa um número negativo. Este é o caso dos números 45.536 e 55.536 , que equivalem respectivamente a -20.000 e -10.000 . 


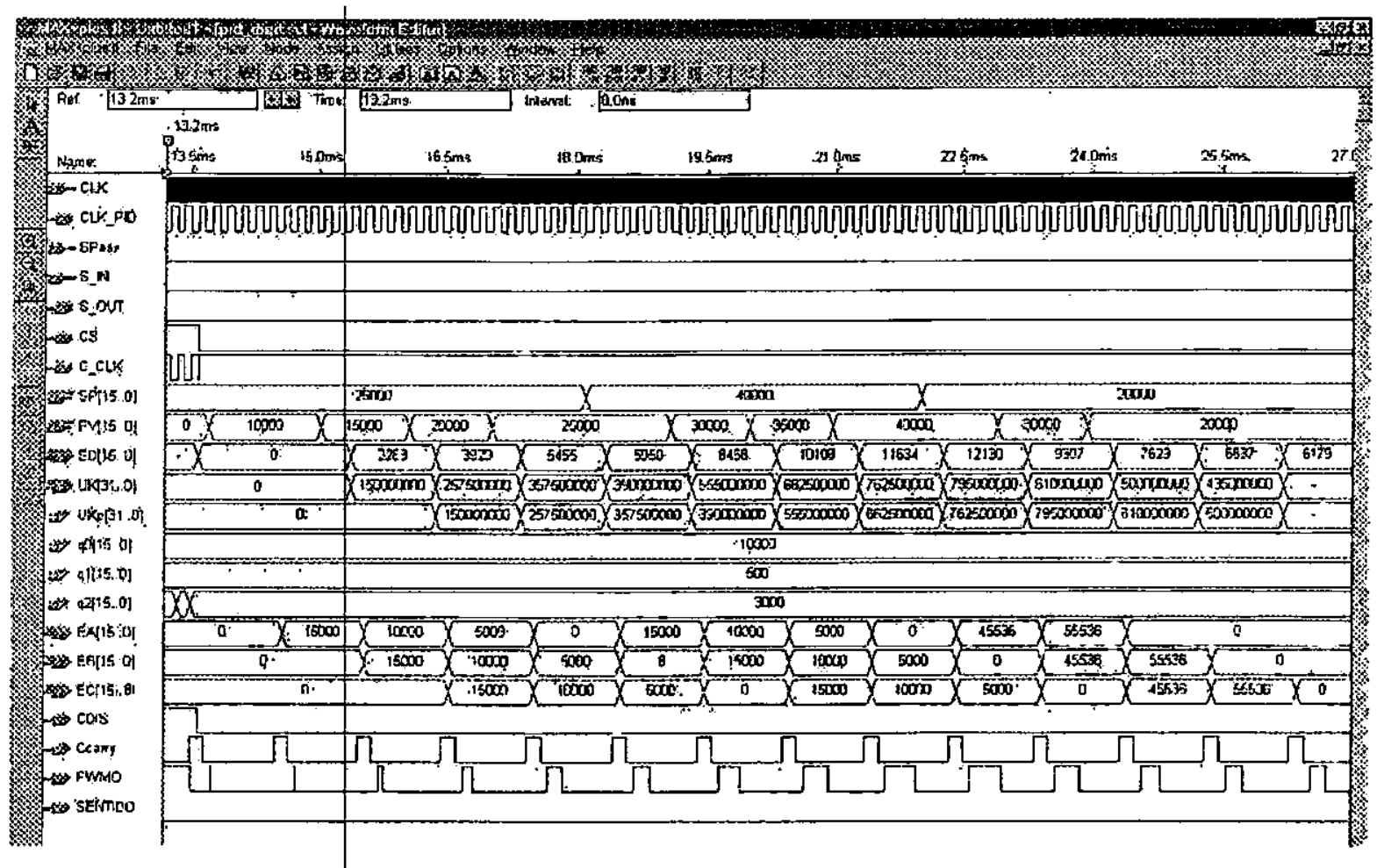

Figura 7.2- TELA DE SIMULAÇÃo DO MÓDULO PID DA ARQUITETURA I.

A tabela 7.1 mostra o cálculo passo a passo do algoritmo PID para comparação com os resultados obtidos por simulação, mostrados nas Figuras 7.2 e 7.3. Na tabela, e(k) recebe o valor da diferença entre SP e PY e U(k) é calculado de acordo com a Equação 5.7 do capítulo 5.

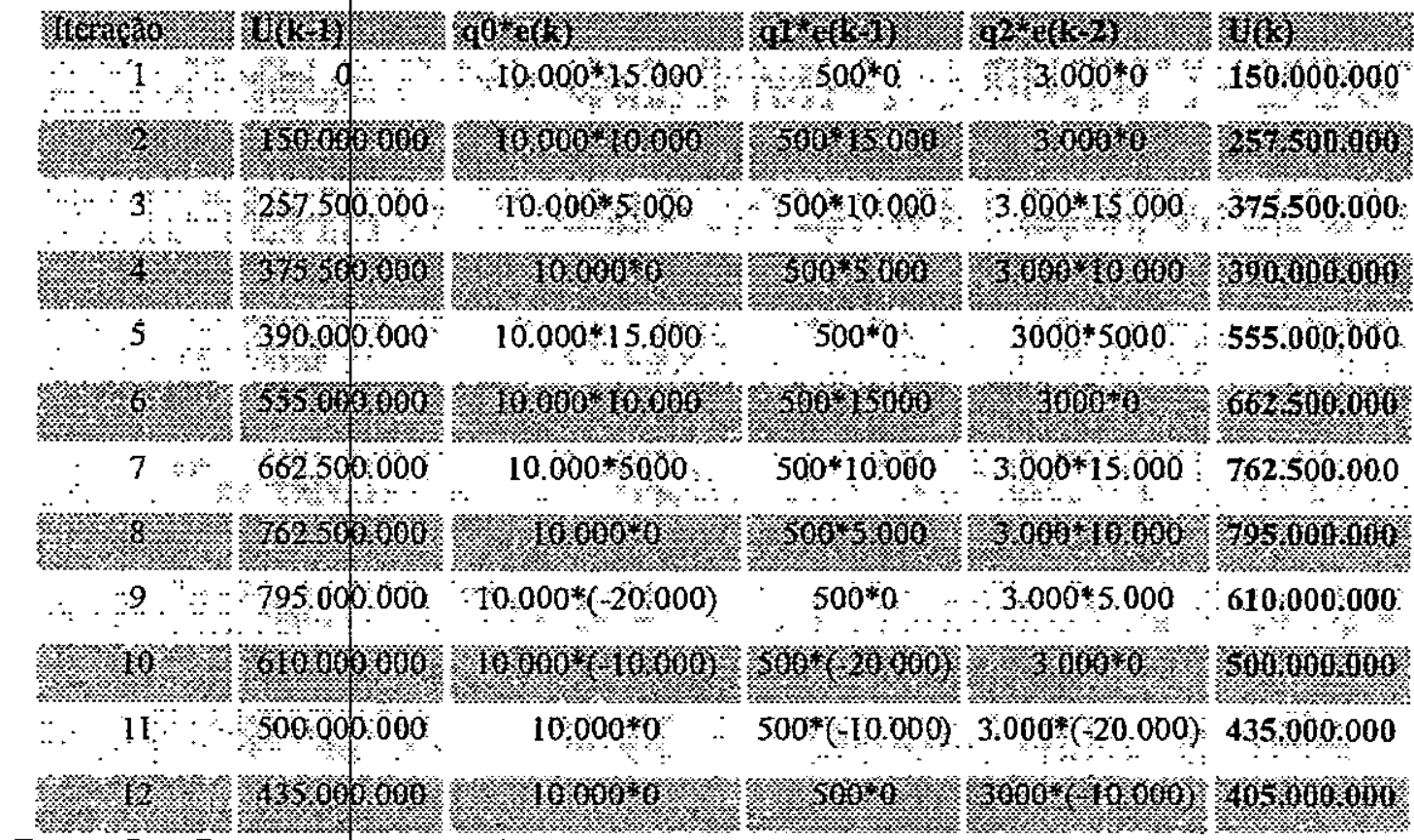

TABELA7. 1- DETALHAMENTO DO CÁLCULO DA ROTINA PID PARA COMPARAÇĀO COM A SIMULAÇȦO. 
Do mesmo|modo, a arquitetura da versão II do controlador PID foi simulada com a ferramenta de simulação temporal do MAX+PLUS II. A etapa de busca dos parâmetros q0, q1 e q2 é idêntica a da primeira arquitetura e, portanto não há necessidade de mostrá-la novamente.

A figura 7.3 ilustra a operação do módulo PID da segunda arquitetura. Para efeito de comparação, nesta simulação foram utilizados os mesmos valores de entrada e de parâmetros da simulação da arquitetura I. Pode ser observado que, nesta arquitetura, a cada ciclo de CLK_PID é calculado um valor de saída U(k). Pode-se, do mesmo modo, confrontar os resultados dos cálculos desta arquitetura com os valores da tabela 7.1.

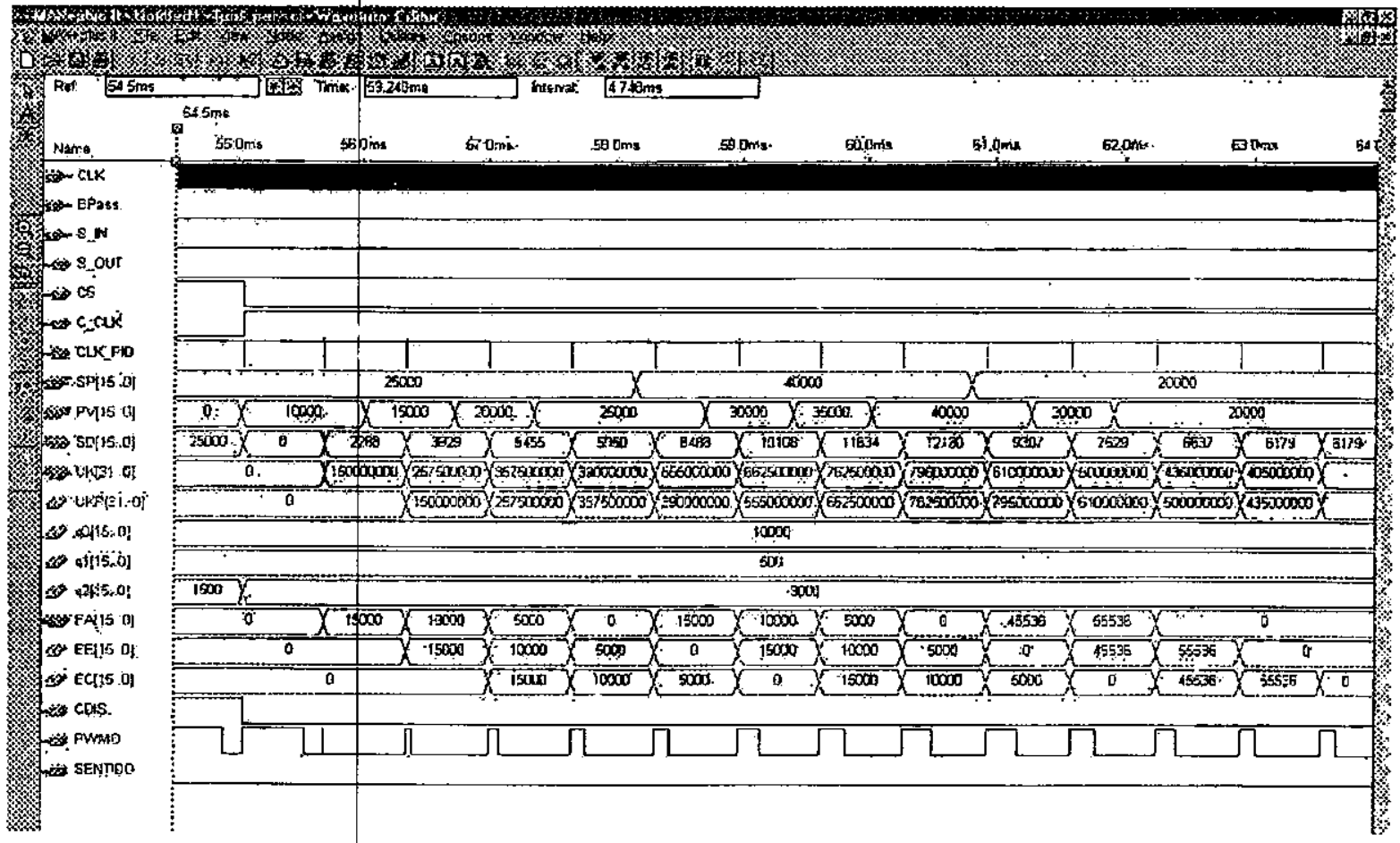

FIGURA7.3- TELA DE SIMULAÇÃo DO MÓDULO PID DA ARQUITETURA I.I.

A seguir é feita uma comparação das características e do desempenho das duas arquiteturas de controlador PID com alguns controladores existentes no mercado. 


\subsection{Analise de Desempenho}

Um modo bastante prático de se analisar o desempenho das arquiteturas desenvolvidas neste trabatho é através da comparação com dispositivos existentes no mercado que executam o mesmo tipo de tarefa. Para tal, foram selecionadas três aplicações que serviram como referência para este rrabalho.

A primeira aplicação está descrita no documento AN718 da empresa Microchip Technology Inc. [BOW99]. Esta aplicação descreve o desenvolvimento de um controlador PID, baseado do microcontrolador PIC17C756A, para controle de um motor CC.

A segunda aplicação é descrita no documento "PID Motor Control with the Z8PE003" [ZIL01], da empresa Zilog Inc. e detalha o controle de um motor CC pelo microcontrolador Z8PE003.

A terceira aplicação consultada foi elaborada pela empresa Motorola Inc., através do documento AN1213/D e descreve o controle de servo motores com o microcontrolador MC68H16Z1 [WIL96].

Como já mencionado no início deste capítulo, as arquiteturas I e II operam respectivamente em $33 \mathrm{MHz}$ e $50 \mathrm{MHz}$. Nas duas arquiteturas a freqüência dos pulsos PWM define e a freqüência de cálculo da rotina PID e também a taxa de amostragem Como as duas arquiteturas possuem saida PWM com resolução de 15 bits, a freqüência dos pulsos PWM pode ser calculada conforme as Equações 7.1 e 7.2.

$T a 1=\frac{33 \mathrm{MHz}}{2^{15}} \approx 1,007 \mathrm{KHz}$
$T a 2=\frac{50 \mathrm{MHz}}{2^{15}} \approx 1,525 \mathrm{KHz}$

Eq̨uaçào 7.1

Equação 7.2 
A Equação 7.1 mostra o valor da taxa de amostragem da para a arquitetura I e a e Equação 7.2 mostra o valor da taxa de amostragem para a arquitetura II. A Tabela 7.2 sumariza as características das aplicações comerciais descritas anteriormente em comparação com as duas arquiteturas de controlador PID deste trabalho.

\begin{tabular}{|c|c|c|c|c|c|}
\hline Sistema & Clock & $\begin{array}{l}\text { Precisão } \\
\text { Interna }\end{array}$ & $\begin{array}{l}\text { Resolucão } \\
\text { de } \\
\text { Saída PW M }\end{array}$ & $\begin{array}{l}\text { Freqüência } \\
\text { PWM }\end{array}$ & $\begin{array}{l}\text { Amostras } \\
\text { Processadas } \\
\text { por Segundo }\end{array}$ \\
\hline Arquitetura I & $33 \mathrm{MHz}$ & 32 Bits & 15 Bits & $1,007 \mathrm{KHz}$ & $1,007 \mathrm{KSPS}^{*}$ \\
\hline Arquitetura 1 & $50 \mathrm{MH}$ z & 32 Bits & 15 Bits & $1.525 \mathrm{KH}$ & $1.525 \mathrm{KSPS}$ \\
\hline Zilog & $10 \mathrm{MHz}$ & 16 Bits & 16 Bits & Não Fornecida & $6,66 \mathrm{KSPS}$ \\
\hline Microchip & $33 \mathrm{MHz}$ & 32 Bits & I0 Bits & $32,2 \mathrm{~K} \cdot 1 \mathrm{z}$ & $3,9 \mathrm{KSPS}$ \\
\hline Motorola & $25 \mathrm{MHz}$ & .32 Bits & 8 Bits & $2,049 \mathrm{KHz}$ & $2,05 \mathrm{KSPS}$ \\
\hline
\end{tabular}

TABELA7. 2- COMPARAÇÃO ENTRE TRÊS SOLUÇõES COMERCIAIS E AS ARQUITETURAS DESTE TRABALHO.

Pode ser observado na Tabela 7.2 que as arquiteturas I e II não apresentaram processamento superior aos dos outros sistemas, no entanto, a resolução da saída PWM de 15 bits é 32 vezes maior do que um sistema com PWM de 10 bits e 128 vezes maior que o de PWM de 8 bits

Nas duas arquiteturas, a taxa de processamento dos dados é inversamente proporcional a resolução de saída PWM. Facilmente pode-se alterar as arquiteturas PID para que operem com PWM de 10 bits, neste caso, haveria um aumento em 32 vezes na velocidade de processamento da rotina PID e do módulo PWM. Isto aumentaria o desempenho da arquitetura I para 32,2 KSPS, tornando-a mais rápida que o sistema da Microchip. Com o mesmo procedimento, a arquitetura II passaria a ter o melhor desempenho de todos os sistemas, com uma taxa de processamento de 48,8 KSPS e uma freqüência PWM também de 48,8 KHz. Neste trabalho houve a opção por assegurar uma melhor resolução de saída, em detrimento de um maior desempenho. Uma taxa de processamento maior pode ser conseguida, no futuro, com a mudança para uma família de FPGAs mais rápida, sem alteração da resolução de saída. 


\section{Conclusões}

Parte deste trabalho de mestrado se traduziu no aprendizado das modernas técnicas e ferramentas de projeto digital, além de um estudo básico na teoria de processamento digital de sinais, permitindo deste modo, o desenvolvimento de um controlador PID digital para ser utilizado como um bloco ou core em sistemas que utilizam FPGAs.

A utilização de Hdrdwares dedicados para tarefas de controle, como as duas arquiteturas aqui apresentadas, mostraram-se bastante eficientes e viáveis. O desenvolvimento de um controlador PID dedicado em FPGA é uma opção ainda pouco explorada, de modo que esta tarefa é, em geral, realizada por processadores e microcontroladores de utilização genérica.

Uma das principas vantagens da abordagem deste trabalho está na maleabilidade dos sistemas reconfiguráveis como os FPGAs, os quais permitem que alterações de projeto sejam feitas rapidamente. Neste trabalho isto é particularmente importante, pois foi desenvolvido um core de controlador PID que será integrado a um sistema de controle de robô, o Projeto ARMOSH. Para a integracão a este projeto, certamente a arquitetura será modificada e migrada para uma família de FPGA maior, para poder receber uma interface de comunicação com os outros módulos do sisterna. Uma integração como a mencionada apenas será exeqüivel com rapidez e funcionalidade com a utilização das modernas ferramentas de desenvolvimento digital atuais aliadas a reconfigurabilidade dos FPGAs.

Os dois sistemas de controle PID desenvolvidos obviamente podem ser melhorados e moldados de acordo com o sistema que os utilizem. Para tal, na seqüência, algumas modificações e melhorias são sugeridas para trabalhos futuros. 


\subsection{Sugestões para Trabalhos Futuros}

Nas arquiteturas desenvolvidas o módulo de busca dos parâmetros de uma memória EEPROM foi uma solução intermediária, por falta de uma definição de como serão a comunicação e o controle proferidos pelo projeto ARMOSH.

A manipulação dos parâmetros q0, q1 e q2 do controlador PID ainda permitem considerável desenvolvimento. Uma solução interessante seria desenvolver um controlador com capacidade de calcular e ajustar seus parâmetros por si só, sem a necessidade de intervenção do operador. Esta tarefa é conhecida por auto-sintonia do controlador PID.

A completa codificação das arquiteturas em VHDL tomaria os sistemas "portáveis" para qualquer ferramenta de projeto digital que interpretasse VHDL, permitindo a implementação em FPGAs de outras empresas. Uma vantagem adicional ao se codificar as arquiteturas em VHDL seria a possibilidade de desenvolver cores parametrizáveis, permitindo configurações dos hardwares como, por exemplo, escolha do número de bits da palavra digital e escolha da resolução de saída do módulo PWM. 


\section{Referências Bibliográficas}

[ACC97] Pellerin, D., Taylor, D., Inc, An Introduction to VHDL for Synthesis and Simulation, Accolade Desfgn Automation, www page <http://www.acc-eda.com/>, 1999

[ACT95] ACTEL, Corp., FPGA Data Book and Design Guide, 1995.

[ALT96a] ALTERA Inc., Microperipheral MegaCore Library Data Book, September, 1996.

[ALT96b] ALTERA Inc., Data Book, June, 1996.

[ALT99] ALTERA Inc., FLEX 1OKE Device meet the 66-MHz/64-Bit PCI compliance challenge, The Altera Advantage News \& Views, February, 1999.

[ALT98] ALTERA Inc, Implementing FIR Filters in FLEX Devices, Application Note 73, Ver. 1.01, 1988.

[ARA97] ARAGÃO, ANTONIO C. de O. S., Aplicação da Tecnologia FPGA em Arquiteturas Sistólicas, Exame de Qualificação de Mestrado, Instituto de Ciências Matemáticas e de Computação, Universidade de São Paulo, 1997.

[ASH96] ASHENDEN, PETER J., The Designer's Guide to VHDL, Emorgan Kaufmann Publishers, Inc., 1996.

[BAR] BARCZAC C. Controle Digital De Sistemas Dinâmicos - Projeto e análise, Editora Edigard Blücher LTDA,

[BEN88] BENNETT, S. Real Time Computer Control: A Introdiction, Prentice Hall, 1988.

[BOM99] BOMBACINI, MARCOS ROBERTO. Implementação da unidade de controle e da interface hospedeira de uma arquitetura sistólica, utilizando-se metodologias avançadas para projeto de hardware, Dissertação de mestrado, Instituto de ciências matemáticas e de computação da Universidade de São Paulo, 1999.

[BOW99] BOWLING, STEPHEN. Brush DC Servomotor Implementation using PIC17C756A, AN71 8. Microchip Technology Inc., 1999. 
[BRE81] BREWER,M.; HARTESTENN,R. Computer hardware description languages and their applications, North-Holland Publishing Company, 1981

[BRO96a] BROWN, S.; ROSE, J. FPGAs and CPLDs Architecture: A Tutorial, IEEE Design and Test of Computers, vol. 13, No. 2, pp. 42-57, June 1996.

[BRO96b] BROWN, S. D. Recent Advances in Field-Programmable Gate Arrays, WWW page http://www.eecg.toronto.edu/ brown/papers.html , May, 1996.

[BRO97] BROWN, S.; ROSE, J; FRAANCIS R.;VRANESIC, Z. Field Programmable Gate Arrays, Kluwer Acạdemic Publisher, 1997.

[BRU00] BRUCH, M.H., LAIRD, R.T., EVERETT, H.R. Challenges for deploying manportable robots into hostile environments, Space and Naval Warfare Systems Center, San Diego, CA, 2000.

[CAO99] CAON JUNIOR, JOSÉ ROBERTO. Controladores PID industriais com sintonia automática por realimentação a relê, Dissertação de mestrado, Escola de engenharia de São Carlos - Universidade de São Paulo, 1999.

[CHA94] CHAN, P. K.; MOURAD, S. Digital Design using Field Programmable Gate Arrays, Prentice Hall, 1994.

[CAL95] CALAZANS, NEY L.V. Métodos e ferramentas para o projeto de sistemas digitais, Pontificia Universidade Católica do Rio Grande do Sul, 1995.

[COE95] COELHO, D.R. The VHDL Handbook, Kluwer Academic Publisher, 1995.

[DEL96] DeLAUTER,DAVE. A 256 Channel Control System Using FPGAs and PLD,. Application Note, ACTEL Corp., 1996.

[DOU99] DOULOS HOME PAGE, A Hardware Engineer's Guide to VHDL, www page: <http://www.doulos.co.uk/hegv/>, 1999.

[EDT99] EDTN NETWORK, Adobe Photoshop Demonstration Uses Internet and Virtex FPGAs to Upgraqe PC, www page <www.edtn com/pld/pldp261.htm>, 1999. 
[EXP99] ExperTune, Inc., < http://www.expertune.com/tutor:html $>1999$.

[FER87] FERREIRA, EDSON DE PAULA. Robótica, Editorial Kapelusz S.A, 1987.

[FOR99] FORD, RALNDOLPH J. Intellectual property: How what you know can hurt you, EDN Magazine, <http://www. ednmag comednmag/reg/1999/062499/13 ms 564.htm>, 1999.

[GAJ83] Gajski, Daniel D. and Kuhn, Robert H., Guest Editors Introduction - New VLSI Tools, IEEE Computer, pp 11-14, IEEE, 1983

[GRE93] Greene, J.; Hamdy, E.; Beal, S. Antifuse Field Programmable Gate Arrays, Preceedings of the IEEE, p.1042-1056, Vol.81, No.7, July 1993.

[GSC95] GSCHWIND, M.; SALAPURA V. A VHDL Design Methodology for FPGA, Lectures Notes in Computer Science, no. 975, p. 208-217, July, 1995.

[GOS96] GOSLIN, GREGORY R. Implement DSP function in FPGA to reduce cost and boost performance, EDN, p. 155-164, October, 10, 1996.

[12C99] Inter-Integrated Circuit Bus Overview, www page: $<$ http://nsf.me.vt.edu/book/section1/I2CbusOverview.html>, 1999

[IEE94] IEEE, Inc., IEEE Standard VHDL Language Reference Manual, June, 1994.

[ISE89] ISERMANN, R. Digital Control Systems, Vol.1: Fundamentals, Deterministic Control, Springer-Verlag Berlin Heidelberg, 1989.

[LEU97] LEUNG, STEVEN S., ASIC System Design with VHDL: A Paradigm, Kluwer Academic Publishers, 1997.

[LIP96] LIPMAN, JM. EDA tools accelerate high-speed pc-board design, EDN Magazine, < http://www.ednmag. com/ednmag/reg/1996/032896/07df2.htm>, 1996

[LIP99] LIPMAN, ЛM. Chip-core protection: everybody's business, EDN Magazine, $<$ http://www ednmag com/ednmag/reg/1999/101499/21cs. htm>, 1999.

[LUB91] LUBECK, PAUL. Using National's MICROWIRE ${ }^{\mathrm{tm}}$ EEPROM, Application Note 758, National Semiconductor, 1991. 
[MOD88] MODARES, JAVAR. Small DC motor Control, Application Note AP-425, Intel Corporation, 1988.

[NAT96] NATIONAL SEMICONDURCTOR CORP. NM93C06/C46/C56/C66 256/1024-/2048-/4096-Bit Serial EEPROM (MICROWIRE TM Bus Interface), 1996.

[OGA93] OGATA, KATSUHIKO. Engenharia de Controle Moderno, Prentice/Hall do Brasil, 1993.

[OLD95] OLDFIELD, JOHN V., Field-programmable gate arrays: reconfigurable logic for rapid prototyping and implementation of digital systems, John Wiley \& Sons, Inc., 1995.

[OWY96] OWYANG, K.; JORGENS, B. High level design form high density programmable logic, Synopsys Inc., June, 1996.

[PAY97] PAYNE, ROBERT. Self-timed Field Programmable Gate Array architecture, PHD THESIS, University of Edinburgh, 1997.

[PER94] PERRY, D. L. VHDL, McGraw-Hill, 1994.

[REG99] REGAN, TIM. A DMOS 3A, 55V, H-Bridge: The LMD18200, Application Note 694, National Semiconductor, Dezembro 1999.

[RN99] RINCON, ANN MARIE, LEE, R. WILLIAM, SLATTERY, MICHAEL. The Changing Landscape of System-on-a-Chip Design, MicroNews, $<$ http://www.chips.ibm.com/micronews/vol5 no3/1incon.html $>$, Third Quarter 1999, Vol. 5, No.3.

[ROS93] ROSE, J.; GAMAL A.E.; VINCENTELLI, A. S. Architecture of FieldProgrammable Gate Arraps, Proceedings of the IEEE, vol. 81, no. 7, p.1013-28, Julho, 1993.

[STO96] STOKES, IAY; SOHIE, GUY R.L.; Implementation of PID Controllers on the Motorola DSP56000/DSP56001 Digital Signal Processors, APR5, Motorola Inc, 1996.

[SYN94] SYNOPSYSS, Inc., Making the Transition to High-Level Design, 1994.

[TEX96] TEXAS INSTRUMENTS, Digital control application with the TMS320 family - Selected application notes, 1996. 
[VIN93a] VINCENTELLI, A. S. Some Considerations on Field-Programmable Gate Arrays and their Impact on System Design, Lectures Notes in Computer Science, no. 705, p. 26-34, June, 1993.

[VIN93b] VINCENTELLI, A. S.; GAMAL A.E.; ROSE, J. Synthesis Methods for FieldProgrammable Gate Arrays, Proceedings of the IEEE, vol. 81, no. 7, p. 1057-83, July, 1993.

[VCC97] VIRTUAL COMPUTER CORPORATION, H.O.T. User's Guide, Revision 1.0, September, 1997.

[WES99] WESTFELDT, WALLACE. Networks drive remote configurability, <ttp://content.techweb.com/se/directlink.cgi?EET19990920S0061> EETIMES, Isue 1079, 1999.

[WIL96] WILSON, DAVID. 16-Bit DSP Servo Control With the MC68HC16Z1, Application Note AN1213/D, Motorola Inc., 1996.

[WIL99] Williams, Gharles D.H. Feedback and Temperature Control, University of Exeter, $<$ http://newton.ex.ac.uk/teaching/CDHW/Feedback/index.html >, 1999

[WIS97] WISEMAN JOHN, Modern digital design for the radio amateur, QEX magazine, December, 1997.

[ULS99] UNIVERSITY OF ULSTER, A small VHDL-Tutorial, <www.eej.ulst.ac.uk/tutor/vhdnotes.html>

[XIL99a] XILINX, Inc., The Programmable Logic Data Book, February, 1999.

[XIL99b] XILINX, Inc., Xcell - The quaterly journal for programmable logic users, Second quarter, 1999.

[ZIL01] ZILOG, INC, PD Motor Control With The Z8PE003, Application Note AN003002-0401, 2001. 